\title{
Differential interaction of Magnaporthe grisea and Fusarium graminearum with ears of wheat cultivars varying in resistance
}

\author{
Dissertation \\ to obtain the $\mathrm{Ph}$. D. degree \\ in the International Ph. D. Program for Agricultural Sciences in Goettingen (IPAG) \\ at the Faculty of Agricultural Sciences, \\ Georg-August-University Göttingen, Germany
}

\author{
Presented by \\ Xia Ha \\ born in Hanzhong-China
}

Göttingen, September 2014 
1. Name of referee: Prof. Dr. Andreas von Tiedemann

2. Name of co-referee: Prof. Dr. Petr Karlovsky

Date of dissertation: November 2014 


\section{Contents}

Abbreviation 4

1. Introduction 5

1.1 Wheat (Triticum aestivum $\mathrm{L}$ ) 5

1.2 Wheat blast (Magnaporthe grisea) 5

1.2.1 Occurrence and significance 5

1.2.2 Host range and taxonomy 6

1.2.3 Epidemiology 6

1.2.4 Disease control 8

1.3 Fusarium head blight (Fusarium graminearum) 9

1.3.1 Occurrence and significance 9

1.3.2 Epidemiology 9

1.3.3 Disease control 10

1.4 Defense responses in plants to pathogens 11

1.4.1 ROS generation and functions 11

1.4.2 Defense-related gene expression 13

1.5 Objectives of the study 15

2. Materials and Methods 17

2.1 Plant material 20

2.2 Fungal material 20

2.3 Inoculum preparation of pathogens 21

2.3.1 M. grisea 21

2.3.2 F. graminearum 21

2.4 Inoculation procedures 21

2.4.1 Whole ear inoculation 21 
2.4.2 Leaf inoculation __ 22

2.4.3 Point inoculation on ears $\_22$

2.5 Disease assessment _ 22

2.5.1 Wheat blast___ 22

2.5.2 Fusarium Head Blight___ 23

2.6 Detection of pathogen growth in plant tissue _ 24

2.6.1 Fluorescence microscopy observation

2.6.2 Fungal colonization on infected ear sections __ 24

2.7 Histological investigation of fungal expansion on ears

2.7.1 Time course determination on spikelet and rachilla___ 25

2.7.2 Observation of fungal spread in spikelets by Confocal Laser Scanning Microscope

(CLSM) and fluorescence microscopy ___ 26

2.7.3 Observation of fungal spread in rachilla by CLSM _ 27

2.8 Biochemical examination of ears

2.8.1 Experimental design __ 28

2.8.2 Quantification of ROS _ 29

2.8.3 Detection of ROS in plant tissue __ 30

2.9 Gene expression studies ___ 31

2.9.1 Experimental design ___ 31

2.9.2 Determination of target genes __ 31

2.9.3 Expression of target genes by quantitative reverse transcription PCR (qRT-PCR) _ 34

2.10 Statistical analysis 35

3. Results — 36

3.1 Disease severity assessment and cultivar responses __ 36

3.1.1 Wheat blast__ 36

3.1.2 Fusarium Head Blight___ 40

3.2 Fungal growth on ears 
3.2.1 Macroscopic investigation with bright field and fluorescence microscopy 43

3.2.2 Fungal colonization on the infected ears 49

3.3 Fungal spread on ears followed by microscopic observation 54

3.3.1 Fungal spread in spikelets 54

3.3.2 Fungal spread in the rachilla 60

3.4 Biochemical analyses of diseased ears 70

3.4.1 ROS production in infected tissue 70

3.4.2 Histochemical localization of ROS 76

3.5 Differential gene expression in infected ears 79

3.5.1 Pathogenesis-related (PR) genes 79

3.5.2 Peroxidase, lignification and signaling concerned genes 81

3.5.3 Genes related to mycotoxin detoxification 83

4. Discussion 86

4.1 Differential resistance of cultivars to wheat blast and FHB 86

4.2 Differential development of both pathogens on wheat ears 90

4.3 Defense responses in wheat ears to $M$. grisea and F. graminearum 94

4.3.1 ROS in ears 94

4.3.2 Differential gene expression in infected ears 100

Summary 107

References 110

Appendix 130

Acknowledgements 136 


\section{Abbreviation}

bp

${ }^{\circ} \mathrm{C}$

$\mathrm{cm}$

CTAB

$\mathrm{Ct}$

cV.

DNA

dNTP

dpi

$\mathrm{ddH}_{2} \mathrm{O}$

EDTA

et al.

g

$g$

GS

$\mathrm{h}$

$\mathrm{H}_{2} \mathrm{O}$

$\mathrm{L}$

M

$\mathrm{m}$

$\mathrm{mg}$

$\mathrm{mL}$

$\mu$

$\mu \mathrm{L}$

$\mu \mathrm{mol}$

$\mathrm{mM}$

$\mathrm{mm}$

$\min$

ng

PCR

pg

$\mathrm{pH}$

qPCR

$\mathrm{r}$

ROS

RNA

RNAse

RPM

SDS

SD

TE

$\mathrm{Tm}$ base pairs

degree Celsius

centimeter

hexadecyltrimethylammoniumbromid

threshold cycle

cultivar

deoxyribonucleic acid

deoxyribonucleoside triphosphate

days post inoculation

double distilled water

ethylene diamine tetra acetic acid

et alii (and others)

gram

gravitational acceleration

growth stage

hour

water

litre

mol per litre

milli

milligram

millilitre

micro

microlitre

micromole

millimolar

millimetre

minute

nanogram

polymerase chain reaction

picogram

a measure of the acidity or basicity of an aqueous solution

quantitative real-time PCR

correlation coefficient

reactive oxygen species

ribonucleic acid

ribonuclease

revolutions per minute

sodium dodecyl sulfate

standard deviation

tris-EDTA buffer

Primer Melting Temperature 


\section{Introduction}

\subsection{Wheat (Triticum aestivum $\mathrm{L}$ )}

Wheat (Triticum aestivum L.) is one of the first domesticated food crops and has a long cultivation history of about 8,000 years in Europe, Asia and Africa. Today, wheat is one of the most important grain foods for humans. It is estimated that 715 million tons will be produced in 2013/14 globally (WASDE, 2014).

Wheat grows well in a wide range of temperatures, ranging from $3-32^{\circ} \mathrm{C}$, with $25^{\circ} \mathrm{C}$ being the optimum (Briggle and Curtis, 1987). Although the wheat cropping systems are well developed, abiotic and biotic stresses are challenges for wheat yield. Among the biotic threats, diseases caused by pathogens are the main constraints to wheat production (William et al., 2011).

\subsection{Wheat blast (Magnaporthe grisea)}

\subsubsection{Occurrence and significance}

Wheat blast "brusone" caused by Magnaporthe grisea (Hebert) Barr [anamorph Pyricularia grisea (Cooke) Sacc.] is a relatively new disease on wheat (Igarashi et al., 1986). The disease was first reported in Brazil from the northern region of the State of Paraná in 1985 (Igarashi et al., 1986). Subsequently, it rapidly spread to a number of major wheat producing regions of Brazil and the neighbouring wheat growing countries, including Paraguay, Uruguay, Argentina and Bolivia (Prabhu et al., 1992; Goulart and Paiva, 2000). At present, it is one of the major diseases of wheat in Brazil (Urashima et al., 2004).

Due to its widespread distribution, blast is becoming a limiting factor for wheat production of subtropical and tropical regions in South America. Depending on environmental conditions, the extent of yield damage may vary from low to complete loss (100\%) (Picinini and Fernandez, 1990; Maciel, 2012). For instance, in 1991/92, 51\% yield loss due to a mean disease incidence of $86 \%$ was reported in Brazil (Igarashi, 1990; Urashima et al., 1993). 
There is a concern that wheat blast may be distributed to other wheat growing areas in the world with elevated temperatures and humidity similar to South America.

\subsubsection{Host range and taxonomy}

Magnaporthe grisea can infect many small cereal grain crops including barley (Hordeum vulgare L.), foxtail millet (Setaria italica), triticale (X. triticosecale Wittmack) and black oat (Avena strigosa). Additionally, several grass weeds, including Digitaria sanguinalis, Pennisetum setosum, Brachiaria plantaginea, Eleusine indica, Cenchrus echinatus and Hyparrhenia rufa, can be alternative hosts in or near wheat fields (Urashima et al., 1993; Oh et al., 2002; Urashima et al., 2004). Besides, rice (Oryza sativa L.) is an important traditional host for Magnaporthe. It was previously assumed that both rice and wheat were infected by one species, M. oryzae (Rossman et al., 1990). However, subsequent studies have shown that wheat infecting strains are different from rice infecting strains, and therefore they were renamed to M. grisea (Couch \& Kohn, 2002). DNA fingerprinting studies have shown that M. grisea strains infecting triticale and barley descended from wheat strains, which probably originate from a weed, Digitaria insularis (Urashima et al., 2004a). Prabhu et al. (1992) tested the pathogenicity of seventeen Magnaporthe isolates from wheat and grass and found that they were pathogenic on wheat and barley, but none of the same isolates infected rice cultivars. It was therefore proposed that rice strains should be considered as a separate species, M. oryzae, based on the aforementioned pathogenicity and tracked hosts studies (Couch et al., 2005). It was proved that Magnaporthe isolates from triticale, wheat and barley could not infect rice, whereas rice isolates were pathogenic on triticale, wheat and barley, and the Southern hybridization analysis demonstrated the isolates from triticale and barley to originate from the wheat pathotype (Urashima et al., 2004).

\subsubsection{Epidemiology}

M. grisea infects plants by conidia (asexual spores) (Zeigler, 1998). Normally, the dormant mycelium is for survival in dead plant debris during the winter (Harmon and Latin, 2005). The primary inoculum of $M$. grisea derives from the sporulation of overwintered mycelium in spring (Uddin et al., 2003). Wind is considered as the factor for dispersal of inoculum 
(Harmon and Latin, 2005). A series of further infections increases the inoculum triggered by favourable environmental conditions during the summer period (Uddin et al., 2003a).

Temperature and humidity is essential for $M$. grisea infection. Higher temperatures accelerate biological processes in both the pathogen and the host plant. Pathogens are by far more aggressive and more capable to infect susceptible plants with increasing temperature (Cardoso et al., 2008). A humid environment is required for spore germination and infection. A sufficient wetness time and suitable temperature allow colonization of the host to be initiated. As Rotem (2012) mentioned, frequent rainfall, high humidity, and heavy dew that coincide with sensitive periods of the crop favour infections. The optimal temperature of M. grisea is in the range of $20-28^{\circ} \mathrm{C}$, and the highly humid conditions, especially several days of continuous rain after sunny and hot days contribute to the blast spreading (Uddin et al., 2003a). The weather is generally hot and wet in Bolivia, Paraguay, Uruguay, as well as in the northern part of Argentina and southern Brazil, where wheat blast is well distributed. In these places, average temperatures stay around $27^{\circ} \mathrm{C}$ in summer (November to March), with an average rainfall of 5-6 inches $(13-15 \mathrm{~cm})$ per month (http://www.climateandweather.com/weather-in-south-america). These weather conditions undoubtly influence the epidemiology of wheat blast. It has been observed that the years with high blast severity coincided with years with high wetness, especially in the year with El Nino, which causes hot and wet weather along the coasts of South America (Kohli et al., 2011). Cardoso et al. (2008) reported increased wheat blast severity associated with wetness periods. A $40 \%$ wheat blast severity can be reached at temperatures up to $25^{\circ} \mathrm{C}$ and wetness duration of $40 \mathrm{~h}$.

M. grisea can attack all above ground parts of the wheat plant, but the typical symptom of wheat blast is the head infection, partially infected ears that turn bleached or to straw colour (Urashima and Kato, 1994; Picinini and Fernandez, 1990). The uptake of nutrients is blocked so that the bleached ear portions do not produce grain and this can be easily distinguished from healthy green ears (Fig. 1A) (Mehta and Baier, 1998; Urashima et al., 2009). Under certain environmental conditions, lesions occur on leaves, with the colour varying from straw 
yellow to grey, and variable in shape and size (Fig. 1B) (Urashima et al., 2004).
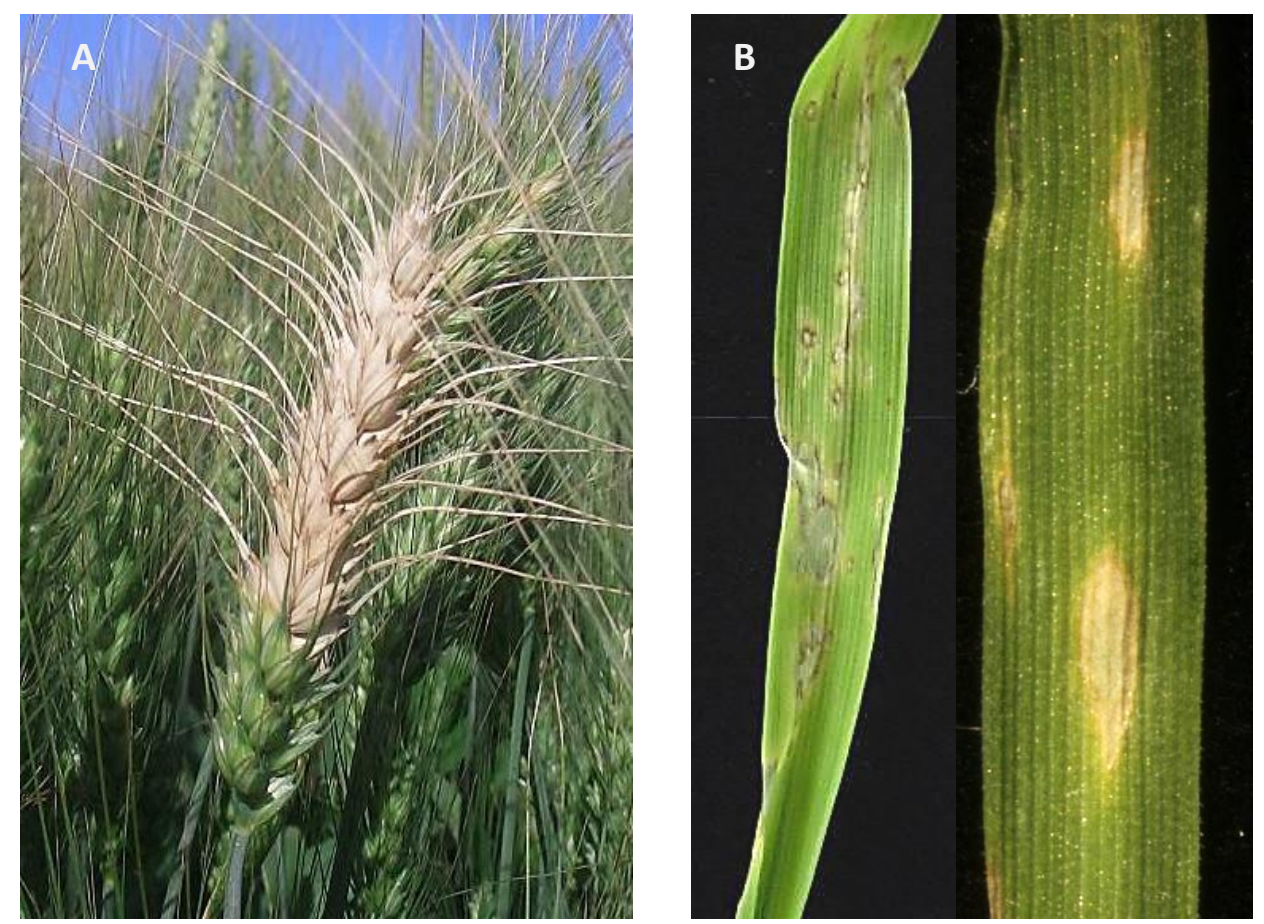

Fig.1. A. Typical symptoms of wheat blast infection on the wheat ear (von Tiedemann, 2009); B. infected leaves by wheat blast showed various grey or pale lesions.

\subsubsection{Disease control}

Disease control can be achieved by integration of different approaches such as crop rotation, adjustment of sowing time, and use of resistant cultivars and effective fungicides (Pirgozliev et al., 2003). Among these methods, the use of plant resistance is the most economic and promising measure. However, this may be difficult if the virulence of a pathogen varies, such as $M$. grisea. Thus finding a broad genetic resistance is a challenge (Kohli et al., 2011). Some of the cultivars that have been shown to display stable resistance include the Brazilian varieties BR18, IPR 85 and CD 113 (Urashima et al., 2004). Similarly, the Bolivian cultivars Paragua CIAT and Parapeti CIAT also showed higher levels of resistance (Kohli et al., 2011). However, commercially available wheat cultivars are still lacking. On moderately resistant cultivars, fungicides containing triazoles and strobilurins were effective at the heading stage (Wiedma, 2005). However, the low efficacy of fungicides is a constraint for their use. Due to the lack of resistant cultivars and low efficacy of fungicide use, wheat blast has become a major disease in wheat production in South America (Urashima and Kato, 1994; Goulart and 
Paiva, 2000, Urashima et al., 2004). Considering that wheat blast is a relatively new disease, the pathogenesis and wheat resistance reaction needs further study. This could provide useful information for managing the disease.

\subsection{Fusarium head blight (Fusarium graminearum)}

\subsubsection{Occurrence and significance}

Fusarium graminearum Schwabe (teleomorph Gibberella zeae (Schw.) Petch) is an ascomycetous fungus that causes Fusarium Head Blight (FHB), a common and destructive disease to small cereal grain crops worldwide (Parry et al., 1995; Bai and Shaner, 2004). Many important crops such as wheat, maize (Zea mays) and barley (Hordeum vulgare L.) can be infected by this pathogen and serious economic losses have been reported in many wheat growing regions, including North America, Europe and Asia (McMullen et al., 1997; Bai et al., 2000).

Infected ears often fail to produce grain or form shrivelled small kernels, contaminated with mycotoxins which are harmful to animal and human health (Dexter et al., 2003; Bushnell et al., 2003). Thus, FHB has become a persistent threat to cereal production (Bushnell et al., 2003; Stack, 2003).

\subsubsection{Epidemiology}

F. graminearum infects plants by ascospores (sexual spores) or macroconidia (asexual spores). Spores are released under favourable conditions from the overwintered infected plant debris in spring time (Parry et al., 1995; Trail et al., 2002). Wind and rain drive spore dispersal and short distance movement around $0.5 \mathrm{~m}$ from the upwind edge of the inoculum area (Gilbert and Fernando, 2004). Climate is a critical factor for disease epidemics. F. graminearum has a wide temperature range from $13-22^{\circ} \mathrm{C}$ for ascospore dispersal, with an optimum at $16^{\circ} \mathrm{C}$. FHB symptoms on the head appear at $20-30^{\circ} \mathrm{C}$, with an optimum at $25^{\circ} \mathrm{C}$ (Brennan et al., 2003). FHB occurrence is clearly associated with wet years (Clear and Patrick, 2000). Wheat ears are susceptible to F. graminearum at the flowering stage (Parry et al., 1995; Bai et al., 1996). 
The initial symptom of FHB is similar to wheat blast, as the infected ears show brown watersoaked lesions on the glumes or rachis. Later, a part or the whole ear is bleached or becomes dark brown (Parry et al., 1995; Bai and Shaner, 2004). Under high humidity and warm conditions, FHB severity and intensity is higher, and pink or white mycelia will cover the attacked ears (Fernando et al., 2000). FHB is not limited to the ears. Stem bases, grains, seedlings and roots can also be an appropriate tissue for colonization (Clement and Parry, 1998).

\subsubsection{Disease control}

Various disease managing approaches are employed to control FHB. The application of genetic resistance provides an economic and effective management option. Genetic resistance provides a reliable and promising strategy to control FHB, and some progress has been made in identifying resistant cultivars in the past decades (Bai et al., 2000; Ban and Suenaga, 2000; Lu et al., 2001; Mesterhazy et al., 2003). Resistant cultivars such as Chinese landraces Wangshuibai and Sumai 3 have a high level of FHB resistance, and have been used as a parent in many breeding programs (Bai and Shaner, 2004). Five different types of resistance of wheat to FHB have been identified, where type I is the resistance to initial infection, type II is the resistance to fungal spreading (Schroeder and Christensen, 1963), and the other types are resistance to kernel infection, DON accumulation, and tolerance (Mesterhazy, 1995).

Foliar fungicide application provides little protection at anthesis (Mesterhazy et al., 2003). Triazole-based fungicides such as prothioconazole, metconazole and prothioconazole plus tebuconazole show a superior efficacy compared to tebuconazole alone (Paul et al., 2008). Applications of fungicides containing triazoles (such as tebuconazole and prothioconazole) during flowering stage (GS 61) can effectively reduce the disease severity and DON accumulation (Mesterhazy, 2003; Paul et al., 2008; Haidukowski et al., 2012). However, the timing of application, lack of highly effective fungicides still limits chemical control of FHB (Bai and Shaner, 2004; Haidukowski et al., 2012). Moreover, soil tillage and cultivar resistance, crop rotation and removing the residues are also practices to reduce FHB (Bai and Shaner, 2004). 


\subsection{Defense responses in plants to pathogens}

\subsubsection{ROS generation and functions}

Reactive oxygen species (ROS) are rapid and transient products, defining 'oxidative burst'. ROS generation is a remarkable feature during the plant defense activation, and represents one of the earliest responses in plant defense against pathogen invasion (Lamb and Dixon, 1997; Santos et al., 2001; Langebartels et al., 2002). ROS play an important role in the plant defense system and are related to various functions which take effect during pathogen development (Morel and Dangl, 1997; Mur et al., 2008; Müller et al., 2009). The well-known functions of ROS in the establishment of plant defense include signal transduction, cell wall strengthening, programmed cell death (PCD), hypersensitive response (HR) or activation of relevant defense genes (Neill et al., 2002; Collins et al., 2003; Robatzek et al., 2006; Asselbergh et al., 2007; Miller et al., 2009).

The family of ROS consists of four members: the superoxide radical anion $\left(\mathrm{O}_{2}{ }^{-}\right)$, hydrogen peroxide $\left(\mathrm{H}_{2} \mathrm{O}_{2}\right)$, the hydroperoxyl radical $\left(\mathrm{HO}_{2}\right)$ and the hydroxyl radical $(\mathrm{OH})$. The hydroperoxyl radical and hydroxyl radical have an extremely short half-life and high toxicity to the cell (Grant and Loake, 2000; Hückelhoven and Koge, 2003). The superoxide radical anion and hydrogen peroxide have a half-life of $1-4 \mu \mathrm{s}$ and $1 \mathrm{~ms}$ (Dat et al., 2000; Bhattacharjee, 2012), respectively, and are detectable by various ways from biochemical and histological facets (Thordal-Christensen, 1997; Overmyer et al., 2000; Montillet et al., 2005). It is assumed that $\mathrm{O}_{2}^{-}$is the primary product in the initial phase of pathogen infection, which is dominant in the transient phase. By contrast, $\mathrm{H}_{2} \mathrm{O}_{2}$ is relatively stable, can cross membranes and is easier to detect (Van Camp, 1998; Pellinen et al., 2002; Simon-Plas et al., 2002).

The general idea is that an NADPH oxidase located in the plasma membrane is the main source of extracellular oxidative burst during plant pathogen interaction (Torres and Dangl, 2005; Kobayashi et al., 2006). In addition, intracellular ROS accumulation is altered by chloroplasts and peroxisomes. Many reports have indicated that ROS generated from chloroplasts and peroxisomes are essential for HR (Karpinski et al., 2003; Vidal et al., 2007; 
Zurbriggen et al., 2009). Mitochondria may also be a source of intracellular ROS, and suppression of ROS scavenging systems may further increase ROS accumulation in plant response to stress (Tiwari et al., 2002; Mittler et al., 2004).

Usually, the accumulation of ROS is associated with plant defense response to fungal, bacterial and viral pathogen invasion or insect attack (Draper, 1997; Glazener et al., 1996; Govrin and Levine, 2000; Musser et al., 2006). ROS induction is typically biphasic (Levine et al., 1994; Liu et al., 2007). The first phase of oxidative burst in plants occurs right after recognition of microbe associated molecular patterns (MAMPs). Some of the MAMPs recognized by various host surface receptors and capable of activating basal immunity are conserved cell structures like flagellin, lipopolysaccharides, glucan or chitosan (Galletti et al., 2008; Torres et al., 2010). This first phase is a non-specific transient phase and occurs in both compatible and incompatible interactions. In the subsequent phase, a more intense ROS accumulation occurs several hours after pathogen attack, mainly in incompatible interactions, leading to HR, cell death or secondary metabolite production (Glazener et al., 1996; Ren et al., 2002; Rentel et al., 2004; Grant et al., 2000). In effector triggered immunity (ETI), ROS are stronger induced when pathogen effectors are recognized by resistant $(R)$ genes. The relationship between ROS, HR cell death and plant resistance has been shown in some studies. For instance, Nbrboh-silencing in Nicotiana benthamiana decreases resistance and hydrogen peroxide accumulation in response to Phytophthora infestans (Yoshioka et al., 2003). ROS also contributes to cell wall strengthening or papillae formation (Bradley, 1992; Hückelhoven, 2007) and act as signaling molecules in mediating related gene expression to activate defense enzymes. In addition, ROS may also interact with other signaling components like kinases, calcium or generate lipid derivatives (Kovtun 2000; Piedra et al., 1998). ROS production has also been reported in a number of successful plant pathogen interactions. For instance, the necrotrophic pathogen Botrytis cinerea was found to induce an oxidative burst and hypersensitive cell death in Arabidopsis, and pathogenicity was directly dependent on superoxide and hydrogen peroxide generation and accumulation (Govrin and Levine, 2000). 
During plant defense activation, numerous signaling factors can act on the ROS generation and accumulation. A network of biological reactions contributes to the generation, diversity, and biochemical and molecular roles of ROS (Kunkel and Brooks, 2002; Jones et al., 2006). Until today, much of the research work into ROS related signaling or concerning enzyme production has been conducted with the early infection stages in the rice-M. oryzae interaction (Jarosch et al., 2003; Parker et al., 2009; Huang et al., 2011). In addition, most of the current knowledge on disease resistance is based on the model plant Arabidopsis thaliana. Thus, only limited information is available from wheat. Consequently, investigations on ROS in wheat against $M$. grisea and F. graminearum are required.

\subsubsection{Defense-related gene expression}

Upon pathogen attack, compatible or incompatible plant responses are induced, and activation of the immune system is associated with an induction of various defense genes (Dangl and Jones, 2001; Veronese et al., 2003). Multifaceted functions and molecules are mediating and regulating gene expression during plant defense responses. These include the generation or accumulation of reactive oxygen species, nitric oxide, salicylic acid, jasmonic acid or ethylene, which regulate the defense response through similar or different signaling pathways (Xu et al., 1994; Schaffrath et al., 1997; Anand et al., 2004). Some pathways lead to expression of pathogenesis-related (PR) proteins, which widely exist in the plant and constitute a major component in plant defense response. PR proteins include several functional classes, such as cell wall related $\beta-1,3$-glucanase $(P R 2)$, chitinases $(P R 3, P R 4)$, membrane related thaumatin-like proteins (PR5) and protein inhibitors (PR 6) (Dangl et al., 2001). A northern blotting analysis showed that $P R 2, P R 3$ and $P R 4, P R 5$ genes were expressed in wheat ears from 6 to $12 \mathrm{~h}$ with a highest expression in 36-48 $\mathrm{h}$ after inoculation with F. graminearum (Pritsch et al., 2000). Peroxidases (POX) are oxido-reductive enzymes that play a role in certain procedures like oxidation of phenols, suberization, and lignification of host plant cells during plant-pathogen defense response (Chittoor et al., 1999; Hiraga et al., 2001). Expression of the respective Pox genes in distinct tissues of wheat was assessed by RNA analysis, suggesting that three Pox genes were predominantly expressed in wheat roots. Furthermore, the Pox2 gene was selectively expressed in the infected wheat leaves by the 
powdery mildew fungus (Baga et al., 1995). Jasmonic acid or ethylene signaling is required for increased expression of defensin genes such as PDF1.2 (Thomma et al., 1998; Glazebrook, 2005). Jasmonic acid inhibited Arabidopsis seedling growth and induced the expression of the Arabidopsis vegetative storage protein, defensin (PDF1.2) and plant defense-related proteins, thionins (Manners et al., 1998; Bohlmann et al., 1998).

Lignin is mainly present in the secondary thickened cell walls of plants and plays an important role in development, growth, and resistance to biotic and abiotic stress. It is a complex biopolymer derived from oxidative polymerization of monolignols (Lacombe et al., 1997; Piquemal et al., 1998). During mechanical stress or pathogen attack, lignin synthesis can be induced in the plant as response to those biotic and abiotic stresses (Vance et al., 1980). In the initial stage of the lignin synthesis pathway, it is considered that cinnamoyl-CoA reductase $(C C R)$ is a key enzyme regulating the carbon flux towards lignins, meaning that the down-regulation of $C C R$ could affect the lignin content (Lacombe et al., 1997). It was reported that significant down-regulation of tobacco $C C R$ activity was shown through the ectopic expression of antisense genes, and several morphological alterations of leaves and vascular bundles were induced by the metabolic changes accompanying the reduction of $C C R$ activity (Piquemal et al., 1998).

Most of uridine diphosphate-glycosyltransferase $(U G T)$ genes are considered to code for enzymes transferring glucose to small molecules (Bowles D, 2006). Meanwhile, UGT genes with a potential function in deoxynivalenol (DON) detoxification have been identified in wheat and barley to be up-regulated in response to Fusarium spp. (Hill-Ambroz et al., 2006; Desmond et al., 2008; Steiner B, 2009). A glucosyltransferase gene from a DON resistant phenotype of Arabidopsis thaliana, encoding for an enzyme to transfer DON into a nontoxic component had been cloned through the respective cDNA in a toxin-sensitive yeast strain (Poppenberger et al. 2003). Numerous reports are about diverse candidate $U G T$ genes being differentially induced by Fusarium spp., or differential $U G T$ gene expression in hosts (Gardiner et al., 2010; Schweiger et al., 2010).

In addition, cytochrome P450 proteins are one of the largest superfamilies of enzyme proteins 
and named for their carbon-monoxide bound form and the $450 \mathrm{~nm}$ absorption band. The cytochrome $\mathrm{P} 450$ genes $(C Y P)$ are found in a large variety in plants (Werck-Reichhart and Feyereisen, 2000; Barlier et al., 2000). In the plant defense system, different chemical signaling pathways seem to induce P450 diversity. Derivatives from P450 proteins can be involved in plant defense or directly against fungal activity in the infection stage (Bak and Feyereisen, 2001; Noordermeer et al., 2001). Furthermore, P450 catalyze activation of molecular oxygen that leads to oxidative attack on a plethora of substrates (Werck-Reichhart and Feyereisen, 2000). In addition to P450 gene expression induction by fungal invasion, this can also result from interaction with the jasmonic acid pathway (Kandel et al., 2007; Walter et al., 2008).

Numerous investigations have been carried out on wheat against F. graminearum spp. infection about transcriptomic, genomic or proteomic facets for better understanding the molecular mechanisms behind the incompatible and compatible interactions (Bernardo et al., 2007; Cho et al., 2012; Jia et al., 2009). The rice-M. oryzae interaction is a typical model to study the plant-pathogen multiple mechanisms, particularly since the sequencing of the entire genome of M. oryzae has been accomplished (Dean et al., 2005). However, few reports on genetic analysis are available related to the interaction of wheat with the wheat blast fungus, M. grisea. This is not satisfactory in view of a better understanding of the molecular mechanisms of the wheat- $M$. grisea interaction. Hence, a transcriptomic study is required with $M$. grisea on wheat, which may be contrasting the events in the F. graminearum-wheat interaction, which thus may be useful to comprehend the differential gene regulation in the two interactions.

\subsection{Objectives of the study}

Wheat blast and FHB are highly important and serious diseases on wheat. They can infect wheat or other crops together and lead to high yield losses. Since fundamental studies on pathogenesis and the plant-pathogen interaction of both pathogens on wheat ears are lacking, the present study was initiated in order to figure out the differential development of $M$. grisea and F. graminearum on ears of wheat cultivars differing in resistance to the two pathogens. 
Therefore, a reliable inoculation and evaluation system has been established under controlled conditions and fungal development on the ears was followed macro- and microscopically. Moreover, ROS responses and gene expression were analyzed related to the differential interactions. The main specific objectives were the following:

To evaluate the response of different wheat cultivars to wheat blast and FHB.

$>$ To study the temporal and histological patterns of disease development on ears by macroscopic and microscopic methods.

$>$ To analyze the role of ROS and plant defense genes in wheat-M. grisea and wheat$F$. graminearum interactions. 


\section{Materials and Methods}

\section{Chemicals}

Acetic acid

Applichem, Darmstadt

Agar Agar

Merk, Darmstadt

Agarose

Albi Vegetable juice

Applichem, Darmstadt

Ammonium acetate

Benzimidazole

Calcium carbonate $\left(\mathrm{CaCO}_{3}\right)$

Albi, Bühlenhausen

Applichem, Darmstadt

Merk, Hohenbrunn

Casein

Roth, Karlsruhe

Chloroform

Diethylpyrocarbonate (DEPC)

Roth, Karlsruhe

Applichem, Darmstadt

dNTPs-Mix (10 mM)

Dream Taq-buffer $(10 \mathrm{X})$

EDTA

Ethanol (100\%)

Ethidium bromide

Glucose

Glycerine

Hakaphos

Hydrogen chloride $(\mathrm{HCl})$

Hydrogen peroxide (30\%)

hexadecyltrimethylammonium bromide (CTAB)

Isoamyalcohol

Isopropyl alcohol

Magnesium sulphate $\left(\mathrm{MgSO}_{4} \cdot 7 \mathrm{H}_{2} \mathrm{O}\right)$

Methanol

Monopotassium phosphate $\left(\mathrm{KH}_{2} \mathrm{PO}_{4}\right)$

$\mathrm{Na}_{2} \mathrm{HPO}_{4} \cdot 12 \mathrm{H}_{2} \mathrm{O}$

$\mathrm{NaH}_{2} \mathrm{PO}_{4} \cdot 2 \mathrm{H}_{2} \mathrm{O}$

PCR-Puffer

Potassium chloride $(\mathrm{KCl})$

Potassium nitrate $\left(\mathrm{KNO}_{3}\right)$

Proteinase K

RNAse

Saccharose

Sodium azide $\left(\mathrm{NaN}_{3}\right)$

Sodium chloride

Sodium hypochlorite $(\mathrm{NaClO})$

Streptomycin sulphate

Taq DNA polymerase $(5 \mathrm{U} / \mu \mathrm{l})$

TE buffer

Tris $\mathrm{pH} 8.0$

Roth, Karlsruhe

Fermentas, St. Leon-Rot

Fermentas, St. Leon-Rot

Roth, Karlsruhe

Sigma, Taufkirchen

Applichem, Darmstadt

Applichem, Darmstadt

Roth, Karlsruhe

Compo, Münster

Applichem, Darmstadt

Roth, Karlsruhe

Applichem, Darmstadt

Applichem, Darmstadt

Applichem, Darmstadt

Applichem, Darmstadt

Applichem, Darmstadt

Applichem, Darmstadt

Roth, Karlsruhe

Roth, Karlsruhe

Fermentas, St. Leon-Rot

Applichem, Darmstadt

Applichem, Darmstadt

Fermentas, St. Leon-Rot

Applichem, Darmstadt

Roth, Karlsruhe

Scharlau, Barcleona

Applichem, Darmstadt

Roth, Karlsruhe

Duchefa, Biochemi

Fermentas, St. Leon-Rot

Applichem, Darmstadt

Fermentas, St.Leon-Rot

Scarlau Chemie S.A.

Tween 20

Applichem, Darmstadt 
100bp Ladder Plus

Sodium dodecyl sulfate (SDS)
Fermentas, St. Leon-Rot

Applichem, Darmstadt

\section{Medium and buffers}

All medium in study were autoclaved at $121^{\circ} \mathrm{C}, 103.4 \mathrm{kPa}$ pressure for $20 \mathrm{~min}$, after were supplemented with $200 \mathrm{mg} \mathrm{L}^{-1}$ streptomycin sulphate to prevent bacteria contamination.

Complete Media Agar (CM)

Yeast extract $3 \mathrm{~g}$

Casaminoacid $\quad 3 \mathrm{~g}$

Sucrose $\quad 5 \mathrm{~g}$

Agar $\quad 15 \mathrm{~g}$

Distilled water $1000 \mathrm{~mL}$

$\underline{\text { V8-Agar (V8A) }}$

V8 juice $\quad 100 \mathrm{~mL}$

$\mathrm{CaCO}_{3} \quad 2 \mathrm{~g}$

Agar $\quad 15 \mathrm{~g}$

Distilled water $\quad 900 \mathrm{~mL}$

Synthetic nutrient-poor agar (SNA)

$\mathrm{KH}_{2} \mathrm{PO}_{4} \quad 1 \mathrm{~g}$

$\mathrm{KNO}_{3} \quad 1 \mathrm{~g}$

$\mathrm{MgSO}_{4} \cdot 7 \mathrm{H}_{2} \mathrm{O} \quad 0.5 \mathrm{~g}$

$\mathrm{KCl} \quad 0.5 \mathrm{~g}$

Glucose $\quad 0.2 \mathrm{~g}$

Saccharose $\quad 0.2 \mathrm{~g}$

Agar $\quad 15 \mathrm{~g}$

Distilled water $1000 \mathrm{~mL}$

2\% straw extract agar (SEA)

chopped dry straw $2 \mathrm{~g}$

Agar $\quad 15 \mathrm{~g}$

Distilled water $\quad 1000 \mathrm{~mL}$ 
Straw liquid medium (autoclaved twice at an interval of 24 hours and after cooling)

Chopped dry straw $12 \mathrm{~g}$

Distilled water $\quad 500 \mathrm{~mL}$

$\underline{\text { Potato dextrose agar (PDA) }}$

Potato extract $4 \mathrm{~g}$

Dextrose $20 \mathrm{~g}$

Agar $\quad 15 \mathrm{~g}$

Distilled water $\quad 1000 \mathrm{~mL}$

$\underline{\text { CTAB extraction buffer }}$

CTAB $\quad 1 \%$

$\mathrm{NaCl} \quad 0.7 \mathrm{M}$

Tris $\mathrm{pH} 8.0 \quad 50 \mathrm{mM}$

EDTA $\quad 10 \mathrm{mM}$

Distilled water up to $100 \mathrm{~mL}$

$\underline{\text { TE-buffer }}$

Tris $\mathrm{pH} 8.0 \quad 10 \mathrm{mM}$

EDTA $\quad 1 \mathrm{mM}$

$\underline{0.2 \mathrm{M} \text { Sodium phosphate buffer }}$

$0.2 \mathrm{M} \mathrm{NaH}_{2} \mathrm{PO} 4 \cdot 2 \mathrm{H}_{2} \mathrm{O}: 3.12 \mathrm{~g}$ in $100 \mathrm{~mL}$

$0.2 \mathrm{M} \mathrm{Na}_{2} \mathrm{HPO}_{4} \cdot 12 \mathrm{H}_{2} \mathrm{O}: 7.17 \mathrm{~g}$ in $100 \mathrm{~mL}$

$\underline{\mathrm{pH}} 7.0$

$0.2 \mathrm{M} \mathrm{NaH}_{2} \mathrm{PO} 4 \cdot 2 \mathrm{H}_{2} \mathrm{O} \quad 19.5 \mathrm{~mL}$

$0.2 \mathrm{M} \mathrm{Na}_{2} \mathrm{HPO} \cdot 12 \mathrm{H}_{2} \mathrm{O} \quad 30.5 \mathrm{~mL}$

Distilled water $\quad 100 \mathrm{~mL}$

$\underline{\mathrm{pH}} 7.8$

$0.2 \mathrm{M} \mathrm{NaH}_{2} \mathrm{PO} 4 \cdot 2 \mathrm{H}_{2} \mathrm{O} \quad 4.25 \mathrm{~mL}$

$0.2 \mathrm{M} \mathrm{Na}_{2} \mathrm{HPO}_{4} \cdot 12 \mathrm{H}_{2} \mathrm{O} \quad 45.75 \mathrm{~mL}$

Distilled water $\quad 100 \mathrm{~mL}$ 


\subsection{Plant material}

A set of twenty-seven wheat genotypes was provided by the International Maize and Wheat Improvement Center (CIMMYT, Texcoco, Mexico). It was composed of various commercial varieties from South America. All the wheat seeds were sown in a small size plastic pot $(9 \mathrm{~cm} \mathrm{x}$ $9 \mathrm{~cm})$ filled with a soil mixture of sand, peat and compost (1:1:2). Each pot contained two seeds and was cultured in the greenhouse at $23 \pm 2{ }^{\circ} \mathrm{C}$ with a $14 \mathrm{~h}$ photoperiod per day. Regular nutrition (Hakaphos, $3 \mathrm{~g} / \mathrm{L}$ ) was applied to the seedlings since the four-leaf stage (GS 13-15, Zadoks et al., 1974). Each pot was thinned to two main tillers. Uniform plants were selected when mature ears were in anthesis stage (growth stage, GS 61-69).

Twenty-seven wheat cultivars obtained from South America were used in this study. These were IAN 10-DON Arte, ITAPAU 50-Amistad, ITAPAU 45-DON PANI, ITAPAU 55-DON H. BERTONI, BR 23, BR 35, BRS 177, BRS 179, CANINDE 1" 'S", ITAPAU 70, CANINDE 2 , CANINDE 3, ITAPAU 60, ITAPAU 65-DON VALERIO, BR 8, BR 14/ CEP 847, THORNBIRD, Chirya 3, GONDO/ CBRD, CROC 1/ AE.SQARROSSA (224) OPATA, PF 87512/ CBRD, BR 23 EMB 27 // CEP, 21 / BOMB, BR 18, Milan and Sumai 3.

\subsection{Fungal material}

M. grisea isolates IPP 0683, IPP 0685 and IPP 0693 were used (isolates IPP 0683 and 0685 from St. Cruz of Bolivia (2008), isolate IPP 0693 from Brazil, all isolated in 2008). M. grisea was cultured on $5 \%$ V8A medium supplied with streptomycin $(200 \mathrm{ppm})$, the plates being incubated in a growth chamber at $25^{\circ} \mathrm{C}$ under $10 / 14$ hour light/dark alternation. For long term storage, pure cultures were grown on 5\% V8A plates covered with sterilized filter paper discs (Baumwoll-Linter, 6mm, Roth, Karlsruhe, Germany). Those plates were cultivated for 7 to 10 days until the filter papers were fully covered with $M$. grisea mycelia. The filter papers then were dried under $4{ }^{\circ} \mathrm{C}$ for two days and stored at $-20^{\circ} \mathrm{C}$.

F. graminearum isolates 141, 142 and 143 were derived from infected winter wheat ears obtained from a field in Göttingen (2008) and grown on synthetic nutrient-poor agar (SNA) plates containing $200 \mathrm{mg} \mathrm{L}^{-1}$ streptomycin. Plates were placed at room temperature (RT) and the 
fungus was stored on $2 \%$ straw extract agar (SEA) at $-4^{\circ} \mathrm{C}$.

A GFP labelled F. graminearum strain with stable fluorescence was employed in the microscopic investigations. The GFP-tagged $F$. graminearum strain was kindly provided by Professor Dr. Wilhelm Schäfer (Biocenter Klein-Flottbek, Molecular Phytopathology and Genetics, University of Hamburg). For this strain, similar cultivation methods were used as described above.

\subsection{Inoculum preparation of pathogens}

\subsubsection{M. grisea}

Conidial suspension was prepared by scratching aerial mycelia from V8A plates, and harvesting in distilled water with a sterile spatula and filtering through sterilized cheesecloth. Conidia density was determined by haemocytometer and adjusted to 1 x $10^{5}$ spores $\mathrm{mL}^{-1}$. Since the virulence of isolates was unclear, a mixed spore suspension was used for cultivars resistance screening including three isolates: IPP 0683, IPP 0685 and IPP 0693. Isolate $M$. grisea IPP 0685 was used in the microscopic and plant defense related studies.

\subsubsection{F. graminearum}

F. graminearum inoculum was prepared according to the following steps: First, five to seven $1 \mathrm{~cm}^{2}$ fungal plugs were punched out from a 3-5 day old PDA culture and transferred into a straw liquid medium. This liquid medium was subsequently incubated for 2 weeks on a rotary shaker at $25^{\circ} \mathrm{C}(100 \mathrm{RPM})$. Afterwards, the conidia suspension was filtered through sterilized cheesecloth and the concentration was adjusted to $1 \times 10^{5}$ spores $\mathrm{mL}^{-1}$. Mixed spore suspension of F. graminearum consisting of three isolates 141,142 and 143 was used in cultivar screening, while isolate $F$. graminearum 143 was used in microscopic and defense related studies.

\subsection{Inoculation procedures}

\subsubsection{Whole ear inoculation}

Whole ear inoculation was performed in a climate chamber with favorable conditions $\left(23^{\circ} \mathrm{C}\right.$, $80 \%$ humidity and 12/12 hour light/dark alternation) for both pathogens. Inoculation was 
performed at flowering stage (GS 60-69) by spraying spore suspension on the ear using an air compressor. On the average, $2 \mathrm{~mL}$ of the individual spore suspensions were sprayed per ear. To maintain $100 \%$ relative humidity, the inoculated ears were covered with plastic bags and kept in the dark for $24 \mathrm{~h}$. The covering bags were removed afterwards and the plants were cultivated in the climate chamber with $12 \mathrm{~h}$ light per day. Control ears were sprayed with sterilized distilled water.

\subsubsection{Leaf inoculation}

Leaf inoculation was done at the 3 leaf-stage (GS13) in a similar fashion as the whole ear inoculation. However, the inoculated was conducted without packing of leaves in bags.

\subsubsection{Point inoculation on ears}

Point inoculation was done in climate chamber with the same conditions as ear inoculation. Two adjacent and oppositely located spikelets at the midpoint of ears were selected. About ten $\mu \mathrm{L}$ of spore suspension were injected in each spikelet with a sterile disposable syringe. The cultivation steps were same as with the ear inoculation.

\subsection{Disease assessment}

\subsubsection{Wheat blast}

For wheat blast assessment, each cultivar consisted of fourteen replicates to be tested. Two independent experiments were conducted. M. grisea disease assessment was performed at $7 \mathrm{dpi}$. Blast severity on ears was evaluated by the visual scoring system using a 5 class disease index modified from Murakami et al., 2000 (Table 1; Figure 2). Disease evaluation on leaves was performed at 9 dpi following the methods described in Murakami et al. (2000). 
Table 1. Assessment key for visual disease scoring of wheat blast caused by M. grisea (modified from Murakami et al., 2000)

\begin{tabular}{c|c}
\hline Score & Symptom development \\
\hline 0 & Healthy plant with no symptoms \\
1 & Less than $5 \%$ of ears show symptom \\
2 & $5-35 \%$ of ears show symptom \\
3 & $35-65 \%$ of ears show symptom \\
4 & $65-80 \%$ of ears show symptom \\
5 & More than $80 \%$ of ears show symptom \\
\hline
\end{tabular}
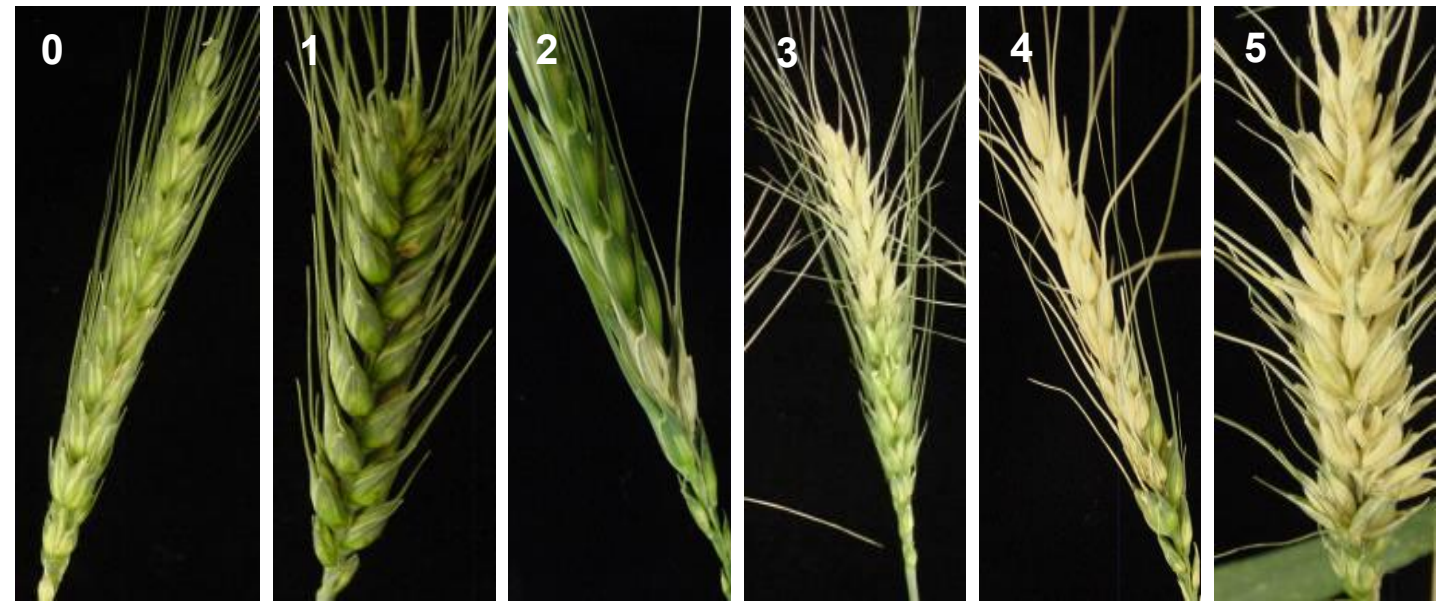

Fig. 2. Phenotypes of blast disease severity on wheat ears. The number 0-5 indicate disease index.

\subsubsection{Fusarium Head Blight}

Twenty-four replicates of each cultivar were tested in the Head Blight test and the experiment was repeated twice. The disease severity level was determined by counting the number of infected spikelets per ear (Engle et al., 2003). Disease assessment was done at 7, 14, 21 dpi. The area under the disease progress curve (AUDPC) was calculated according to the following formula (Madden \& Campbell, 1990): 
$\operatorname{AUDPC}=\sum_{i=1}^{n}\left(y_{i}+\frac{y_{i+1}}{2}\right) *\left(t_{i+1}-\mathrm{t}\right)$

Where $y_{i}$ is the disease severity value (percentage) for the observation number $i, t_{i}$ is the time (days) of $i$ observation and $\mathrm{n}$ is the total number of observations.

In the point inoculation assays, severity of both diseases was evaluated by AUDPC continuously at $3,4,5,7,10,15$, and 21 days after inoculation (dpi).

\subsection{Detection of pathogen growth in plant tissue}

\subsubsection{Fluorescence microscopy observation}

Twelve inoculated plants of culivars Milan and Sumai 3 with M. grisea and F. graminearum were used. Disease symptom progress on infected ears was recored at 3, 4, 5, 7, 10, 15, 21 dpi. Fluorescence microscopy was applied to confirm the level of pathogenesis on ears. The whole inoculated ear was checked by fluorescence stereomicroscopy (Leica MZ16 FA, Bensheim, Germany) under bright field and with GFP Plus excitation filter from 460 to $500 \mathrm{~nm}$, and the barrier filter was a 510nm longpass (LP) filter.

\subsubsection{Fungal colonization on infected ear sections}

Six individual $M$. grisea and $F$. graminearum infected ears of culivars Milan and Sumai 3 were collected at $21 \mathrm{dpi}$. After removing all spikelets, the rachis was cut into 11-13 segments depending on the genotype. The size of each segment was delimited by two adjacent longitudinal spikelets. The upward/downward parts were marked as 1, 2, 3, 4, 5, 6 in sequence, and the original inoculated point as 0 .

All segments were disinfected in $10 \% \mathrm{NaOCl}$ for 3-5 min, washed twice in sterilized $\mathrm{H}_{2} \mathrm{O}$ and placed on PDA plates. After 3 to 5 days, the small colonies which occurred around the segments were checked by light microscopy, and putative M. grisea and F. graminearum colonies were transferred to 5\% V8A and SNA plates. Microscopic confirmation of these colonies was carried out at 3 to 7 days after incubation. 
The disease index (DI) represents the fungal development in the rachis and its calculation was based on the isolations from various sections. The formula is shown below, where $i$ is the number of sections, $y_{i}$ is the fungal isolates obtained from corresponding sections and $n$ is the total number of observations.

$\mathrm{DI}=\sum_{i=0}^{n}\left(y_{i} * i\right)$

\subsection{Histological investigation of fungal expansion on ears}

\subsubsection{Time course determination on spikelet and rachilla}

To assess pathogen growth in the outer tissue of the ear, the spikelet was used for histological observation. Spikelet can be defined as the ultimate floret bunch in the grass family. It is composed of glume, lemma, palea, stamen and pistil, further stamen and pistil contains anther, filament and stigma, and ovary separately (Figure 3). The fungal development inside the plant was investigated in the rachilla, the part connecting spikelet and rachis. The rachilla plays a role at the later infection stage (Figure 3).

For measurement of fungal growth on cultivars Sumai 3 and Milan inoculated with M. grisea and F. graminearum, six time points within 72 hpi with 12 hour intervals were adopted: 12, 24, $36,48,60,72 \mathrm{hpi}$. In the interest of exploring the pathogen development in the spikelets, anthers, filaments, stigmae and paleae, these plant parts were separately investigated under the microscope. Besides these six time points, additional observations were conducted at 5, 7, 10, 14 dpi for rachilla examination.

Both studies included five biological repetitions for each time point, and each repetition involved 8-10 spikelets or 5-7 rachilla locations, eventually at each time point 40-50 dissected spikelets and 80-100 transverse or longitudinal sections from the rachilla were examined in a single interaction. This evaluation was conducted at least in three independent experiments. 
The histological examination of spikelets and rachillae was conducted with a Leica TCS SP5 Confocal Laser Scanning Microscope (CLSM; Leica, Mannheim, Germany) or a normal fluorescence light microscopy (Leica DFC 420; Mannheim, Germany).
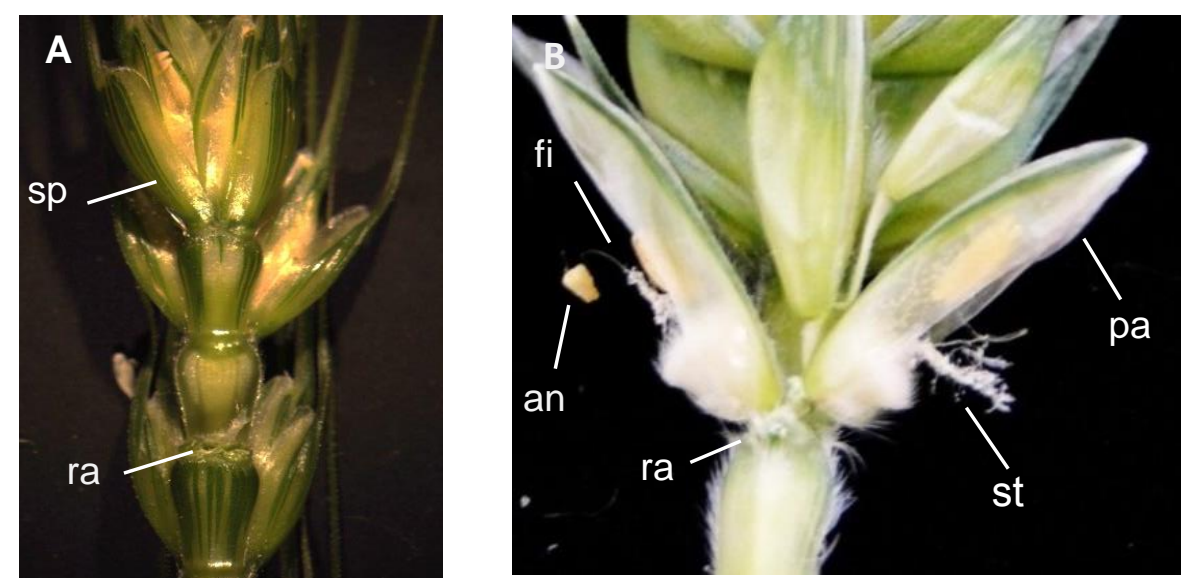

Fig. 3. Bright field views of ear and spikelet from cvs. Sumai 3 and Milan. A, non-inoculated ear from Sumai 3 with a complete spikelet, rachilla is presented below after removing the spikelet. B, non-inoculated dissected spikelet from Milan, showing different details from the inner part of the spikelet. $\mathrm{fi}=$ filament, $\mathrm{an}=$ anther, $\mathrm{ra}=$ rachilla, $\mathrm{st}=$ stigma, $\mathrm{pa}=$ palea, $\mathrm{sp}=$ spikelet.

\subsubsection{Observation of fungal spread in spikelets by Confocal Laser Scanning Microscope (CLSM) and fluorescence microscopy}

Microscopic detection of $M$. grisea was achieved by WGA-tetramethylrhodamine staining (Invitrogen, Karlsruhe, Germany). Observed samples were detached from spikelets of inoculated ears at the time points indicated above. Lemma and glume parts were excised and the anther, filament, stigma, palea were collected successively. All separated specimen were immersed in 10 $\mu \mathrm{g} \mathrm{mL}^{-1}$ WGA-tetramethylrhodamine staining solution for $20 \mathrm{~min}$ with vacuum infiltration, then rinsed twice in sterilized water to get rid of background staining before microscopic observation. Different samples were placed on glass slides, sealed with a cover slip and immediately examined by CLSM.

For F. graminearum infection analysis, the GFP labelled strain was used. Accordingly, specimen from infected spikelets were placed directly on glass slides in drops of water with covering slips and evaluated. 
Microscopic evaluation of spikelets was done by CLSM. During the CLSM procedure, wavelength settings for WGA-tetramethylrhodamine observation were $514 \mathrm{~nm}$ for excitation and 560-580 $\mathrm{nm}$ for emission. Digital images were obtained by two-channel-analysis including the background and required excitation channels. Rhodamine stained hyphae red and grey colour was given for the background channel. Digital images of GFP-labelled strains were acquired by scanning with $488 \mathrm{~nm}$ excitation and 520-536 nm emission filters, additionally with the background channel. Overlay images were generated by digital stacking of optical sections.

In addition, common fluorescence light microscopy was applied during $F$. graminearum-GFP and M. grisea staining. F. graminearum-GFP under filter I3 (excitation 450-490 nm, suppression $515 \mathrm{~nm}$ ) showed a green colour, rhodamine stained M. grisea hyphae red under the DsRed filter (excitation 515-575 nm, suppression 560-680 nm; Figure 4).
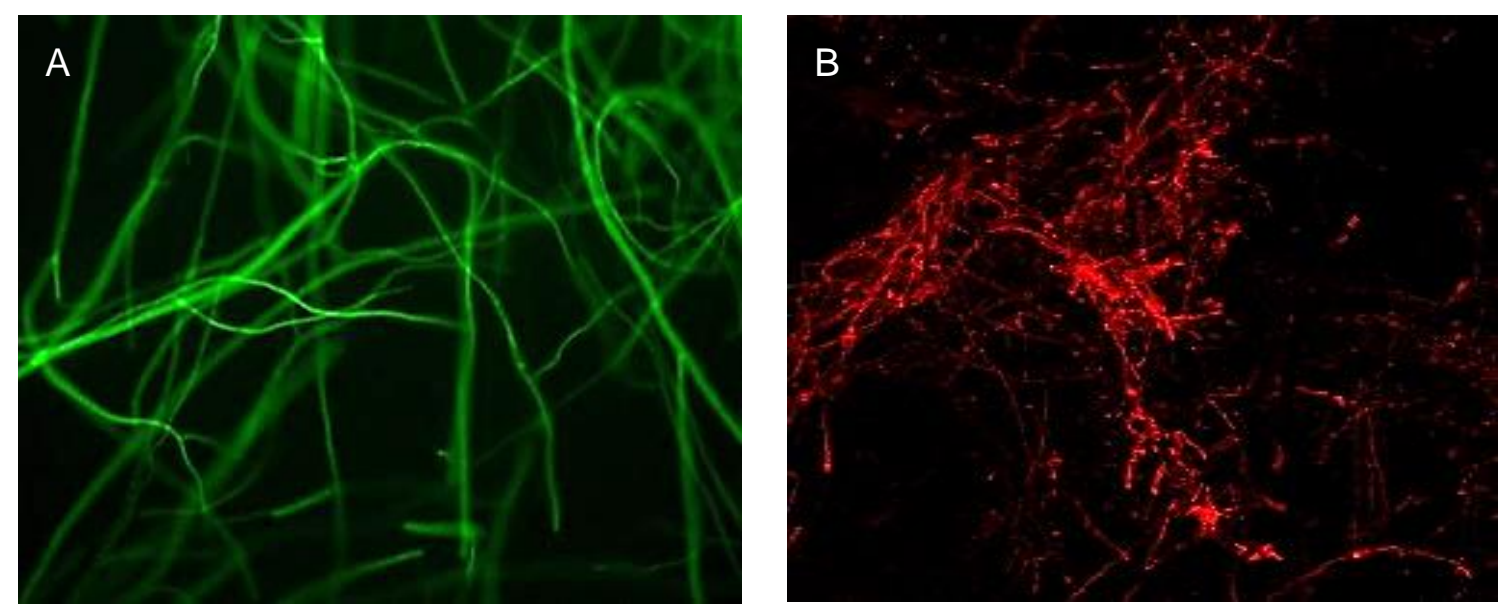

Fig. 4. Fluorescence images of F. graminearum-GFP and M. grisea. A, green fluorescence of the GFP-tagged F. graminearum strain (x200). B, red mycelia of M. grisea stained by WGAtetramethylrhodamine (x100).

\subsubsection{Observation of fungal spread in rachilla by CLSM}

Microscopic investigations of the fungal development in the rachilla were conducted with Alexa Fluor 488 and propidium iodide staining (Invitrogen, Karlsruhe, Germany). Specifically, Alexa Fluor 488 stained hyphae green while propidium iodide gave a red colour of hyphae against plant tissue. Sample preparation started by removing all the spikelets and manually cutting the rachilla into thin longitudinal and transverse sections. These sections were dipped into staining 
solution containing Alexa Fluor $488\left(1 \mathrm{mg} \mathrm{mL}^{-1}\right)$ and propidium iodide $\left(100 \mathrm{~g} \mathrm{~mL}^{-1}\right)$ with vacuum infiltration for $20 \mathrm{~min}$. The samples were rinsed afterwards in sterilized water at least twice to remove excess staining. Finally, the sections were placed on glass slides with water and sealed with cover glass before microscopical observation.

CLSM analyses were performed for rachilla investigation. The digital images of stained specimen were acquired by two-channel-analysis with subsequent drafting of an overlay. Settings for Alexa Fluor 488 were $488 \mathrm{~nm}$ for excitation and 515-523 nm for emission and for propidium iodide $540 \mathrm{~nm}$ for excitation and 560-620 nm for emission. Stacks of optical sections were processed to projection.

Moreover, a normal fluorescence light microscope was employed for the observation of the initial infection in rachillae. In this procedure, infected rachillae were stained with Alexa Fluor and propidium iodide and checked under filter I3 (excitation filter 450-490 nm, suppression filter $515 \mathrm{~nm}$ ). The hyphae of F. graminearum and M. grisea showed green colour, while plant tissue was between red and orange. Images were created at 100x or 200x magnification.

\subsection{Biochemical examination of ears}

\subsubsection{Experimental design}

The palea part of spikelets was collected for biochemical measurement and histological observation of ROS on infected ears. In the grass family, the palea is the inner layer enclosing the floret and is much thinner and more transparent than the outer layers, the lemma and glume (Figure 5). Normally, in 3-7 days after inoculation, distinct brownish or water-soaked lesions were detectable on the palea after M. grisea inoculation.

The ROS detection experiment consisted of four interactions: Sumai 3-M. grisea, Milan-F. graminearum, Sumai 3-F. graminearum, Milan-M. grisea, with six time points for sampling (12, 24, 36, 48, 60, $72 \mathrm{hpi})$. Each interaction at each time point was studied on three individual biological replicates, each replicate included three technical repetitions. Likewise this experiment was carried out in two independent repetitions. 

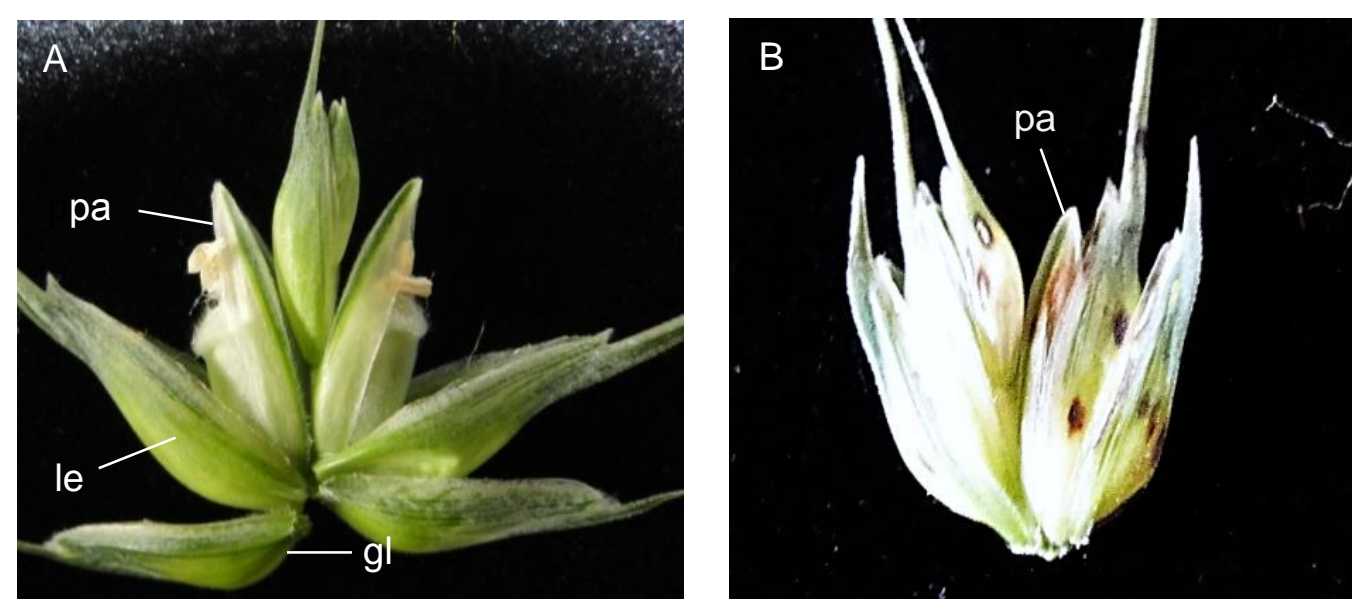

Fig. 5. Bright field views of spikelets from cv. Milan. A, a non-inoculated spikelet in ripening stage. B, a diseased spikelet at $10 \mathrm{dpi}$ after $M$. grisea inoculation with typical clear brown soaking lesions. $\mathrm{Pa}=$ palea, $\mathrm{le}=$ lemma, $\mathrm{gl}=$ glume.

\subsubsection{Quantification of ROS}

Superoxide radical

Seven palea samples derived from three ears were collected from each independent inoculation and sampling time point, the samples were incubated in $2 \mathrm{~mL}$ of a solution containing $100 \mu \mathrm{M}$ EDTA, $20 \mu \mathrm{M} \beta$-nicotinamide adenine nucleotide reduced ( $\beta$-NADPH, Sigma, St. Louis, USA), and $20 \mathrm{mM}$ sodium phosphate buffer (pH 7.8).

The mixture was prepared in septum-stoppered flasks. The reaction was initiated after the addition of $100 \mu \mathrm{L}$ of $25.2 \mathrm{mM}$ epinephrine (Sigma, St. Louis, USA) in $0.1 \mathrm{~N} \mathrm{HCl}$ using a syringe. Samples were incubated for $5 \mathrm{~min}$ at $28^{\circ} \mathrm{C}$ under shaking. Then, the palea tissues were carefully removed using plain sterile forceps and after $7 \mathrm{~min}$, the absorbance in the reaction mixture was measured at $480 \mathrm{~nm}$ for $5 \mathrm{~min}$ in a cuvette on a plate reader photometer (Analytikjena, Jena, Germany). The controls consisted of mixtures without addition of palea tissue (Misra and Fridovich, 1971).

The $\mathrm{O}_{2}{ }^{-}$production was determined by the rate of adrenochrome accumulation. Formula $\mathrm{C}=$ $\mathrm{A} / \mathrm{Kb}$ was used to calculate $\mathrm{O}_{2}{ }^{-}$concentration (A is absorbance value; $\mathrm{b}=1 \mathrm{~cm}$, the cuvette thickness; $\mathrm{K}=4.02 \times 10^{3} \mathrm{M}^{-1} \mathrm{~cm}^{-1}$ (Green et al., 1956) is the adrenochrome extinction 
coefficient at $480 \mathrm{~nm}$; $\mathrm{C}$ is the required concentration).

Hydrogen peroxide

The method of $\mathrm{H}_{2} \mathrm{O}_{2}$ detection was modified following the protocol by von Tiedemann (1997).

Paleae (7 pieces) from three ears were collected from independent inoculations at continuous time intervals as before, and submerged in $500 \mu \mathrm{L}$ reagent mixture containing $0.05 \%$ guaiacol $\left(\mathrm{C}_{7} \mathrm{H}_{8} \mathrm{O}_{2}\right.$, Sigma, St. Louis, USA) and horseradish peroxidase (HRP, $350 \mu \mathrm{L} \mathrm{L}^{-1} ; 2,500 \mathrm{U} \mathrm{mL}^{-1}$, Sigma, St. Louis, USA) in $25 \mathrm{mM}$ sodium phosphate buffer ( $\mathrm{pH} 7.0)$ and incubated for $2 \mathrm{~h}$ at $20^{\circ} \mathrm{C}$ in the dark.

A volume of $250 \mu \mathrm{L}$ was transferred into 96 -well microtitre plates and the absorbance was immediately measured at $470 \mathrm{~nm}$ in a plate reader photometer (Bio-Tek, BadFriedrichschall, Germany). Additionally, a standard curve was calibrated by commercial $\mathrm{H}_{2} \mathrm{O}_{2}$ with HRP.

\subsubsection{Detection of ROS in plant tissue}

Nitroblue tetrazolium (NBT) staining

NBT (Merck, Darmstadt, Germany) can form a dark-blue water-insoluble precipitate upon reduction by superoxide radicals. The method of NBT staining was based on the procedure described by Adam et al. (1989).

Paleae samples were collected and infiltrated in a solution by vacuum containing $300 \mu \mathrm{M}$ NBT, $10 \mathrm{mM} \mathrm{NaN}_{3}$ and $0.1 \mathrm{mM}$ EDTA. After $3.5 \mathrm{~h}$ of incubation, a clearance solution with ethanolchloroform (4:1) was used for destaining, and then the samples were placed at room temperature for 2 days in darkness and conserved in 96\% ethanol. The samples were then cleaned in sterilized water twice and examined by light microscopy (Leica, Bensheim, Germany).

3, 3'-diaminobenzidine (DAB) staining

DAB (Sigma, St. Louis, USA) turns into a reddish-brown colour upon reaction with $\mathrm{H}_{2} \mathrm{O}_{2}$. The DAB staining method was modified according to the protocol from Thordal-Christensen et al. (1997). 
Infected paleae were cleared in a mixture of methanol: acetic acid $(3: 1)$ at $72^{\circ} \mathrm{C}$ for $15-20 \mathrm{~min}$, transparent plant tissues were immersed into $1 \mathrm{mg} \mathrm{mL}^{-1} \mathrm{DAB}$ solution $(\mathrm{pH} \mathrm{3.8)}$ ) and incubated under darkness overnight. Then the solution was removed and the tissues were stored in $96 \%$ ethanol. The samples were cleaned in sterilized water twice before microscopic examination.

\subsection{Gene expression studies}

\subsubsection{Experimental design}

Different plant tissues from Milan and Sumai 3 infected with $M$. grisea and $F$. graminearum were collected at four time points. The parts of spikelets and rachillae were collected at 24 and 48 hpi. At 3 and 5 dpi, there were only rachis samples harvested.. As checks, spikelets, rachillae and rachis were taken from non-inoculated control plants at 0 hpi.

The experiment was designed with three independent biological replicates for each interaction and time point, and each replicate included three individual ears.

\subsubsection{Determination of target genes}

Information of selected genes and primers

Based on literature reviews and previous studies, eighteen genes were selected for initial examination (Table 2). These included housekeeping genes, defense related and pathogenesisrelated (PR) genes, peroxidase and signaling-related genes, and lignification and detoxification related genes. Primers of nine genes were taken from literature sources. For the remaining 6 genes, primers were designed using a primer design tool-Primer 3 Plus. 
Table 2. Related-defense genes for gene analysis in polymerase chain reaction (PCR)

\begin{tabular}{|c|c|c|c|c|}
\hline $\begin{array}{l}\text { Accession } \\
\text { number }\end{array}$ & Gene & Putative function & $\begin{array}{l}\text { Forward ( 5'-3')and reverse ( } 3^{\prime}-5 \text { ') } \\
\text { primer sequence }\end{array}$ & $\begin{array}{l}\text { Primer } \\
\text { resource }\end{array}$ \\
\hline AB181991 & Actin & Housekeeping & $\begin{array}{l}\text { For: GCTGTTCCAGCCATCTCATGT } \\
\text { Rev: ATCAGCAATTCCAGGAAAC }\end{array}$ & Li et al., 2010 \\
\hline X56601 & Ubiquitin & Housekeeping & $\begin{array}{l}\text { For: CTGGAGGTGGAGTCATCTGA } \\
\text { Rev: GGCCATCCTCAAGCTGCTTA }\end{array}$ & $\begin{array}{l}\text { Gottwald et al., } \\
2012\end{array}$ \\
\hline AF 112963 & Chi 2 & Class VII acidic chitinase & $\begin{array}{l}\text { For: GGAAAATCAACAGTGGCGA } \\
\text { Rev: GTCGATCAAGAATCTAGCAA }\end{array}$ & Li et al., 2010 \\
\hline X58394.1 & $P R 5$ & thaumatin-like protein & $\begin{array}{l}\text { For: TGCTCCTTCAATGGCGGTAG } \\
\text { Rev: GTTGGGGTGTTGGTAGGCTT }\end{array}$ & Present study \\
\hline AF112965.1 & $P R 2$ & $\beta-1,3$ glucanase, acidic & $\begin{array}{l}\text { For: CAGAGATAGGCGACGAGGA } \\
\text { Rev: CTTTATGGCCGGGAGGATGG }\end{array}$ & Present study \\
\hline AM180656.1 & Pgip 1 & $\begin{array}{l}\text { polygalacturonase } \\
\text { inhibiting protein }\end{array}$ & $\begin{array}{l}\text { For: TTCGGCAATCAGAGCCACTT } \\
\text { Rev: AGGTGGTTGTTGGAGAGCA }\end{array}$ & Present study \\
\hline D13795.1 & Trig 7 & $\begin{array}{l}\text { Ribosome inhibiting } \\
\text { protein }\end{array}$ & $\begin{array}{l}\text { For: GGGAAGATCGGCAATGAGA } \\
\text { Rev: TATGAAACAGCTCCAGCGCC }\end{array}$ & Present study \\
\hline X85228 & Pox 2 & Peroxidase & $\begin{array}{l}\text { For: AACGACACCACCGACAACA } \\
\text { Rev: GTCCATCACGAGTTCACCTT }\end{array}$ & Li et al., 2010 \\
\hline BQ161883 & $C C R$ & cinnamoyl-CoA reductase & $\begin{array}{l}\text { For: GCTCCTGGCTGTAGGATCAC } \\
\text { Rev: CGAGTAAGCAGCCGTACAA }\end{array}$ & Present study \\
\hline FG985273 & $U G T$ & $\begin{array}{l}\text { UDP-Glycosyl } \\
\text { Transferase }\end{array}$ & $\begin{array}{l}\text { For: CAACCCACCATTGCAAAGTA } \\
\text { Rev: TTTTGCATCCACTTCACAGC }\end{array}$ & $\begin{array}{l}\text { Winter et al., } \\
2013\end{array}$ \\
\hline AY641449 & CYP709C1 & Cytochrome P450 & $\begin{array}{l}\text { For: GCATCAAAGTGACCGAAGG } \\
\text { Rev: CCCACTGGAGAAAGACAAT }\end{array}$ & Li et al., 2010 \\
\hline AB055077 & TaMDRI & $\begin{array}{l}\text { MDR-like ABC } \\
\text { transporter }\end{array}$ & $\begin{array}{l}\text { For: TTTCGCTACCCTGCAAAGAC } \\
\text { Rev: GCCGATCTTCCCTCTTATCC }\end{array}$ & $\begin{array}{l}\text { Gottwald et al., } \\
2012\end{array}$ \\
\hline FJ236328 & TaUGT3 & $\begin{array}{l}\text { UDP-glucosyltransferase } \\
\text { protein }\end{array}$ & $\begin{array}{l}\text { For: TTCGAGGAGCGTGTCAAAG } \\
\text { Rev: ACCTGCACAGATGCCCTCTA }\end{array}$ & $\begin{array}{l}\text { Gottwald et al., } \\
2012\end{array}$ \\
\hline BQ281752 & $\begin{array}{l}\text { UDP- } \\
\text { glucosyltransferase } \\
H v U G T 13248\end{array}$ & $\begin{array}{l}\text { UDP-Glycosyl } \\
\text { Transferase }\end{array}$ & $\begin{array}{l}\text { For: TCTTGTGGGTATTCCGCATT } \\
\text { Rev: CCTTTTGCATCCACTTCACA }\end{array}$ & $\begin{array}{l}\text { Gottwald et al., } \\
2012\end{array}$ \\
\hline GQ449372.1 & PRP I & PDF1.2 homology & $\begin{array}{l}\text { For: TCGCAGAGCCACAACTTCAA } \\
\text { Rev: TCTTGCAGAAGCACTTGCG }\end{array}$ & Present study \\
\hline
\end{tabular}

DNA extraction from plant material and quantification

The DNA extraction method was following the modified CTAB method (Thomson et al., 2007). Approximately $100 \mathrm{mg}$ of fresh leaf tissue were harvested and frozen in $2 \mathrm{~mL}$ tubes above a pool of liquid nitrogen. Subsequently, the frozen tissue was crushed in a chilled mortar and pestle in $800 \mu \mathrm{L}$ of DNA extraction buffer $(100 \mathrm{mM}$ Tris-HCl, $50 \mathrm{mM}$ EDTA, $500 \mathrm{mM} \mathrm{NaCl}$, $1.25 \%$ (w/v) SDS), supplied with $2 \mu \mathrm{L}(20 \mathrm{mg} / \mathrm{ml})$ proteinase $\mathrm{K}$ and $4 \mu \mathrm{L} 1 \% \beta$ mercaptoethanol and mixed until evenly suspended. Then the samples were incubated at $65^{\circ} \mathrm{C}$ for $20 \mathrm{~min}$ and $70 \mu \mathrm{L}$ of $\mathrm{CTAB} / \mathrm{NaCl}$ solution was added. Samples were incubated at $65^{\circ} \mathrm{C}$ for further $15 \mathrm{~min}$. Subsequently, a chloroform extraction was performed with chloroform: isoamylalcohol (24:1) solution, centrifuged for $10 \mathrm{~min}$ at $12,000 \mathrm{x} g$ in a microcentrifuge. From 
the upper aqueous layer, $600 \mu \mathrm{L}$ were removed to a new tube and $1,000 \mu \mathrm{L}$ absolute ethanol was added for precipitation. The DNA was pelleted by centrifugation, followed by washing in $70 \%$ ethanol twice. Finally, the DNA was resuspended in $100 \mu \mathrm{L}$ of TE buffer. The DNA concentration was checked on $1.5 \%$ agarose gel by electrophoresis, and the concentration was adjusted to $5 \mathrm{ng} \mu \mathrm{L}^{-1}$ by using sterilized water or TE buffer.

Gradient PCR and products sequencing

All genes were amplified by gradient PCR to figure out optimal PCR conditions. Identities of partial gene sequences were confirmed by sequencing (Eurofins, Ebersberg, Germany) of PCR products. PCR reaction sets were purchased from a commercial company (Bioline, Luckenwalde, Germany). PCR reaction systems consisted of $2 \mu \mathrm{L} \mathrm{NH}_{4}$-reaction buffer $\left(16 \mathrm{mM}\left(\mathrm{NH}_{4}\right)_{2} \mathrm{SO}_{4}, 67\right.$ $\mathrm{mM}$ Tris-HCl, $0.01 \%(\mathrm{v} / \mathrm{v})$ Tween-20, $\mathrm{pH} 8.8$ at $\left.25^{\circ} \mathrm{C}\right), 0.3 \mu \mathrm{L} 50 \mathrm{mM} \mathrm{MgCl} 2,1.6 \mu \mathrm{L} 2.5 \mathrm{mM}$ of dNTPs, $2 \mu \mathrm{L} 10 \mathrm{pM}$ of each primer, $0.25 \mu \mathrm{L}\left(5 \mathrm{U}^{-1}\right)$ BIOTaq DNA polymerase, $2 \mu \mathrm{L}$ of template DNA and added $\mathrm{ddH}_{2} \mathrm{O}$ up to $20 \mu \mathrm{L}$.

PCR amplification was executed with an initial denaturation step for $5 \mathrm{~min}$ at $94^{\circ} \mathrm{C}$, followed by 36 reaction cycles including a 20 s denaturation step at $94^{\circ} \mathrm{C}$, an annealing step for 30 s from 55 $70^{\circ} \mathrm{C}$ and $40 \mathrm{~s}$ at $72^{\circ} \mathrm{C}$. The final elongation was performed for $5 \mathrm{~min}$ at $72^{\circ} \mathrm{C}$.

PCR products were examined with $1 \%$ agarose electrophoresis and optimal $\mathrm{T}_{\mathrm{m}}$ was determined by the best performance of specific bands.

Based on the sequencing results, nine genes were selected for further analysis, namely Actin, Chi2, PR5, PR2, Pox2, CCR, UGT, CYP709C1, PRPI (Table 2). Three genes encoding for PR proteins (Chi2, PR5, PR2), one peroxidase related gene (Pox2), one homologous gene of PDF1.2 (PRP I), one lignification concerning gene (CCR), one UDP-Glycosyl transferase (UGT) and one gene form the cytochrome P450 family-CYP709C1. Actin served as the reference house-keeping gene. In the $T_{m}$ detection, it showed that $T_{m}$ was in a range of $60-62^{\circ} \mathrm{C}$ for the selected genes, afterwards $62^{\circ} \mathrm{C}$ was adopted by testing with quantitative real-time PCR (qPCR). 


\subsubsection{Expression of target genes by quantitative reverse transcription PCR (qRT-PCR)}

RNA extraction and quantification

TRIzol reagent (Invitrogen, Karlsruhe, Germany) was used for RNA extraction with a few modifications following the protocol SOP $N^{\circ}$ TAL013, Transcriptome Analysis Labor, Department of Developmental Biochemistry, University of Göttingen. Hundred mg of different tissues were ground to powder in liquid nitrogen with mortar and pestle by directly adding 1 $\mathrm{mL}$ of TRIzol reagent, incubated for $5 \mathrm{~min}$ at $\mathrm{RT}$ and centrifuged at $12,000 \mathrm{x} g$ for $10 \mathrm{~min}$ at $4^{\circ} \mathrm{C}$ to remove the insoluble material. Afterwards, $0.2 \mathrm{~mL}$ of chloroform was added. The samples were shaken by hand for $15 \mathrm{~s}$ and incubated for $5 \mathrm{~min}$ at RT. The samples were then centrifuged at $12,000 \times \mathrm{g}$ for $15 \mathrm{~min}$ at $4^{\circ} \mathrm{C}$. The aqueous phase (upper phase) was transferred to a new tube and $0.5 \mathrm{ml}$ isopropyl alcohol was added to precipitate RNA. The samples were then incubated for $1 \mathrm{~h}$ at RT and centrifuged at $12,000 \times \mathrm{g}$ for $30 \mathrm{~min}$ at $4^{\circ} \mathrm{C}$. The supernatant was removed and the RNA pellet was washed twice with $75 \%$ ethanol. After washing, the RNA pellet was dried at RT for 3-5 min and finally dissolved in $80 \mu \mathrm{L}$ DEPC water and stored at $80^{\circ} \mathrm{C}$ until cDNA synthesis. The quality and integrity of RNA samples were tested on a $2 \%$ agarose gel electrophoresis. The quantity of RNA was determined with an Epoch Microplate Spectrophotometer (Bio-Tek, Bad Friedrichschall, Germany).

cDNA synthesis

A first-strand cDNA synthesis kit (Qiagen, Hilden, Germany) was applied for cDNA synthesis in this experiment. Following the manufacturer's instruction, $20 \mu \mathrm{L}$ of cDNA solutions were synthesized from $1 \mu \mathrm{g}$ total RNA. Eventually, 10-fold dilutions were used in the RT-qPCR reactions, all the cDNA samples were kept at $-20^{\circ} \mathrm{C}$.

Quantitative reverse transcription PCR (qRT-PCR)

SYBR quantitative RT-PCR was performed in an optical 384-well reaction plate using a CFX 96 Sequence Detection System. Reaction was performed in a $10 \mu \mathrm{L}$ reaction mixture that consisted of $5 \mu \mathrm{L}$ of 2 X SYBR Green PCR Master Mix solutions (Bioline, Luckenwalde, Germany), 400 
$\mathrm{nM}$ of both forward and reverse primers and $12.5 \mathrm{ng}$ cDNA. Thermal cycling was started at $95^{\circ} \mathrm{C}$ for $15 \mathrm{~min}$, followed by 35 cycles of $95^{\circ} \mathrm{C}$ for $20 \mathrm{~s}, 62{ }^{\circ} \mathrm{C}$ for $30 \mathrm{~s}$ and $72^{\circ} \mathrm{C}$ for $20 \mathrm{~s}$. The final elongation was performed for $5 \mathrm{~min}$ at $72^{\circ} \mathrm{C}$. The melting curve was obtained by heating the reaction temperature to $95^{\circ} \mathrm{C}$ for $1 \mathrm{~min}$, cooling to $55^{\circ} \mathrm{C}$ for the next minute, then slowly increasing the temperature from $65^{\circ} \mathrm{C}$ to $95^{\circ} \mathrm{C}$ in a rate of $0.5^{\circ} \mathrm{C} \mathrm{s}^{-1}$, accompanied with continuous measurement of SYBR green.

The calibration curve was constructed to determine the primer efficiency. Standard curves with a correlation $\geq 0.98$ and efficiency between $90 \%$ and $110 \%$ were considered as appropriate for calibration, and the efficiency was used for the calculation of relative gene expression (Pfaffl, 2001). For each treatment, three technical replicates of PCR reactions were performed. RT-qPCR results were analyzed using Bio-Rad CFX 96 Sequence Detection software.

The following formula compares the target gene with the reference gene (Actin) from inoculated samples to a non-inoculated control (Pfaffl, 2001).

Fold induction $=\frac{\left(E_{\text {target }}\right)^{\Delta C T_{\text {target }}(\text { control-sample })}}{\left(E_{\text {ref }}\right)^{\Delta C T_{\text {ref }}(\text { control-sample })}}$

E: Efficiency $=10^{(-1 / \text { slope })}$, ref: reference gene, target: target gene

\subsection{Statistical analysis}

All statistical analyses were conducted using the STATISTICA 9 (StatSoft, USA) software. The Analysis of variance (ANOVA) to determine the statistical significant differences were considered significant at $\mathrm{p} \leq 0.05$ (significance level at 95\%). 


\section{Results}

\subsection{Disease severity assessment and cultivar responses}

\subsubsection{Wheat blast}

At 7-10 dpi, clear symptoms can be identified on ears of most inoculated cultivars with M. grisea. Partially bleached ears were predominant in many genotypes. During the infection process, initial dark-brownish or pale lesions occurred on some spikelets. Following the initial lesions, these spikelets turned yellow or into a straw-like colour, while the adjacent spikelets became also infected. Ultimately, the main symptoms, bleached ears were present and limited grey lesions occasionally occurred on leaves (Figure $1 \& 13$ ).

According to the blast severity level on ears at $7 \mathrm{dpi}$, four groups of cultivars can be classified in a range from 1.3 to 4.2 (Figure 6). Group 1: wheat genotypes with elevated resistance within a range of disease severity (DS) from 0-2; group 2: moderately resistant genotypes with a DS of 2.0-3.0; group 3: moderately susceptible genotypes with a severity range of 3.0-4.0; group 4: susceptible genotypes in the range of 4.0-5.0. Eventually there was no genotype completely resistant to $M$. grisea under the condition of artificial inoculation in a controlled environment. 


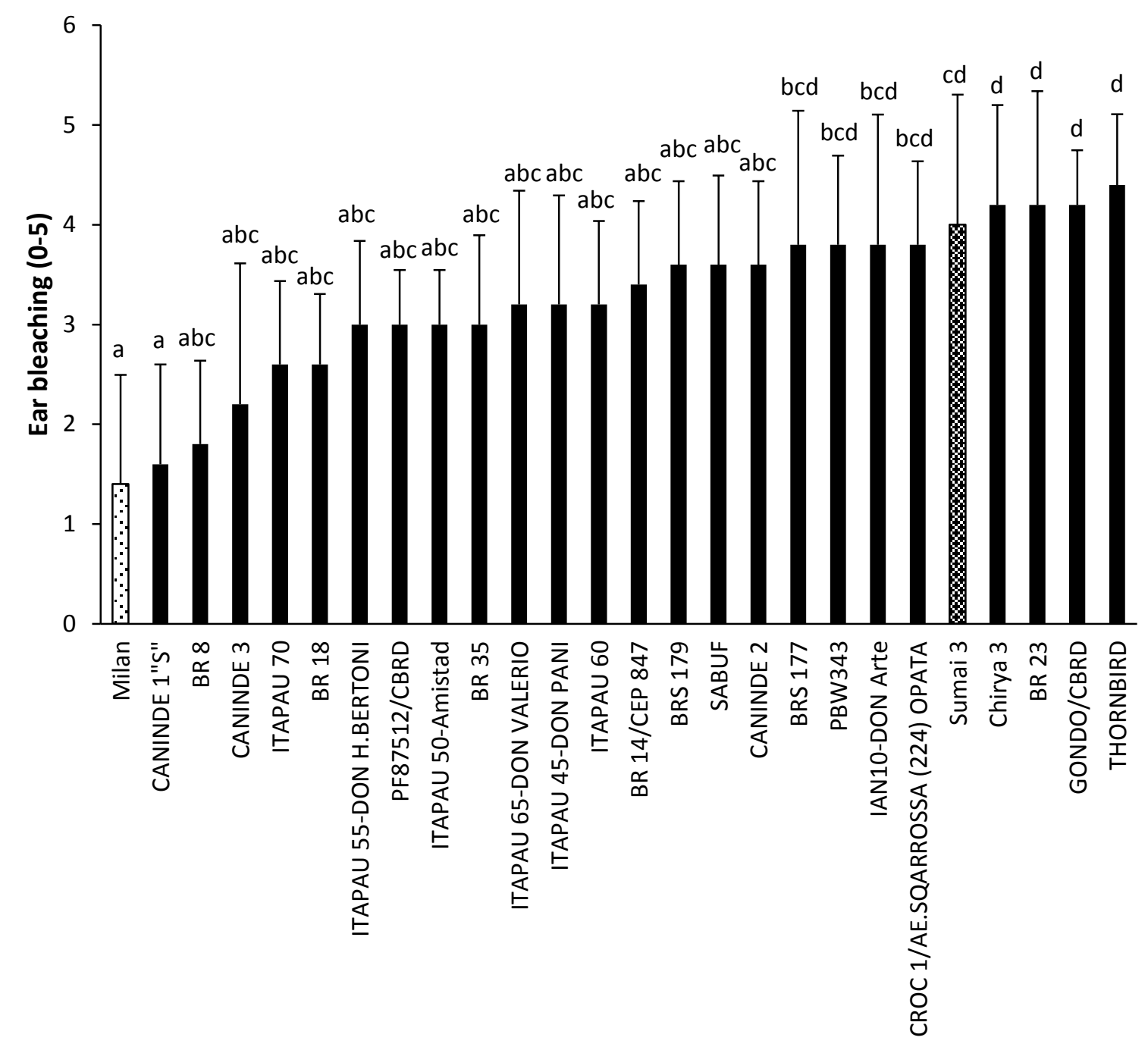

Fig. 6. Disease severity levels of wheat blast on 27 wheat genotypes after 7 days. Among the tested genotypes, Milan displayed the highest resistance and Sumai 3 showed moderate susceptibility. Each bar represents the mean $\pm \mathrm{SD}$ of the disease severity of each genotype. Different letters indicates statistical differences within cultivars according to Tukey test ( $\mathrm{p} \leq$ $0.05)$.

Cultivar Milan presented a striking level of resistance in response to M. grisea with a DS level of about 1.4. Together with cultivars CANINDE 1"'S" and BR 8 belonged to Group 1, displayed a DS lower than 2.0. Conversely, four genotypes: Chirya 3, BR 23, GONDO/CBRD and THORNBIRD had greater susceptibilities than 4.2, were categorized in Group 4. These two groups had significant difference. In Figure 6, Group 2 including the genotypes from CANINDE 3 to BR 35 showed a DS lower than 3.0, the group 4 contained the genotypes in 
Group 3 from ITAPAU 65-DON VALERIO to Sumai 3, which showed DS lower than 4.0. There was no significant difference between group 3 and 4 .

Resistant cultivars confirmation

Following the cultivar screening, cultivars Milan and Sumai 3 were selected for further analysis as they represented opposing levels of resistance to $M$. grisea. To verify the resistant varieties in response to $M$. grisea, point inoculation was conducted on the ears of Milan and Sumai 3, the disease scoring system was applied at 7, 10, 15, 21 dpi (Figure 7).

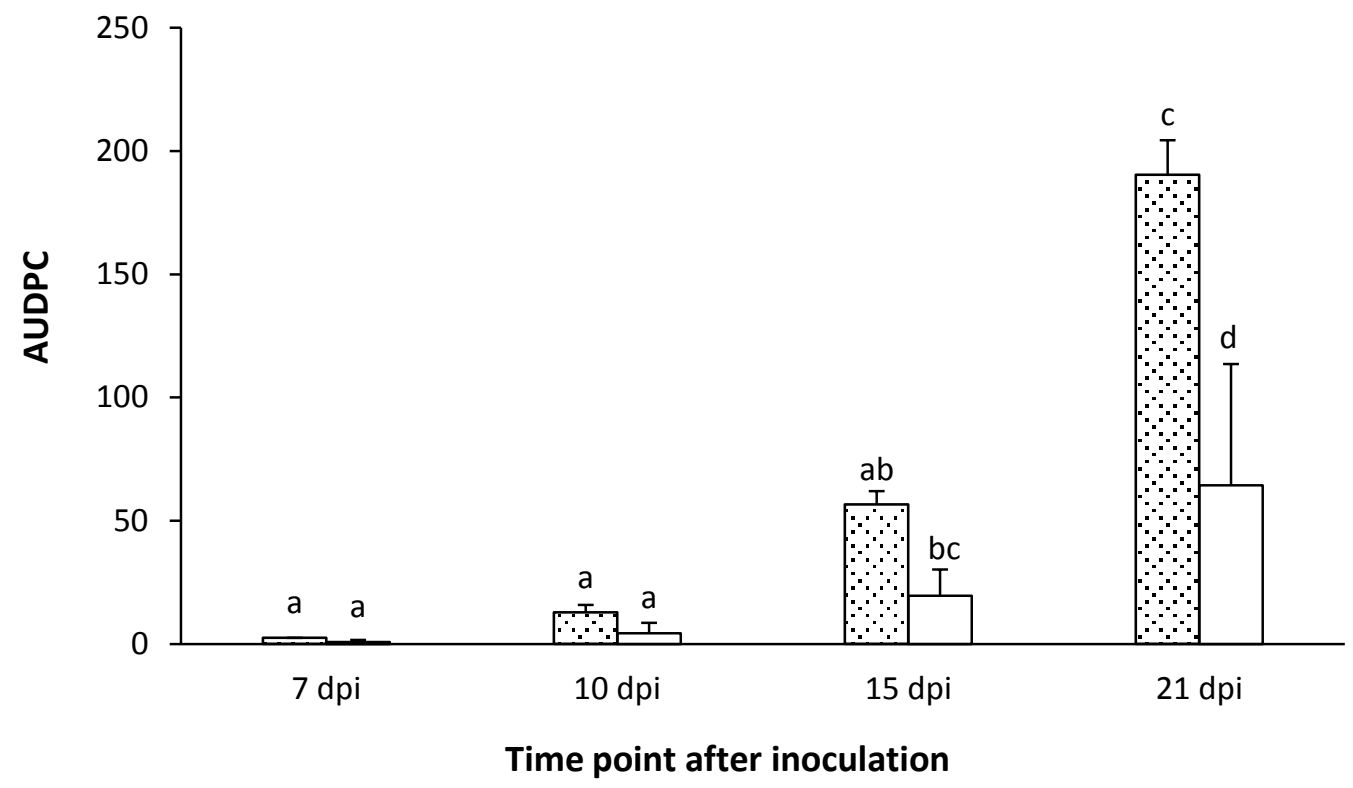

ĐSumai 3- M. grisea $\square$ Milan- M. grisea

Fig. 7. AUDPC was calculated by $\%$ DS from 7 dpi to 21 dpi of wheat blast on cvs. Milan and Sumai 3 after point inoculation. Each bar represents a mean of $A U D P C \pm S D$ at each time point for each interaction. AUDPC followed by different letters significantly differ at $\mathrm{P} \leq 0.05$ according to Fisher's least significant difference (LSD) test.

Point inoculation tests confirmed the high level of resistance in cultivar Milan to M. grisea and the moderate susceptibility in Sumai 3 (Figure 7), which mirrored the results of the previous whole ear inoculation test. AUDPC data obtained from both cultivars were low until 7 dpi, whereas the AUDPC of Sumai 3 progressively developed after 7 dpi. At 21 dpi, a clear increase in DS was noticed in Sumai 3 which was significantly different from Milan. At 21 dpi, AUDPC from 7 dpi to 21 dpiof Sumai 3 was almost up to 1.90, while Milan only had approximately 
0.65. Cultivar Milan certainly presented an effective resistance while Sumai 3 presented clear susceptibility.

Correlation analysis on various symptoms caused by $M$. grisea

With the exception of the dominant symptom of bleached ear, other symptoms caused by M. grisea such as shrunken kernels and lesions on leaves were the associated symptoms. A correlation analysis was carried out in order to illustrate the relationship between ear bleaching and sterility, and infection on the leaf based on the screening results of 27 cultivars in response to M. grisea ear infection (Figure 8 and 9).

Severity of ear bleaching by wheat blast was evaluated together with ear sterility on 27 cultivars. It was assumed that both symptoms are in a positive correlation since bleached ears induce shriveled kernels or even sterile spikelets. This was supported by the statistical analysis with a correlation coefficient of $\mathrm{r}=0.5156, \mathrm{p}=0.00002$ (Figure 8). This indicates that M. grisea may induce both bleached and sterile ears and that both symptoms are correlated.

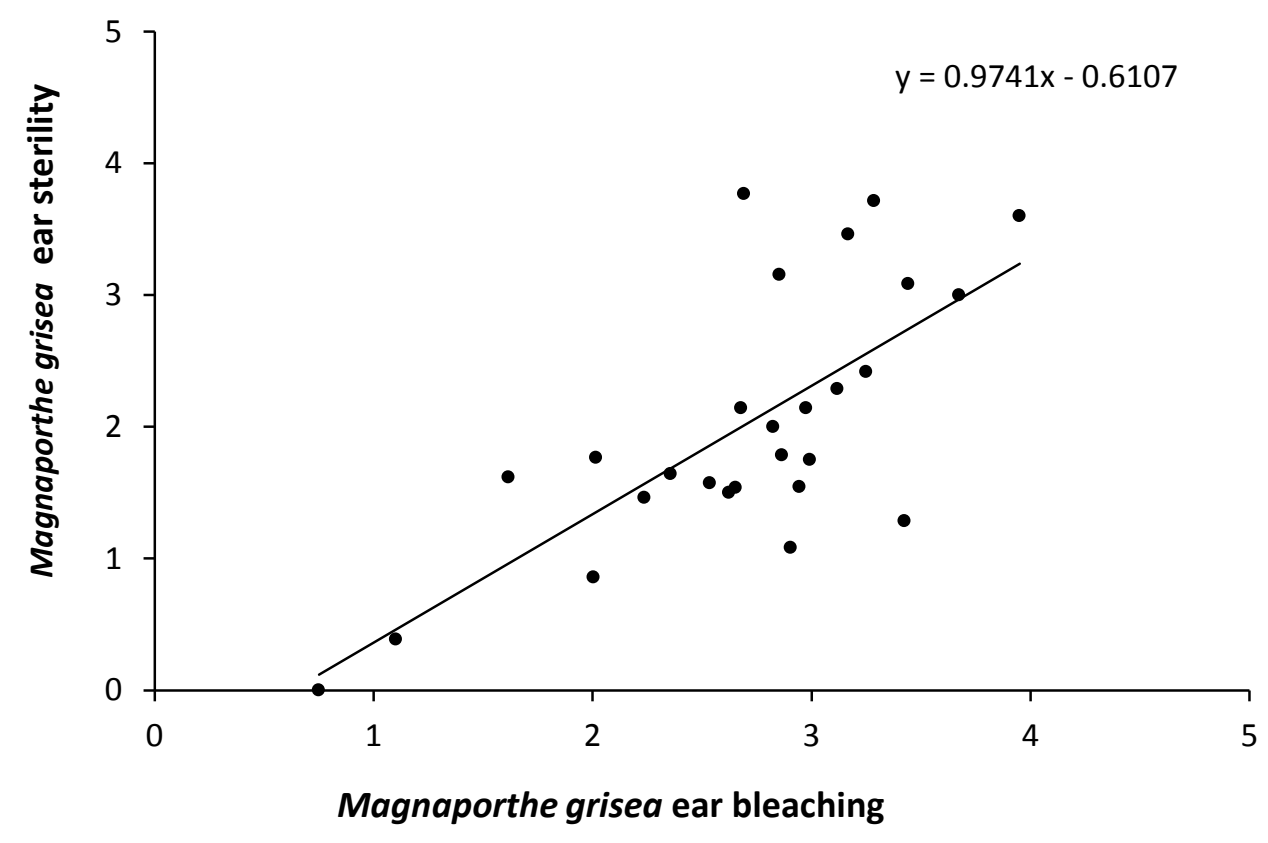

Fig. 8. Correlation between ear sterility and ear bleaching caused by M. grisea at 7 dpi on 27 wheat genotypes following a whole ear inoculation $(r=0.5156 ; p=0.00002)$. Each dot represents one cultivar. $r$, correlation coefficient. 
Data of wheat blast infection on leaves were collected at 9 dpi on 27 cultivars. In the comparison of leaf infection and ear bleaching, no significant correlation was found $(r=0.0433, p=0.2979$, Figure 9). This result implies that there is a no relationship between genotypic resistance levels in leaves and ears to infection with M. grisea.

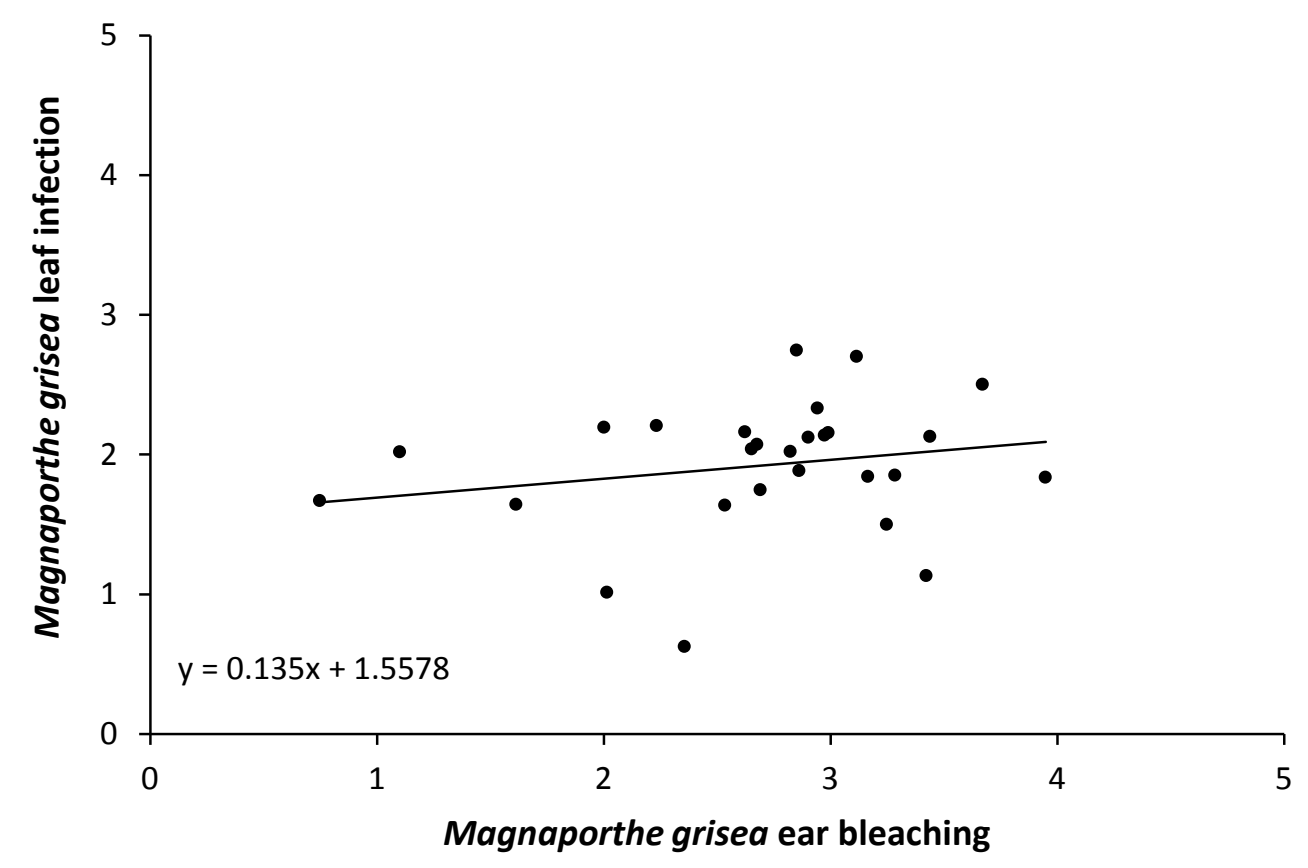

Fig. 9. Comparison of leaf infection and ear bleaching induced by M. grisea on 27 wheat genotypes $(\mathrm{r}=0.0433 ; \mathrm{p}=0.2979)$, indicating no correlation between genotypic resistance levels in ears and leaves to infection with M. grisea. Each dot represents one cultivar.

\subsubsection{Fusarium Head Blight}

Symptoms of FHB emerged on spikelets at 3-5 dpi and varied between genotypes. At 7 dpi, most genotypes showed partially discoloured ears or several burnt-brown spikelets. Up to $21 \mathrm{dpi}$, most genotypes presented a high level of bleached ears, in some cases the ears were covered with white or pink mycelia.

The disease progress of F. graminearum on 27 genotypes was followed as AUDPC (Figure 10). Based on the disease severity results from 27 different genotypes, four groups were formed corresponding to different ranges of percentage disease severity. Group 1: $0 \%-25 \%$, involved wheat genotypes which exhibited elevated resistance against $F$. graminearum; group 2: scaled for moderately resistant genotypes at 25\%-50\%; group 3: included several moderately susceptible 
genotypes with 50\%-75\%; group 4: in a range of 75\%-100\%, included the susceptible genotypes.

Cultivars PF 87512/CBRD and Sumai 3 showed distinct resistance and belonged to Group 1 (Figure 10). However cultivars Milan and BR 18 displayed obvious susceptibility which was classified in Group 4. The genotypes from GONDO/CBRD to PBW 343 showed relatively higher resistance than the genotypes from ITAPAU 65-DON VALERIO to IAN 10-DON Arte, and were assigned to Groups 2 and 3, respectively.

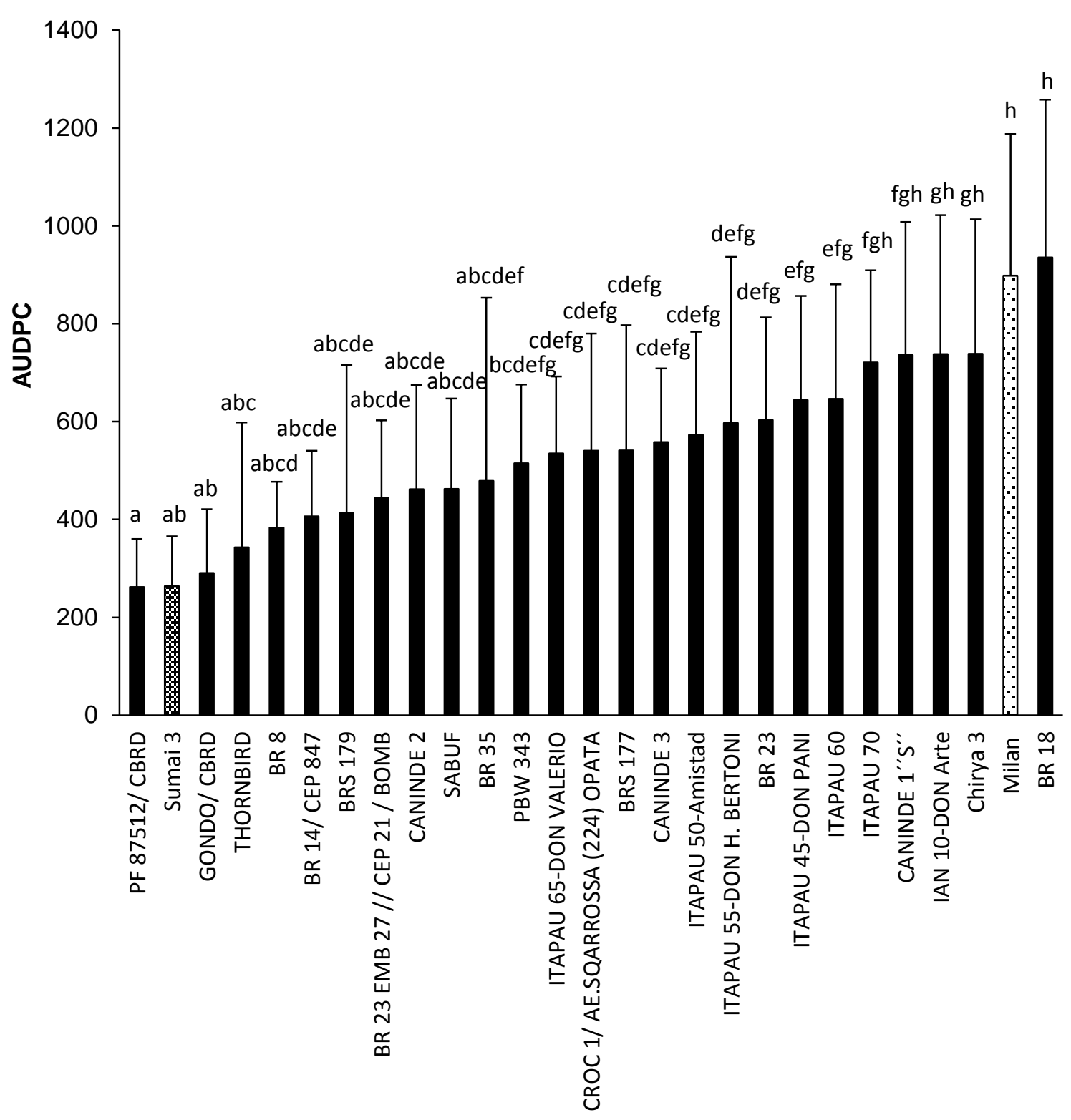

Fig. 10. AUDPC was calculated on DS from 3 dpi to 21 dpi of head blight on 27 wheat genotypes in response to F. graminearum. Milan displaying strong susceptibility and Sumai 3 
showing elevated resistance were selected for further studies. Each bar represents the mean $\pm \mathrm{SD}$ of each genotype. Different letters indicates statistical differences within cultivars according to Tukey test $(\mathrm{p} \leq 0.05)$.

\section{Resistant cultivars confirmation}

According to the screening results from 27 wheat genotypes infected by F. graminearum, cultivars Sumai 3 and Milan exhibited divergent levels of resistance and were selected for the point inoculation analysis (Figure 11).

Clear disease symptoms on ears such as dark brown lesions and bleached spikelets were seen on both cultivars. Until 7 dpi, FHB severity was similar on both cultivars. At 7 dpi, almost the whole rachis of cultivar Milan was bleached indicating a high susceptibility in response to F. graminearum. Disease severity in Milan did not significantly change from 7 dpi to 10 dpi, but significantly differed from Sumai 3 at 15 dpi and 21 dpi (Figure 11).

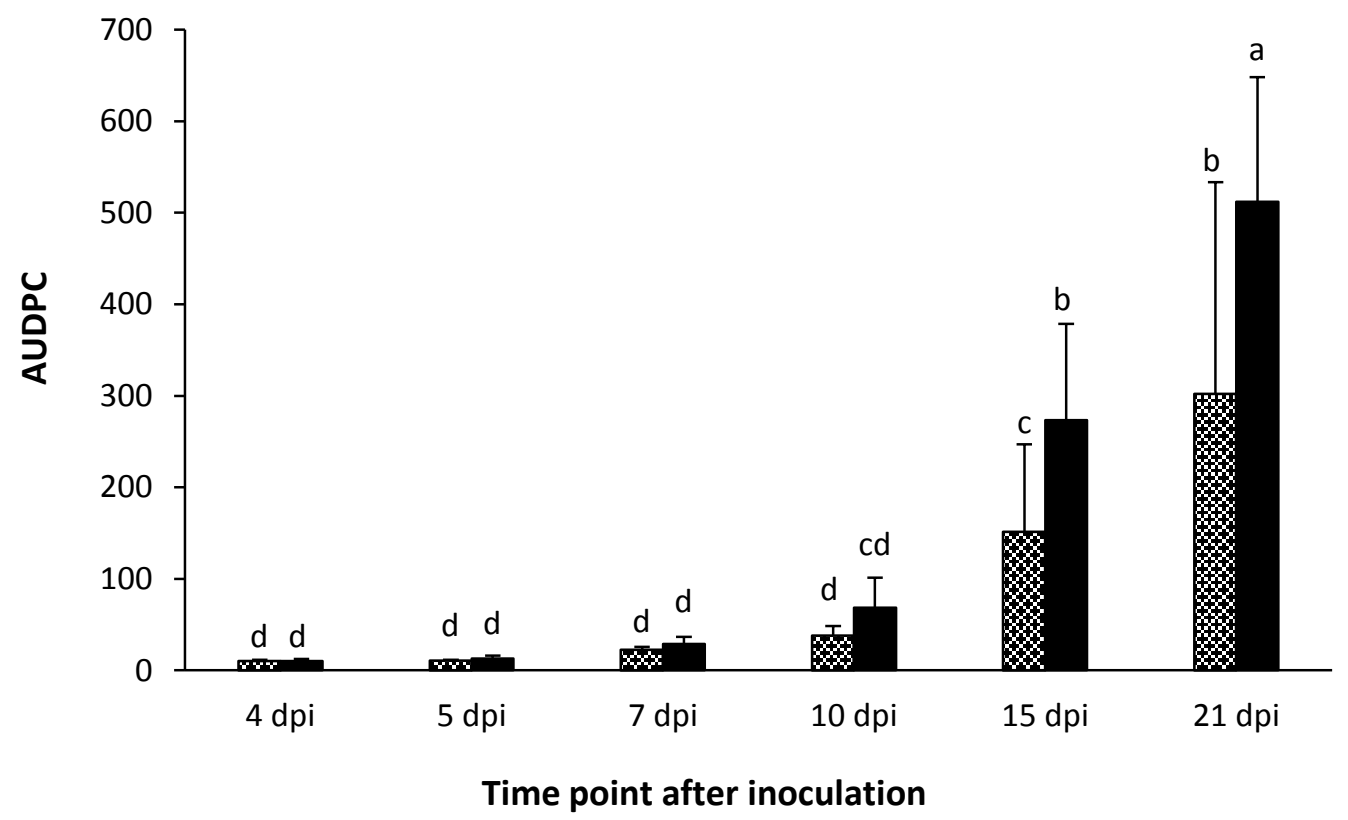

Q Sumai 3-F. graminearum Milan -F. graminearum

Fig. 11. AUDPC was calculated on \%DS from 4 dpi to 21 dpi of FHB on cvs. Milan and Sumai 3 following point inoculation on the ears. Each bar represents a mean of AUDPC \pm SD of each time point for each interaction. AUDPC followed by different letters significantly differ at $\mathrm{P} \leq 0.05$ by (LSD) test. 
Correlation analysis on ear infection by $M$. grisea and $F$. graminearum

A correlation analysis of $F$. graminearum ear infection and $M$. grisea ear bleaching on 27 genotypes revealed that the cultivar responses to both diseases were independent. Consequently, a negative correlation was found with a correlation coefficient of $r=-0.0368, p=0.3379$ (Figure 12).

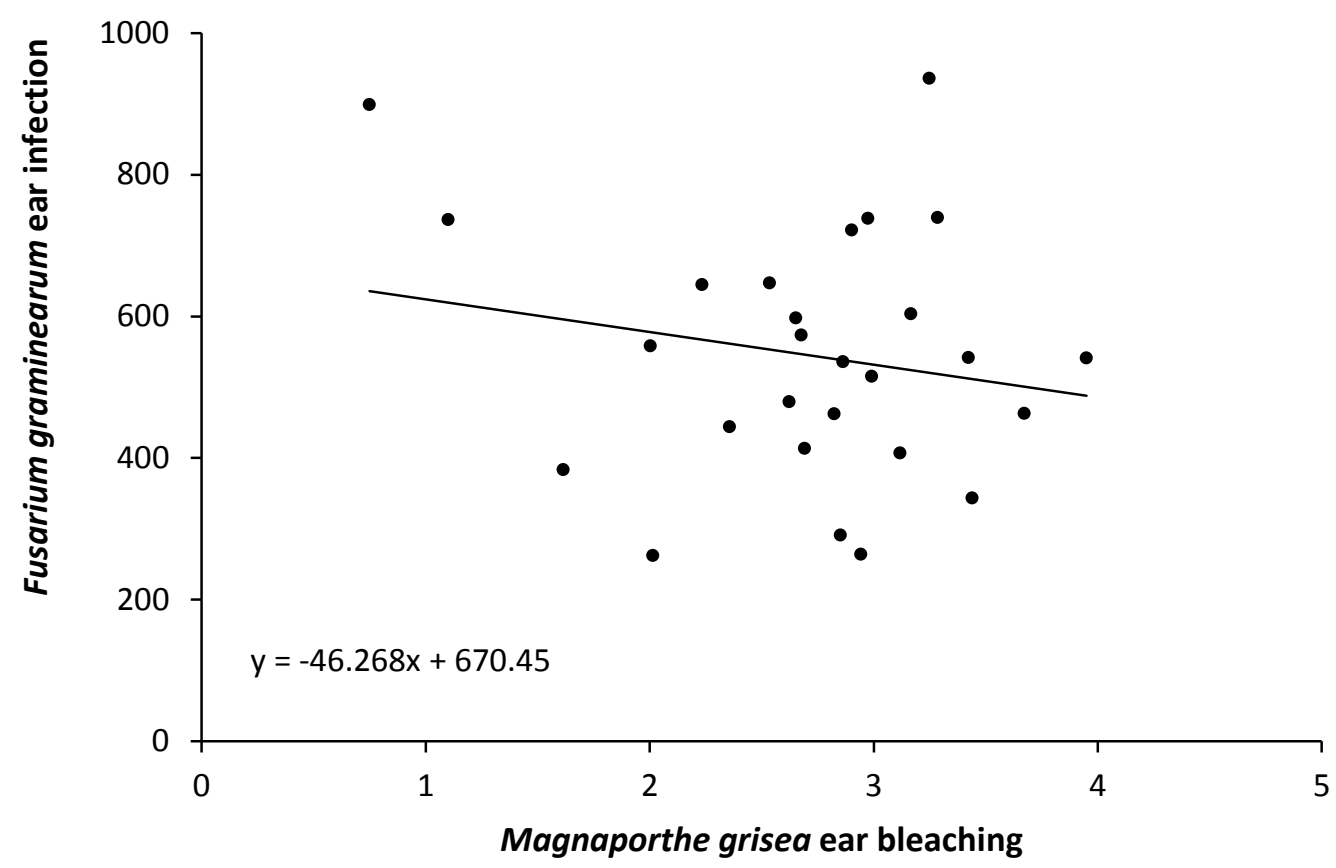

Fig. 12. Correlation between responses of 27 wheat genotypes to $F$. graminearum ear infection (AUDPC) and M. grisea ear bleaching $(\mathrm{r}=0.0368 ; \mathrm{p}=0.3379)$. The analysis showed no significant correlation between the responses to the two diseases. Each data point represents one cultivar.

\subsection{Fungal growth on ears}

\subsubsection{Macroscopic investigation with bright field and fluorescence microscopy}

Bright field inspection

Bright field inspection yielded a macroscopic view of the various levels of resistance displayed by the two genotypes against $M$. grisea and F. graminearum from 3 to 21 dpi (Figure 13 and 14). Dissimilar patterns of disease symptoms were obtained on the ears by point inoculation. However, the development of $M$. grisea in the ears was relatively slower than $F$. graminearum in 
both cultivars. Bleached ears induced by M. grisea in Sumai 3 typically occurred at 15 dpi, while initial FHB symptoms on Milan became visible after 3 days.
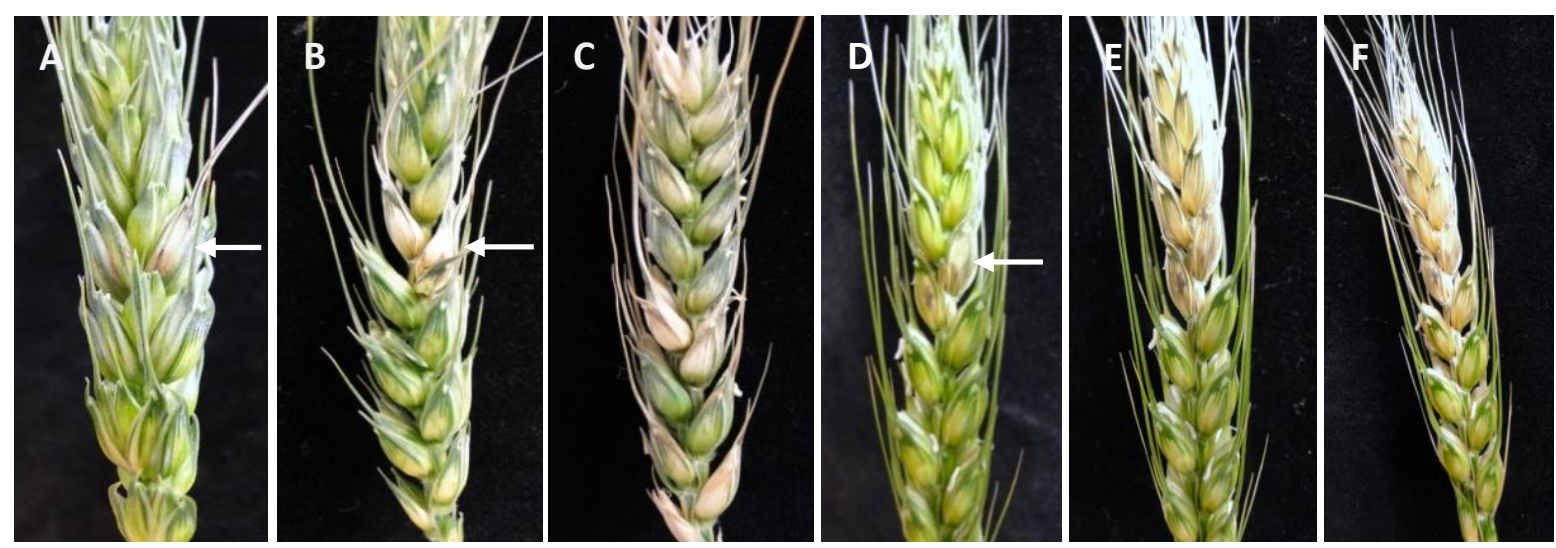

Fig. 13. Macroscopic views of infected ears from wheat cvs. Milan and Sumai 3 in response to M. grisea infection at 10,15 and $21 \mathrm{dpi}$. White arrows indicate the inoculation sites after point inoculation. A-C, ears from Milan. A, 10 dpi, with a partially infected spikelet. B, 15 dpi, with the inoculated spikelets turning bleached. C, $21 \mathrm{dpi}$, where more spikelets become bleached. D-F, views of Sumai 3. D, ears 10 dpi, the inoculated spikelets are bleached. E, 15 dpi, nearly half of the ear has turned bleached. F, 21 dpi, the ear is partially bleached and shrunken.

Generally, M. grisea progressed slowly on the ears. Around 5 dpi, specific symptoms emerged on the spikelets of Milan. Initial visual symptoms were dark-brown necrotic dots or lesions on glumes and lemma. Between 5 and 15 dpi, the symptoms progressed weakly. The inoculated spikelets were partially bleached and a small part of the rachis turned brown (Figure $13 \mathrm{~A}, \mathrm{~B}$ ). Between 15 and $21 \mathrm{dpi}$, one or two of the inoculated spikelets became bleached and as well as a small part of the rachis (Figure $13 \mathrm{C}$ ).

Different disease steps were taken in the susceptible interaction of Sumai 3 towards M. grisea. There were no obvious visual symptoms on the ears before 7 dpi. At 7 dpi, visual symptoms appeared on inoculated spikelets with partial yellowing, and these symptoms increased slowly until 10 dpi (Figure 13 D). At 15 dpi, bleaching was typical in the upper ear, the part at the top of the inoculated spikelets (Figure 13 E). Eventually, a faded, straw-yellow colour on partial ears was evident at 21 dpi (Figure $13 \mathrm{~F}$ ).

The earliest visual symptoms occurred from the susceptible Milan-F. graminearum interaction 
at 3 dpi: mycelia emerged from the inoculated spikelets, which subsequently became pale, and part of the neighbouring rachis became pale or yellowed. In this susceptible reaction, mycelia were observed to have grown quite fast. A few of the upwards spikelets turned yellow at 5 dpi (Figure $14 \mathrm{~A}$ ). Then, together with the upward part, the main part of the downward rachis and spikelets were dark-brownish or bleached at 7 dpi (Figure $14 \mathrm{~B}$ ); the discolouration of the whole downward part of the ear was complete at $10 \mathrm{dpi}$, the entire ear had turned white or yellow by 15 dpi (Figure $14 \mathrm{C}$ ).

Conversely, symptoms on the resistant cultivar Sumai 3 were not as remarkable as those seen on Milan. It was observed that FHB symptoms were occasionally delayed in the inoculated sites in a few plants. The symptoms were only distinguishable at the initial stages and did not become progressive. Normally the inoculated spikelets showed early symptoms within 3 dpi manifesting a yellow or brownish colour (Figure 14 D). At 5-7 dpi the two inoculated spikelets and partially adjacent upward spikelets were discoloured and dry (Figure $14 \mathrm{E}$ ), the rachis between them was turned a dark brown or black colour. However, in some plants, disease developments had stopped at this stage. In other serious developments, following the progression of the disease, part of the rachis was bleaching (Figure $14 \mathrm{~F}$ ). The downwards rachis which neighboured the inoculated spikelets showed a dark brown or black colour from 10 to 14 dpi; eventually most parts of the downward rachis had become yellow or brown by 21 dpi. 

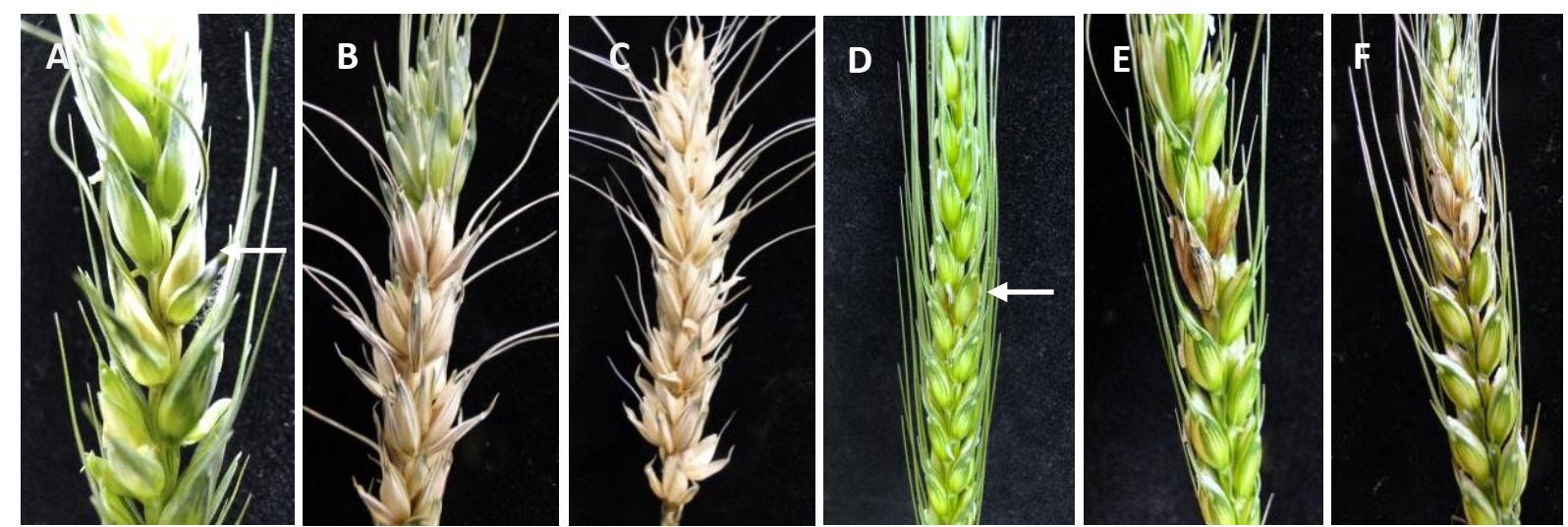

Fig. 14. Macroscopic views of infected ears from wheat cvs. Milan and Sumai 3 in response to F. graminearum infection at 3, 7 and 15 dpi. White arrows point to the infected spikelets. A-C, ears from Milan. A, 3 dpi, the inoculated spikelets become pale and some mycelia are observed. B, 7 dpi, nearly $60 \%$ of the inoculated ear is bleached. C, 15 dpi, the entire ear is bleached. D-F, views of Sumai 3. D, 3 dpi, the inoculated spikelets show a brown colour. E, 15 dpi, the inoculated spikelets show infection. F, 21 dpi, the distal part of the ear is bleached.

Fluorescence microscopy

Since there is a lack of chlorophyll in dead plant tissue, the dry and dead spikelets or the rachis displayed a green colour under the fluorescence microscope, while healthy tissues were red. Fluorescence microscopy was used to evaluate and classify the resistance and susceptibility responses of both Milan and Sumai 3 against M. grisea and F. graminearum (Figure 15 A- L).

The progressing colonization of $M$. grisea on Sumai 3 was illustrated in detail from 11 to 21 dpi (Figure 15). Inoculated spikelets were starting to lose vitality at 11 dpi (Figure $15 \mathrm{~A}, \mathrm{~B}$ ). Subsequently, parts of the upper rachis were green at 18 dpi, implying that $M$. grisea has already occluded some parts of the rachis, leading in the upper parts to suffer from a lack of nutrition or water (Figure $15 \mathrm{C}, \mathrm{D})$. Up to $21 \mathrm{dpi}$, the upper rachis and spikelets remained fully green indicating that the upper part of the ear was dead (Figure 15 I, J). In the case of an interaction between Milan and M. grisea, the inoculated spikelet was the sole evidence of infection at 18 dpi (taking on the green colour) (Figure $15 \mathrm{G}, \mathrm{H}$ ), and remained that way until $21 \mathrm{dpi}$.

F. graminearum conquered the ears of Milan within 16 dpi and the diseased rachis displayed a clear green colour (Figure 15 E, F). However, in the resistant interaction Sumai 3- 
F. graminearum, the rachis around the inoculated sites did not appear green until 21 dpi (Figure $15 \mathrm{~K}, \mathrm{~L}$ ), demonstrating that part of the rachis is still alive and confirming that Sumai 3 displayed a stronger resistance to $F$. graminearum.

Conversely, Milan being more susceptible to F. graminearum demonstrated a greater resistance to M. grisea. Thus, Milan and Sumai 3 displayed opposing resistance responses to M. grisea and F. graminearum, which is consistent with the previous inoculation results. 

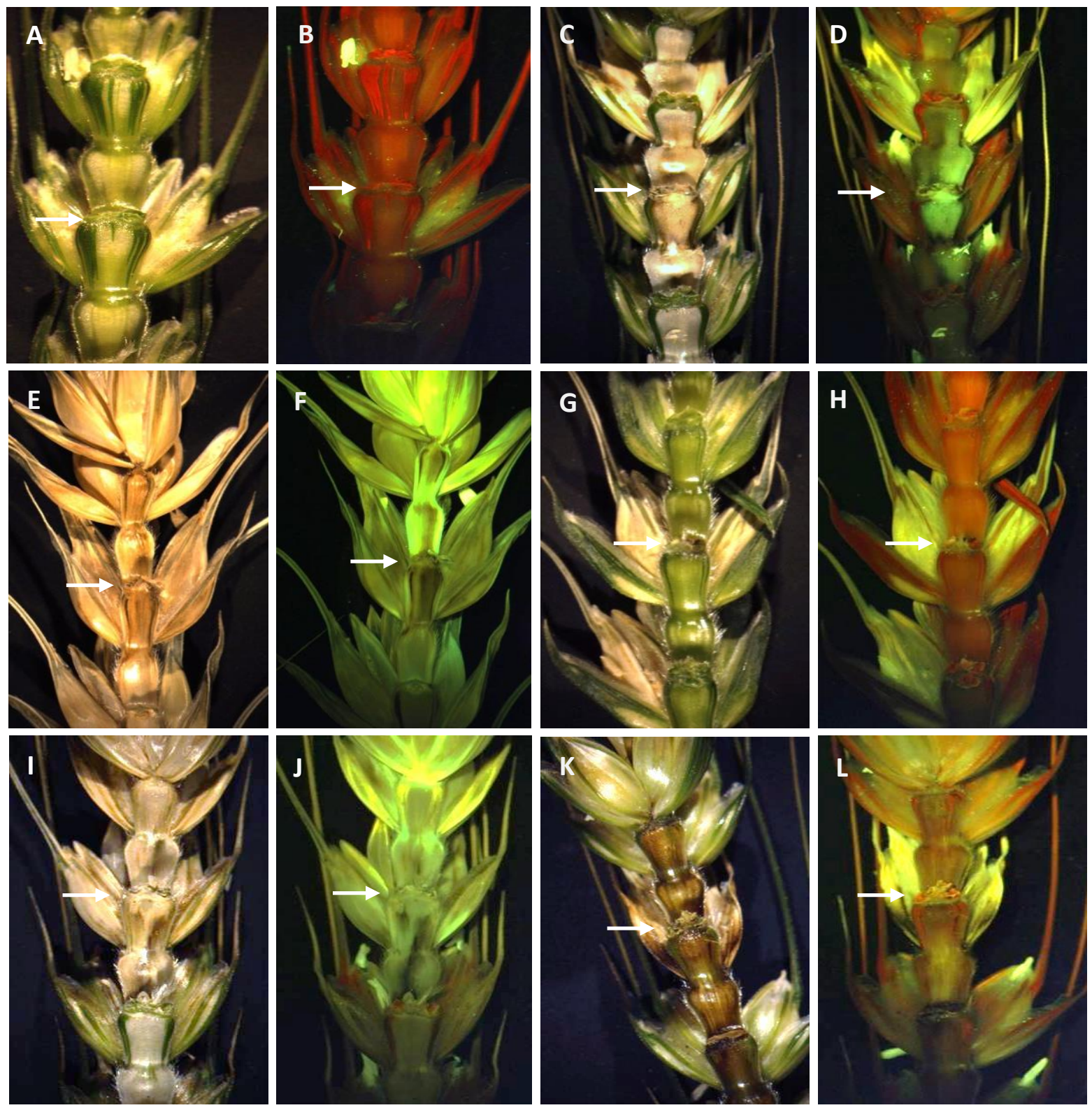

Fig. 15. Macroscopic views of infected ears from Sumai 3 and Milan in response to M. grisea and F. graminearum under bright field or fluorescence stereomicroscopy. A, C, E, G, I, K were from bright field. B, D, F, H, J, L were taken by fluorescence microscope. White arrows indicate the inoculation point. A-D, half excised inoculated ears from Sumai 3-M. grisea. A-B, ears at 11 dpi, in B the rachis is shown to be red, implying that there is no infection of the rachis until $11 \mathrm{dpi}$. A weak green is shown in the inoculated spikelet, and a more pronounced green in spikelet anthers. $\mathrm{C}-\mathrm{D}$, at $18 \mathrm{dpi}$, the green spikelet and rachis in D represents dead plant tissue. E-F, MilanF. graminearum at $16 \mathrm{dpi}$, the whole ear was infected and is shown as green, especially the rachis between the inoculated spikelets in F. G-H, Milan-M. grisea at $18 \mathrm{dpi}$; the single green spikelet is indicating that $M$. grisea was limited this tisssue. I-J, at 21 dpi, Sumai 3-M. grisea, in J nearly the 
whole ear is green displaying dead tissue, only a small part of the lower tissue remained healthy. $\mathrm{K}-\mathrm{L}$, Sumai 3-F. graminearum at 21 dpi. In $\mathrm{K}$ it is clear that the rachis is infected but it still shows some little green, suggesting that the rachis was alive and Sumai 3 was more resistant to F. graminearum.

\subsubsection{Fungal colonization on the infected ears}

After point inoculation, infected ears at $21 \mathrm{dpi}$ were taken and cut into sections depending on the cultivars. The whole rachis of cultivar Milan was divided into 11 segments, whereas cultivar Sumai 3 yielded up to 13 segments. The results of isolations from infected ears and the disease severity index showed that colonization of F. graminearum was different from M. grisea colonization in both cultivars, as F. graminearum displayed a more aggressive response. These results were strongly supported by observations from disease symptoms on ears.

At $21 \mathrm{dpi}$, expansion of $M$. grisea was limited around the inoculated points to contiguous sections of the ear on both cultivars (Figure 16). M. grisea developed separately in Milan and Sumai 3, specifically in the lower part of the rachis. In the resistant cultivar Milan, M. grisea was found at the inoculation position and the next segment, no colonization was obtained beyond segment 2 (both on the upper and lower part of the rachis). This indicated that the resistant cultivar Milan restricted the development of $M$. grisea to the inoculated site on the rachis. In the susceptible cultivar Sumai 3, the development of M. grisea was observed to be different in the two parts of the rachis. Pathogen expansion stopped at segment 2 (upwards), but it remained up to segment 4 in the lower rachis. 


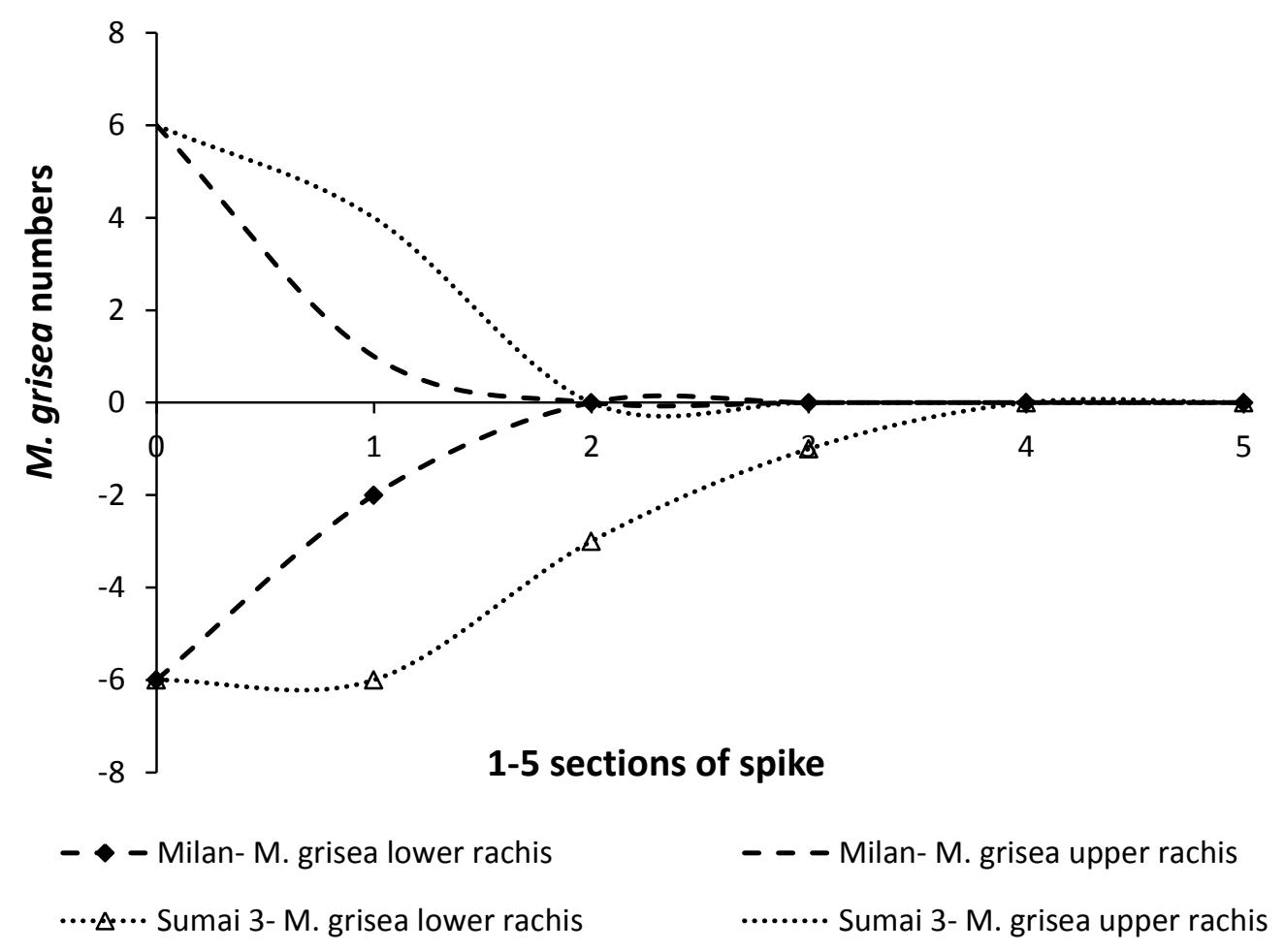

Fig. 16. Colonization of M. grisea in the infected rachis of cvs. Milan and Sumai 3 at 21 dpi. The $\mathrm{X}$-axis represents the sequence of segments along the rachis, 0 on the $\mathrm{X}$-axis indicates the point of inoculation. The $\mathrm{Y}$-axis represents the numbers of $M$. grisea. The positive area above the Y-axis indicates the pathogen from the upper part of the rachis, and the negative area represents the pathogen from the lower rachis.

Fungal colonization was dependent on the expansion of the disease and the rachis segment location. Segments near the inoculation site could be infected sooner, while the most distant segment proved to be most difficult to be infected. Therefore, a severity index was used to sum up the differential disease expansions on the rachis. The results indicated a strong impact on M. grisea development due to the resistance of the cultivars (Figure 17). Sumai 3 achieved a higher disease index than Milan in the upper and lower parts of the rachis, with values of 0.7 and 2.5, respectively. Milan only achieved values of 0.2 and 0.3 for the upper and lower parts, respectively. There was a significant difference of disease index between the upper and lower rachis from Milan, which indicates that $M$. grisea possesses a downward developing tendency in the ear of susceptible genotypes. 


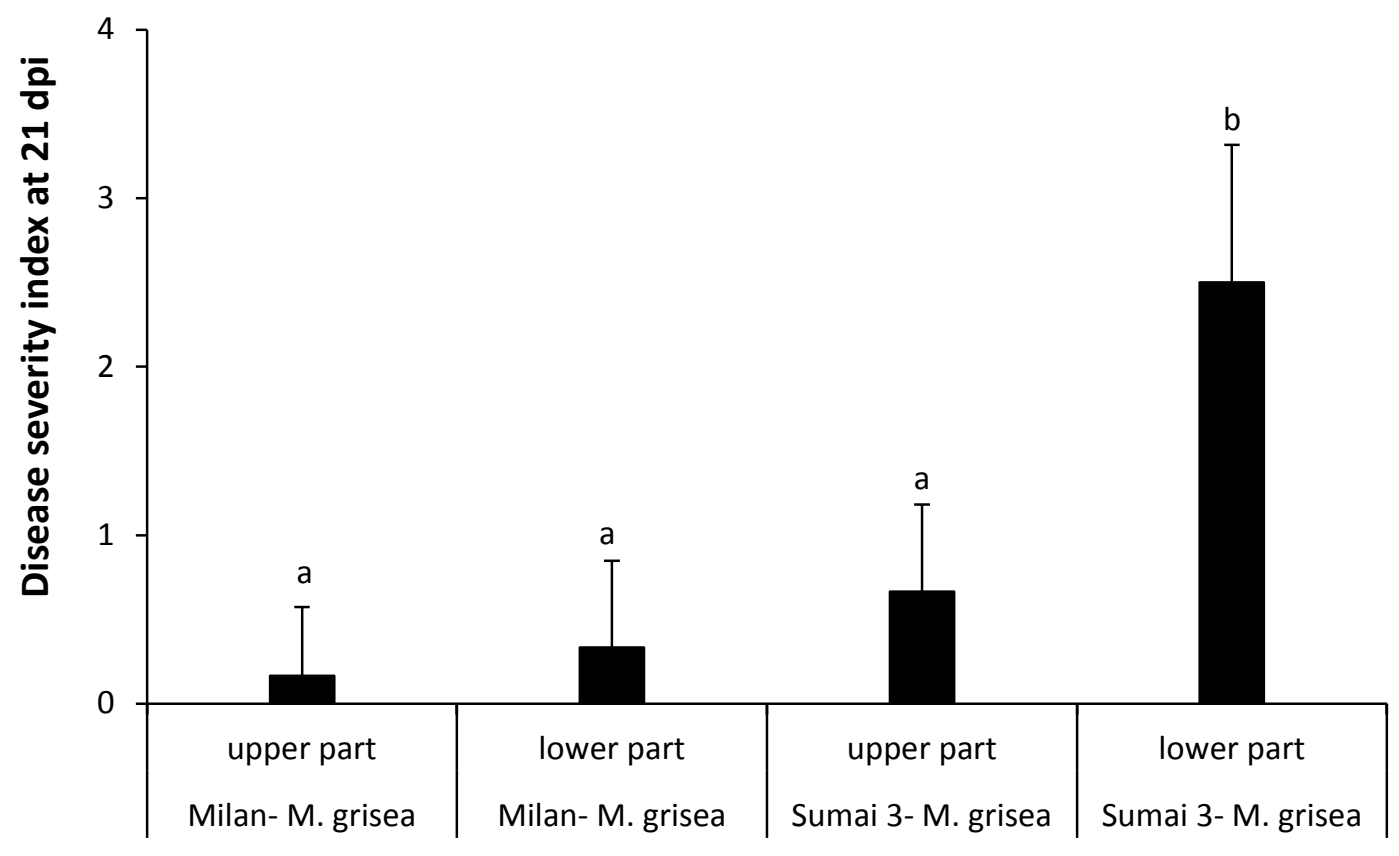

Fig. 17. Disease index of M. grisea spread in the rachis of cvs. Milan and Sumai 3 at 21 dpi. Each bar represents a mean of DS index \pm SD of each time point for each interaction. Index levels followed by different letters significantly differ at $\mathrm{P} \leq 0.05$ by (LSD) test.

F. graminearum colonized the rachis of the two cultivars in both upward and downward directions (Figure 18). In the susceptible cultivar Milan, almost the whole rachis was occupied at 21 dpi. For the resistant cultivar Sumai 3, more pathogen was found in the lower segments. In the detail of fungal development, the progression of F. graminearum in the upper part of the rachis was different in Sumai 3 and Milan. Differences started after segment 3 (upwards), when less colonization was found in Sumai 3. The results imply that F. graminearum expands more rapidly downwards in a susceptible cultivar. In comparison, development of F. graminearum in the lower part of the rachis was similar in both cultivars, while it differed in the upper part. 


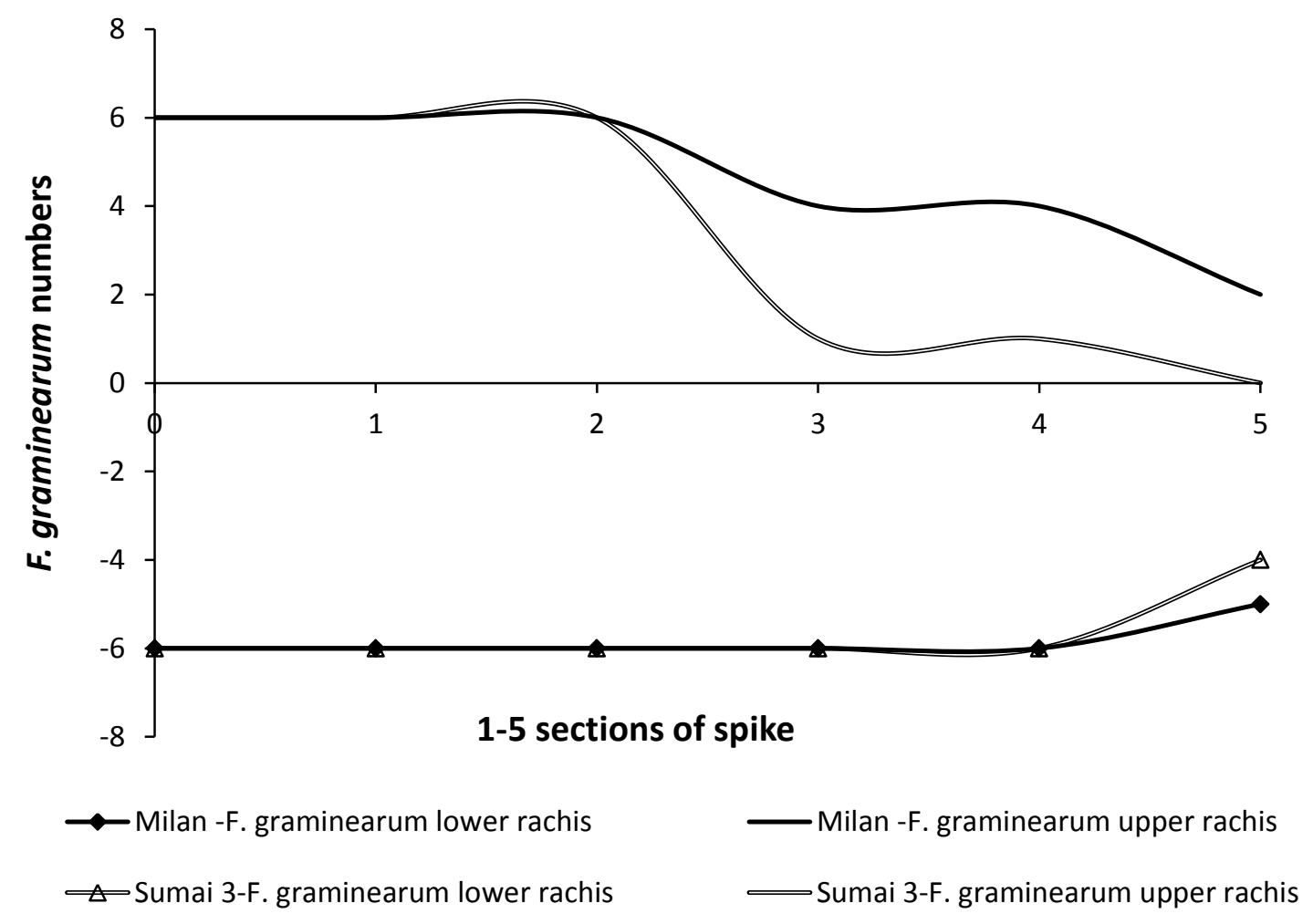

Fig. 18. Spread of F. graminearum in the rachis from cvs. Milan and Sumai 3 at 21 dpi.

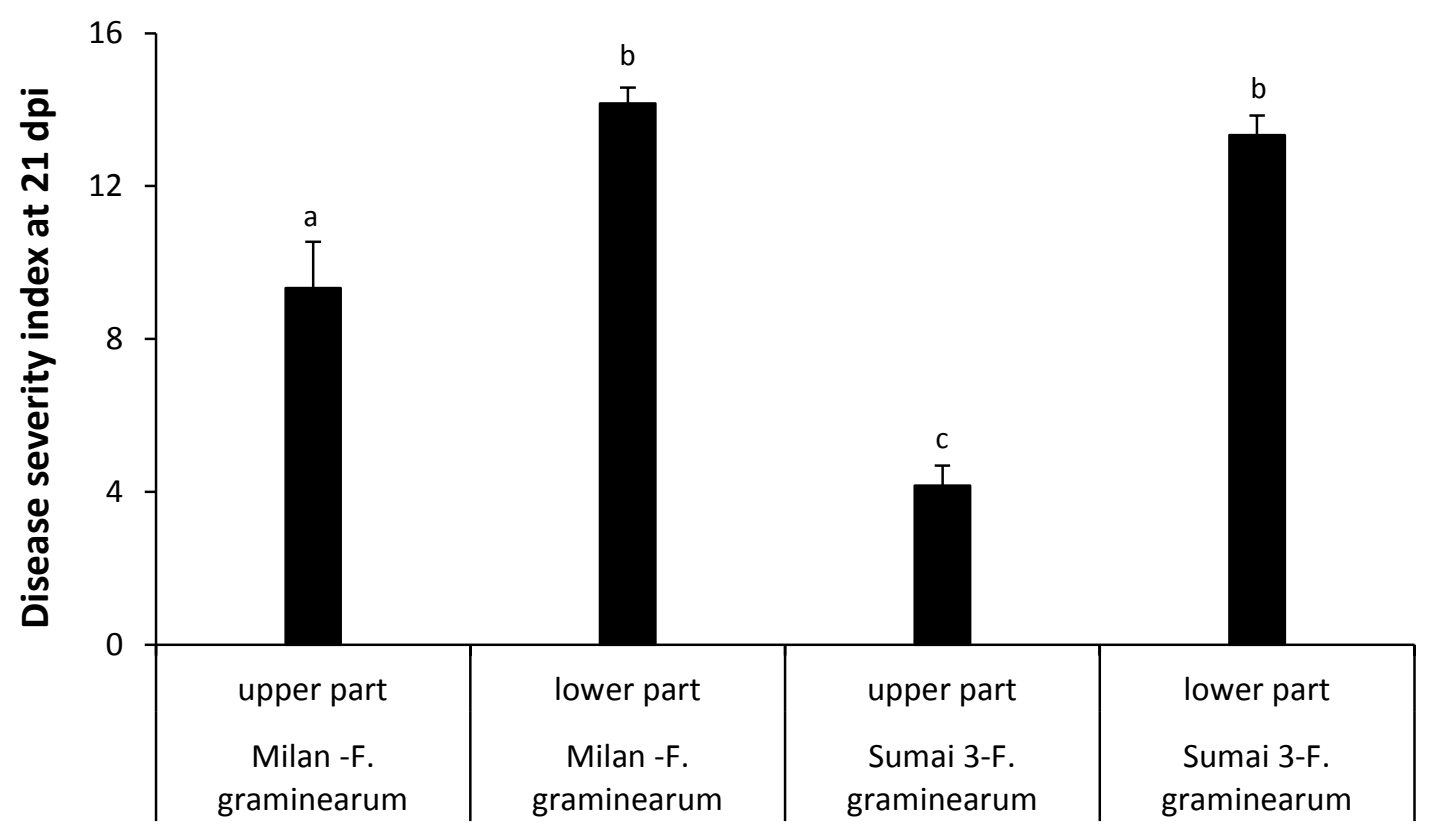

Fig. 19. Disease index of F. graminearum spreading on the rachis of cv. Milan and Sumai 3 at 21 dpi. Each bar represents a mean of DS index \pm SD of each time point for each interaction. Index levels followed by different letters significantly differ at $\mathrm{P} \leq 0.05$ by (LSD) test.

A general concept was that $F$. graminearum could be influenced by downward growth rather 
than the resistance of the cultivars (Figure 19). The genotype resistance was displayed in the upper rachis where the index were significant different, 9.3 and 4.2 for Milan and Sumai 3, respectively. However, fungal downward growths impacted on both cultivars, the inde in lower part of the rachis were significant different with the upper rachis, 14.2 and 13.3 from the lower part, Milan and Sumai 3, respectively.

The analysis of fungal spread from the different interactions suggested that F. graminearum and M. grisea both have distinct colonization patterns (Table 3). In particular, the resistance of cultivars played a role in $M$. grisea interactions, causing a significant difference of colonization between Milan and Sumai 3, suggesting the resistance of the cultivar has a more pronounced influence on $M$. grisea than on F. graminearum, and the colonization of F. graminearum and M. grisea are independent.

Table 3. Comparison of pathogen colonization from M. grisea / F. graminearum-Milan / Sumai 3 interactions. The colonization were significantly different in Milan / Sumai 3-M. grisea interactions, but not in Milan / Sumai 3-F. graminearum interactions (LSD analysis; lower case letters assigned to means indicate significant differences at $\mathrm{P} \leq 0.05$ ).

\begin{tabular}{cc}
\hline Interaction & Mean of colonization \\
\hline Milan- M. grisea & $1.50^{\mathrm{b}}$ \\
Sumai 3- $\boldsymbol{M}$. grisea & $3.33^{\mathrm{c}}$ \\
Milan- $\boldsymbol{F}$. graminearum & $9.83^{\mathrm{a}}$ \\
Sumai 3- $\boldsymbol{F}$. graminearum & $8.67^{\mathrm{a}}$ \\
\hline
\end{tabular}




\subsection{Fungal spread on ears followed by microscopic observation}

\subsubsection{Fungal spread in spikelets}

Infection process of $M$. grisea

Before the experiment was decided to employ WGA-tetramethylrhodamine staining, the GFP and DsRed transformed strains of M. grisea were successfully created. Unfortunately, these labelled strains were not suitable for this examination since the fluorescence was weak or unstably expressed in the progeny of the mutants. In order to acquire a clear overview of how M. grisea spreads in the spikelet, conventional dyes (instead of transformed strains) were applied in the M. grisea observations.

The difference between M. grisea and F. graminearum was noticed in the initial stage. At 12 hpi, germinated conidia and growing hyphae of $M$. grisea could not only be seen in or on the anther, but also in the stigma, filament and palea of both cultivars (Figure 20 A-D), while in these early stages $F$. graminearum tended to stay in the anther.

However, comparing the distinct interactions, the behavior of M. grisea in the spikelet of Milan and Sumai 3 was hardly different. Hyphae developed slightly faster in Sumai 3 in comparison to Milan, but this was mostly observed in the later stages of infection. However, the spreading mode of $M$. grisea in the spikelet was not affected by the type of interaction. 

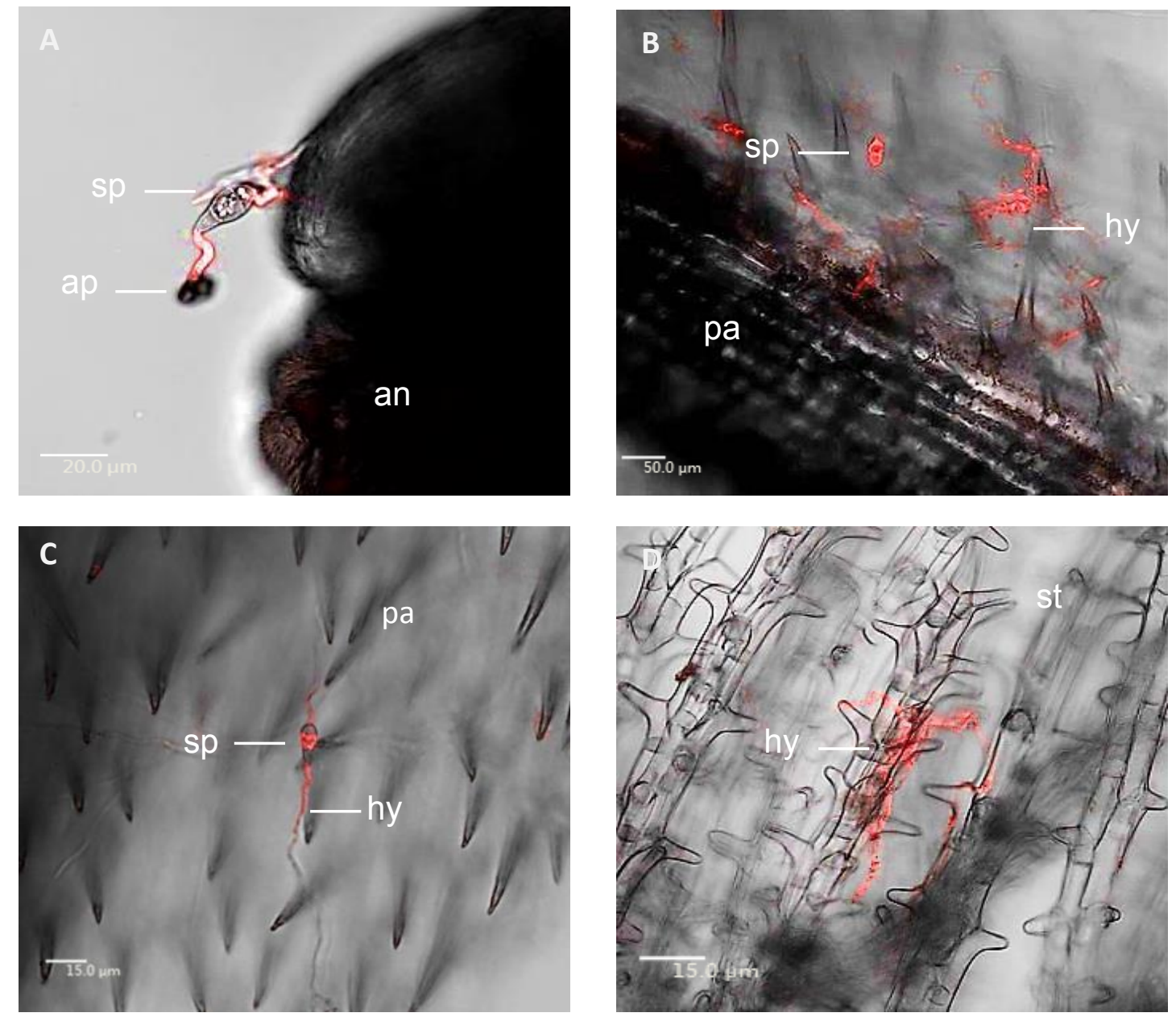

Fig. 20. Confocal microscopy images of M. grisea on the spikelet of cvs. Milan and Sumai 3 at 12 hpi stained with WGA-tetramethylrhodamine. A-B, the spikelet of Milan. A, a germinated conidium was attaching to the anther, the appressorium was visible on the tip. B, the palea was covered with conidia and hyphae. C-D, the spikelet of Sumai 3. C, a germinated conidium was staying on the palea. D, growing hyphae adhered to the stigma. $\mathrm{sp}=$ conidiospores, ap $=$ appressorium, an = anther, hy = hypha, $\mathrm{pa}=$ palea, $\mathrm{st}=$ stigma .

From 24-72 hpi, the spreading of M. grisea in the inner parts of the spikelet was not as fast as of F. graminearum. At 24 hpi, the expansion of M. grisea was similar in both Sumai 3 and Milan on various plant tissues (Figure $21 \mathrm{~A}-\mathrm{B}$ ). At $36 \mathrm{hpi}$, the filament was filled with vigorously growing hyphae in Milan (Figure $21 \mathrm{C}$ ). At 48 hpi, cellular invasion was observed in parenchyma cells of palea in Sumai 3 (Figure 21 D). More hyphae covered the anthers in Sumai 3 from 60 to 72 hpi (Figure 21 E-G). Although the expansion of hyphae on the palea was weak, hyphae often appeared at the edge of the palea where the chlorenchyma and stomata are, which may have implications for the infection (Figure $21 \mathrm{H}$ ). 


\section{Results}
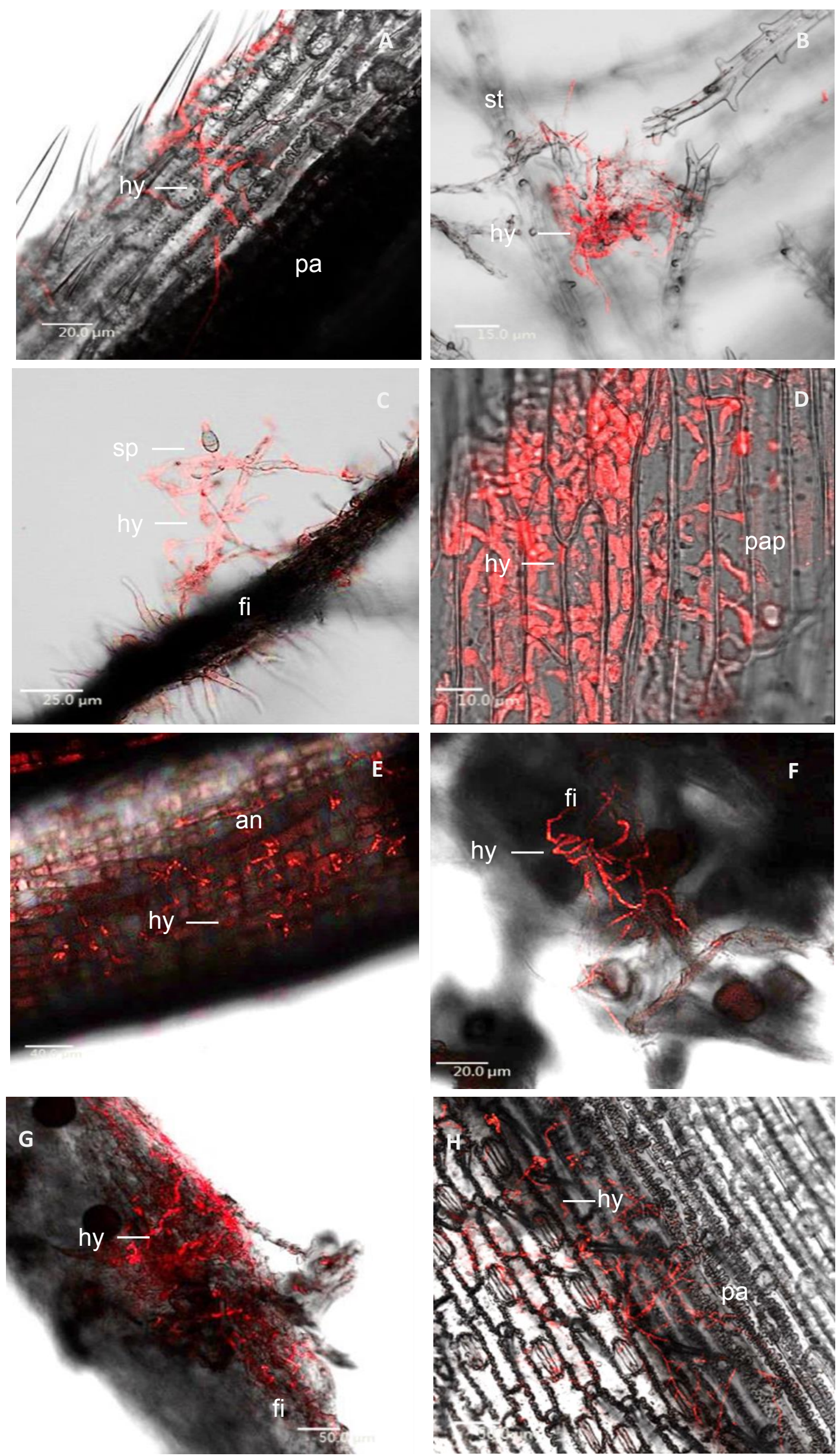
Fig. 21. Confocal microscopy overlay images of $M$. grisea infection in the spikelet of wheat cvs. Milan and Sumai 3 from 24-72 hpi. A, hyphae spread on the palea in Milan at 24 hpi. B-C, hyphae were expanding inside the spikelets. B, growing hyphae gathered between the branches in the stigma of Sumai 3 at 24 hpi. C, developing hyphae curled the filament of Milan at 36 hpi. D, at 48 hpi, ample hyphal colonized of the parenchyma cells of the palea in Sumai 3. E-F, M. grisea expanded in the spikelet of Sumai 3 at 60 hpi. E, a few hyphae grew on the anther. F, hyphae twined around the filament, the black shadow in the corner indicates pollens. G, the aggressive hyphae partially were occupying the filament of Sumai 3 at 72 hpi. H, hyphae were growing on the palea of Milan at 72 hpi. Hy = hypha, sp = conidiospores, an = anther, pa = palea, pap = palea parenchyma, $\mathrm{st}=$ stigma, $\mathrm{fi}=$ filament.

Infection process by $F$. graminearum

In this study, the GFP-labelled F. graminearum strain exhibited steady and bright green fluorescence at the mature stage rather than the primary period. Young hyphae showed a blurry green colour in the beginning which was difficult to recognize, this mainly occurred within $12 \mathrm{~h}$. At 12 hpi, F. graminearum conidia predominantly germinated inside or around the anther not on other plant tissues (Figure $22 \mathrm{~A}, \mathrm{~B}$ ). In the developing anthers, certain compounds were stimulated under the laser resulting in a bright green colour. The advancing hyphae were easily distinguished by their clear green colour. Thus the typical penetration pattern of the pathogen could be determined at particular time points.

Expansion of $F$. graminearum in the spikelets of cultivars Milan and Sumai 3 exhibited a few dissimilarities. First, at 12 hpi, much more germinated spores were observed in the susceptible cultivar Milan than in Sumai 3. Second, hyphal colonization of the spikelets of Milan was somewhat faster than in Sumai 3. In particular, the aerial mycelia were seen to grow more rapidly in Milan at 72 hpi. It is concluded that the expansion of F. graminearum in the spikelet was effectively influenced by the type of resistant/susceptible interaction. 

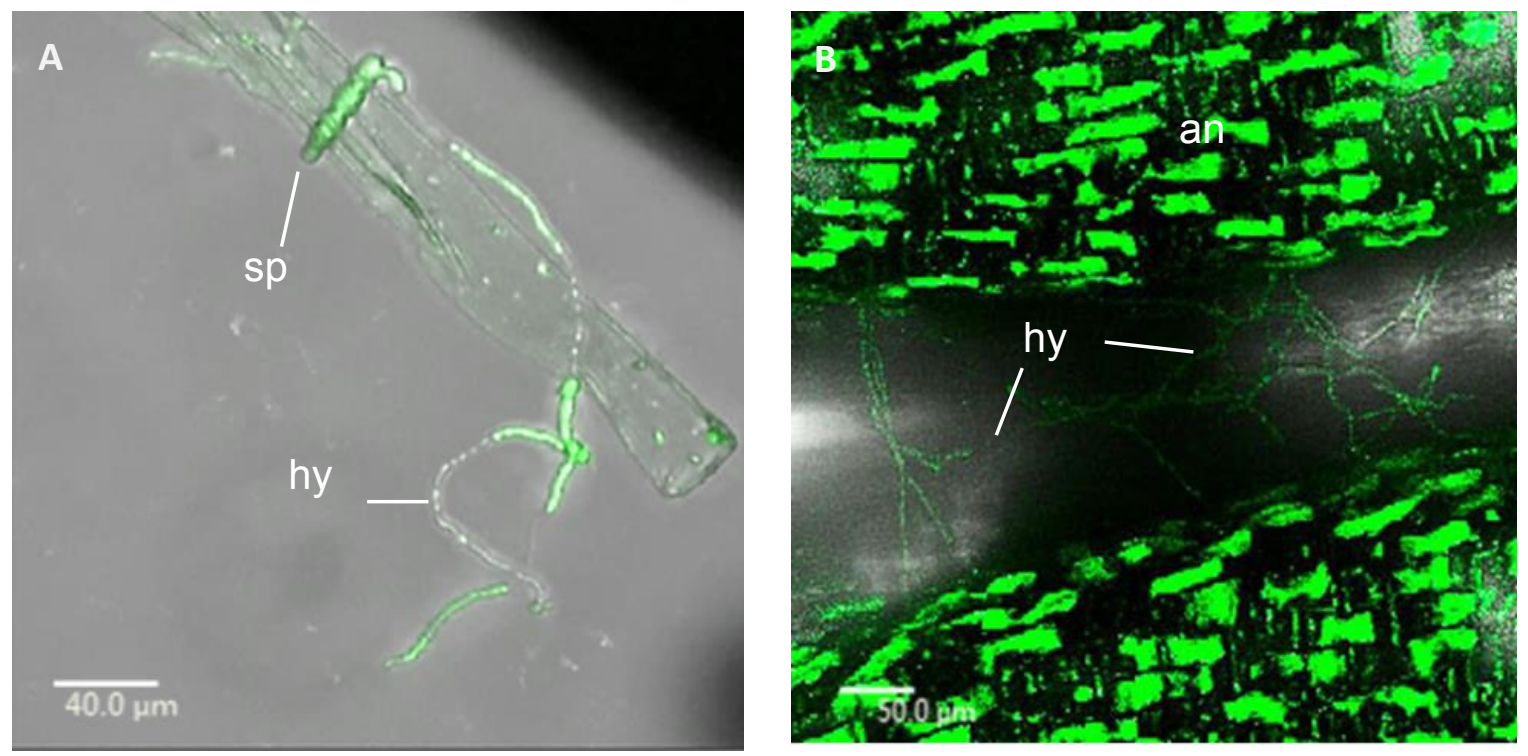

Fig. 22. Confocal microscopy images of the F. graminearum-GFP strain on Milan at 12 hpi. A, a germinated spore with elongated hyphae on the filament. B, mycelia growing on the anther. The central area shows hyphae, the rest of the bright green section is a developing anther. Hy = hypha, $\mathrm{sp}=$ conidiospores, an $=$ anther.

At 24 hpi, masses of hyphae were discovered growing extensively in the whole spikelet of both cultivars, especially in cultivar Milan. Since the filament is next tissue to the anther and connected with the stigma, germinated hyphae twined along the filament directly and continuously colonizing the stigma after $24 \mathrm{hpi}$. Then, the hyphae successfully advanced to the palea part (Figure $23 \mathrm{~A}, \mathrm{C}$ ). At $36 \mathrm{hpi}$, numerous growing mycelia completely occupied the anthers and the filament (Figure $23 \mathrm{~B}, \mathrm{D}$ and E). Then the hyphae were starting cellular penetration, it vigorously invaded parenchyma cells, especially on the palea (Figure 23 F). From 48-72 hpi, masses of mycelium further spread in the inner space of the spikelet in both cultivars (Figure $23 \mathrm{G}-\mathrm{H}$ ): the palea, lemma and glume were gradually colonized by pathogen. Whereafter the entire spikelet was colonized by F. graminearum. 


\section{Results}
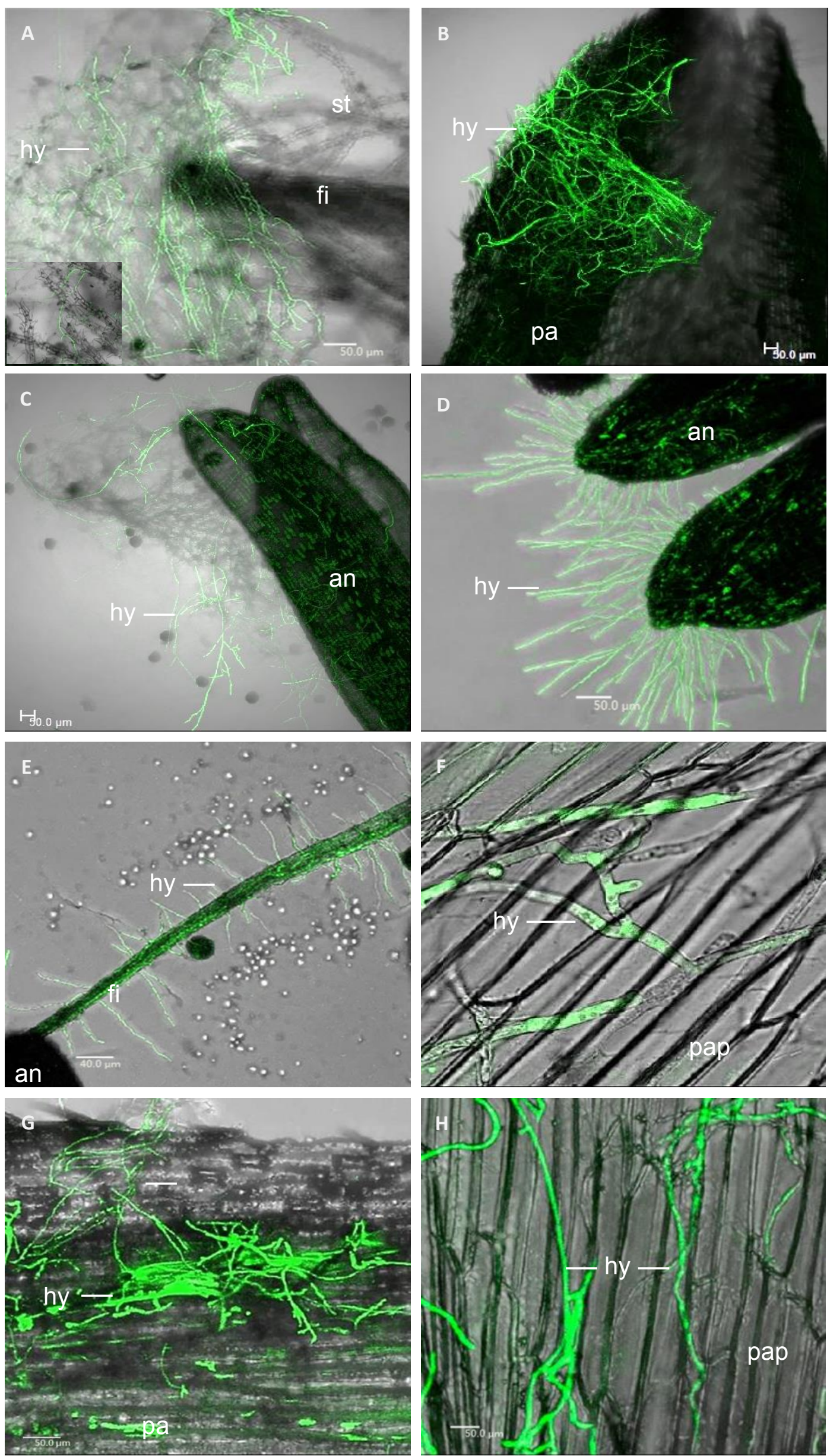
Fig. 23. Confocal microscopy overlay images of $F$. graminearum-GFP strain infection of the spikelets on wheat cvs. Milan and Sumai 3 from 24-72 hpi. A, massive hyphae grew around the stigma and filament from Milan at 24 hpi, left corner presenting the detailed invasion on a stigma branch. B, at $36 \mathrm{hpi}$, the surface of the palea of Milan was covered by numerous hyphae. $\mathrm{C}$, a view of fungal infection on the anther from Sumai 3 at $24 \mathrm{hpi}$, the hyphae were curling around the anther. D-F, further fungal developments were shown inside Sumai 3 or Milan at 36 hpi. D, vigorous hyphae grew through the anther of Sumai 3. E, in Milan, a filament was filled with hyphae. F, in the palea of Sumai 3, parenchyma cells was penetrated by F. graminearum. G, 60 hpi, plenty of hyphae gathered on the edge of the palea in Milan, which was nearby the stomata. H, hyphae developed on the palea of cultivar Sumai 3 at $72 \mathrm{hpi}$.

\subsubsection{Fungal spread in the rachilla}

Advancement of M. grisea

Another aim of CLSM detection was to reveal the differential colonization patterns existing in the rachilla during $M$. grisea and F. graminearum infections. Compared to the results from continuous microscopical monitoring, the resistant and susceptible type of responses affected pathogen progression in the rachilla of cultivar Milan not Sumai 3.

Both pathogens grew towards the vascular bundles in the initial infection stages. Upon the $M$. grisea inoculation, susceptible cultivar Sumai 3 displayed the earliest fungal infection at 12 hpi, M. grisea was first detected in the vessels (Figure $24 \mathrm{~A}$ ), and in the vascular bundles after 24 hpi (Figure 24 B). In resistant Milan, M. grisea was observed in vascular bundles only around 36 hpi (Figure $24 \mathrm{C}$ and D). 

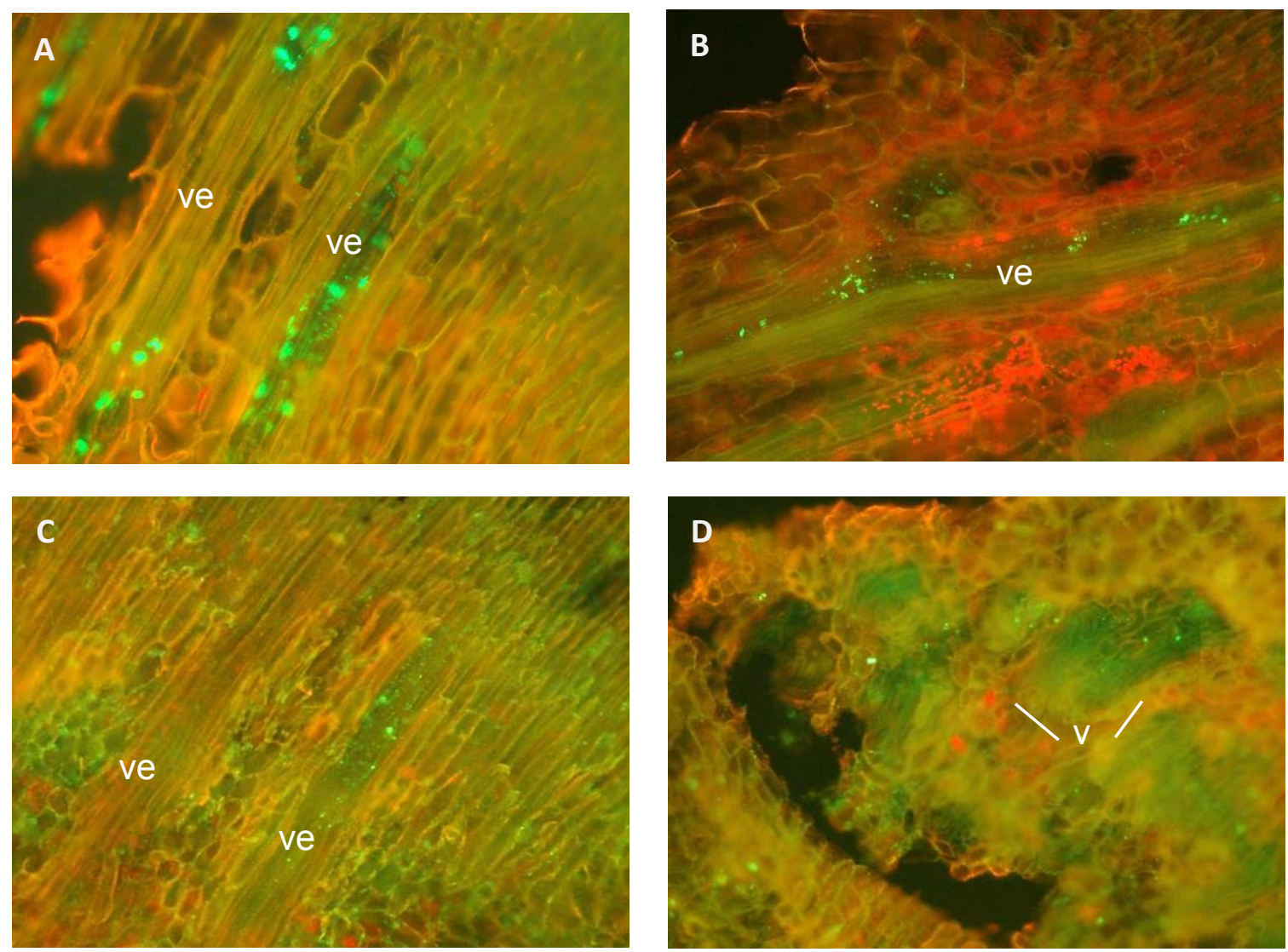

Fig. 24. Fluorescence images of $M$. grisea colonization of the vascular bundles of rachillae from the wheat cvs. Milan and Sumai 3 (200x). Bright green dots indicated the pathogen due to the Alexa Flour staining. The yellow and red tissue was the rachilla because of the propidium iodide staining. A, longitudinal section of rachilla showed $M$. grisea was entering the vascular bundles of Sumai 3 at 12 hpi. B, at 24 hpi, the vascular bundles of Sumai 3 contained fungal propagules. C, initial infection of $M$. grisea in the vascular bundles of Milan at $36 \mathrm{hpi}$, the left vessel was not infected. D, cross section of initial infection in the vascular bundles of Sumai 3 at 36 hpi. $\mathrm{V}=$ vascular bundles, ve $=$ vessels.

In the CLSM investigation, due to the image overlay function, the hyphae colour obtained from the lower emission laser channel was partly interfered with the stronger emission laser channel. Therefore, the colour of the hyphae switched between green and yellow in the combined images. At 72 hpi, the initial period of low fungal development increased to an apparent hyphal growth. In general, M. grisea is not as aggressive as F. graminearum. The common feature of both pathogens is that vascular bundles are the main focus point of rachilla colonization. 

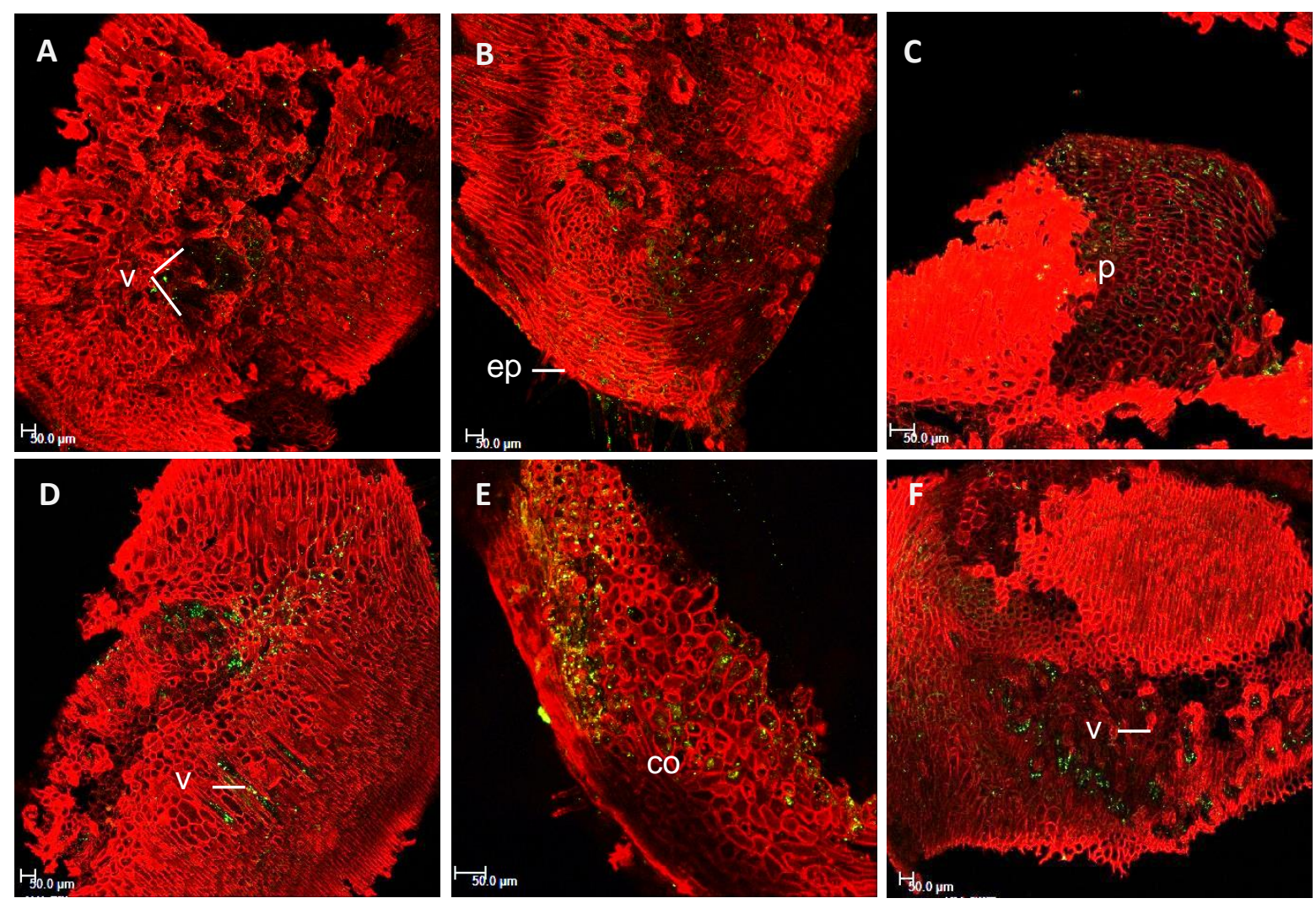

Fig. 25. Confocal overlaid images of the constant development of M. grisea in the rachillae of wheat cvs. Milan and Sumai 3 from 36 to 60 hpi. Plant tissue was shown in red due to the propidium iodide staining, while the pathogen was stained green with Alexa Flour. A-C, M. grisea grew in Milan. A, adaxial cross section of the rachilla at 36 hpi, the pathogen was mainly gathering in the vascular bundles. B, abaxial cross section at 48 hpi, the pathogen was presented in vascular bundles and the parenchyma tissues close to the epidermal tissue. C, adaxial cross section at $60 \mathrm{hpi}$, showing fungal colonization of the peripheral parenchyma region. D-F, fungal developments in Sumai 3. D, sidelong section at 36 hpi with partially infected parenchyma and vascular bundles. E, infected part of cortex, the subepidermal and parenchyma tissue was colonized at 48 hpi. F, cross section of the rachilla at 60 hpi, distinct colonization of vascular bundles and parenchyma tissue. $\mathrm{V}=$ vascular bundles, $\mathrm{p}=$ parenchyma, ep = epidermal, co = cortex.

Before 72 hpi, there was clear evidence of $M$. grisea presented in the hypodermis, parenchyma tissue, sclerenchyma, phloem and vascular bundles. In Milan from 36 to $60 \mathrm{hpi}$, M. grisea gradually emerged in the vascular bundle and parenchyma area that was near to the epidermal 
tissue (Figure 25 A-C). However, the development of $M$. grisea in Sumai 3 advanced more rapidly, leading to the partial vascular bundle and parenchyma areas being colonized after $36 \mathrm{hpi}$ (Figure $25 \mathrm{D}$ ). Subsequently, the major hypodermis and most vascular bundles were found to be attacked by M. grisea in Sumai 3 (Figure 25 E-F).

This distinct spread of M. grisea was exhibited by the further infection process in the rachilla (Figure 26 A-H). At 72 hpi, the parenchyma cells in Sumai 3 collapsed. Around 7 dpi, major parts of the rachilla including the vascular bundles and parenchyma were colonized by M. grisea (Figure 26 C). Conversely, the parenchyma cells in Milan infected by a few hyphae at 72 hpi, the cells were intact and fungal infection was mainly presented in the subepidermal tissue. The entire colonization of the rachilla from Milan by M. grisea was accomplished mostly beyond 14 dpi (Figure 26 F), particularly the xylem which was occluded (Figure 26 G). In addition some amorphous substance was observed intra- and intercellularly in rachilla from Milan at 14 dpi (Figure $26 \mathrm{E}, \mathrm{H}$ ). 
Results
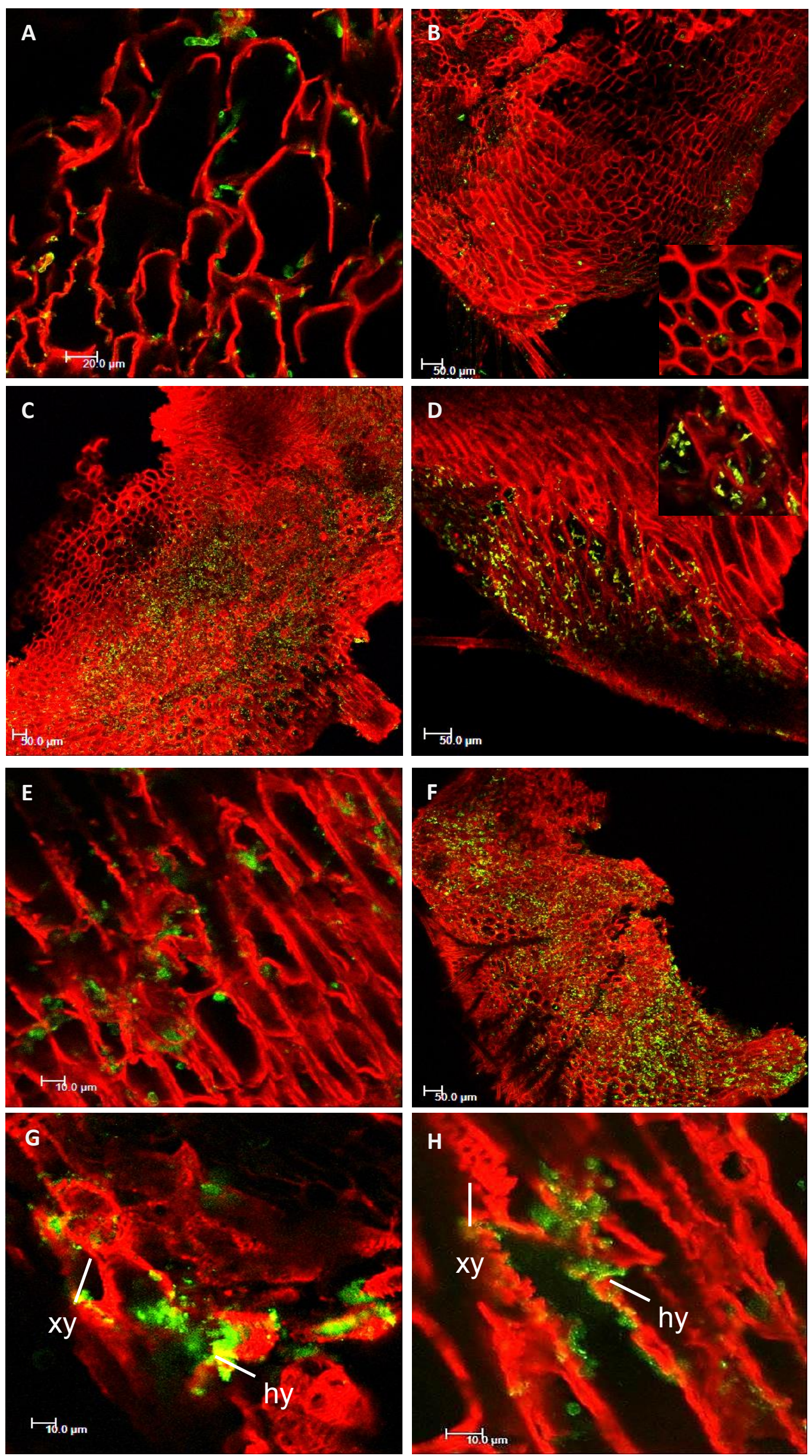
Fig. 26. Confocal overlay images of progressive colonization of $M$. grisea in the rachillae of wheat cvs. Milan and Sumai 3 from 3 to 14 dpi. A, Sumai 3 at 72 hpi, a cellular image of collapsing cells penetrated by hyphae of $M$. grisea. B, rachilla abaxial cross section of Milan at $72 \mathrm{hpi}$, the pathogen emerged in the vascular bundles and the parenchyma tissues which was along the epidermal layer. The lower right corner showed the intracellular traverse of the hyphae. C, the entirely colonized cross section indicated that M. grisea finished the occupation of the rachilla of Sumai 3 at 7 dpi. D, 10 dpi image of a partially infected rachilla of Milan, hyphae evidently advanced in subepidermal and hypodermal tissues. E-F, severely colonized rachilla of Milan by $M$. grisea at $14 \mathrm{dpi}$, image E showed the detail of the hyphal intrecellular invasion, and the cross section in F provided a comprehensive view of the ultimate occupation of M. grisea in the rachilla. G, M. grisea occluded xylem in the rachilla of Milan at 14 dpi. H, cell structure was coiled by $M$. grisea at $14 \mathrm{dpi}$. Xy = xylem, hy = hyphae

Colonization process of $F$. graminearum

In the initial stages of infection, F. graminearum invasion in vascular tissue of the rachilla was observed in both cultivars. F. graminearum occurred in vascular bundles of the susceptible cultivar Milan after 24 hpi (Figure 27 A-B). In the resistant cultivar Sumai 3, the infection in vascular bundles occurred at around 12 and 24 hpi (Figure $27 \mathrm{C}$ and D). 

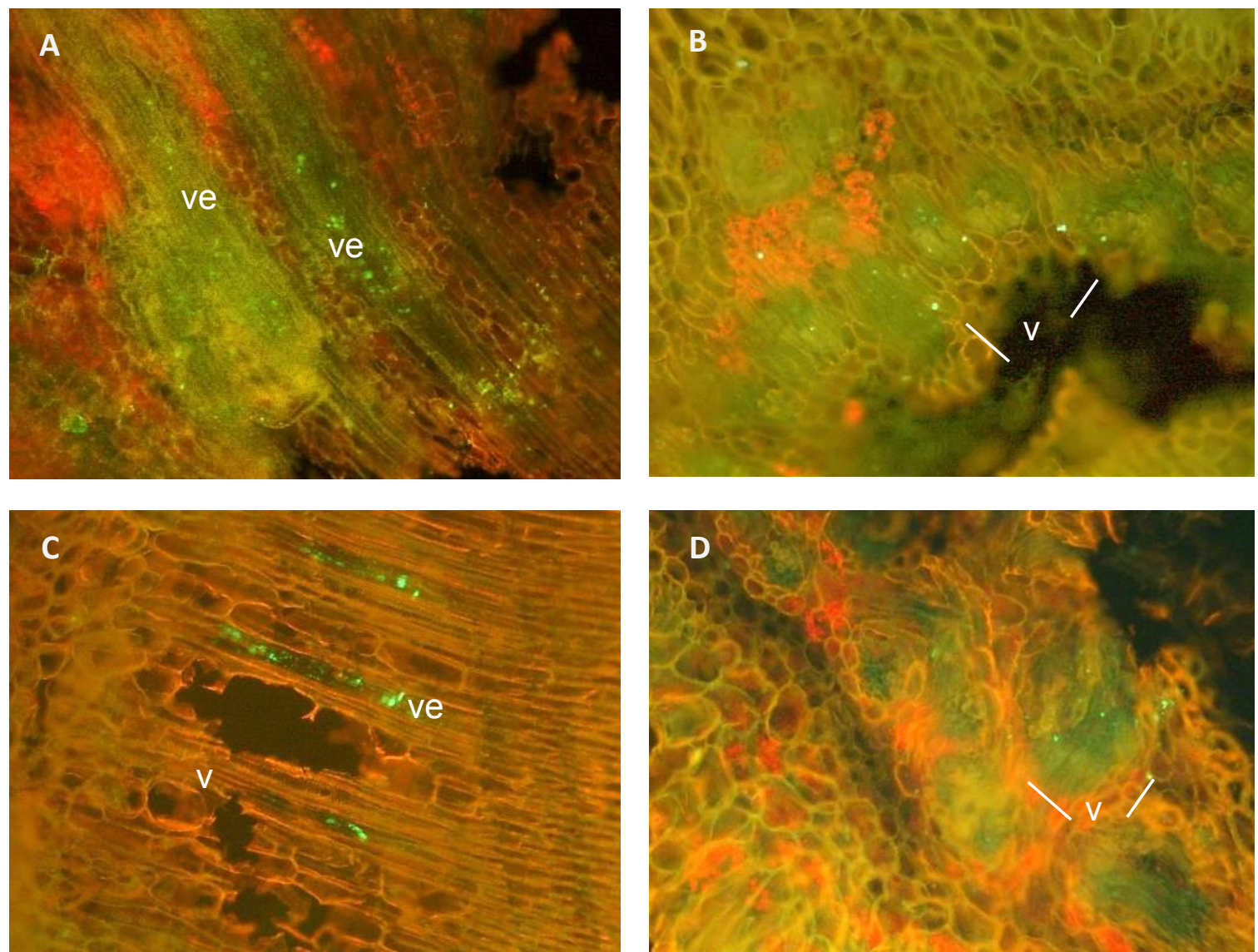

Fig. 27. Fluorescence images of $F$. graminearum colonization of vascular bundles of wheat cvs. Milan and Sumai 3 (200x). A, F. graminearum in the vascular bundles of a longitudinal section in Milan at 24 hpi. B, an initial invasion in vascular bundles of the cross section from Milan at 24 hpi. C, longitudinal section, infection of the vascular bundles of Sumai 3 at 12 hpi. D, initial infection of vascular bundles from a cross section of Sumai 3 at $24 \mathrm{hpi}$. V = vascular bundle.

At 72 hpi, similar to M. grisea, F. graminearum started vigorous hyphal growth. From 36 to 60 hpi, substantial evidence of $F$. graminearum growth was found in the subepidermal, parenchyma tissue and vascular bundles in cross or longitudinal sections of the rachilla (Figure $28 \mathrm{~A}-\mathrm{F}$ ). The pathogen evidently filled in vascular bundles of both cultivars, especially at 60 hpi (Figure $28 \mathrm{C}$, F). 

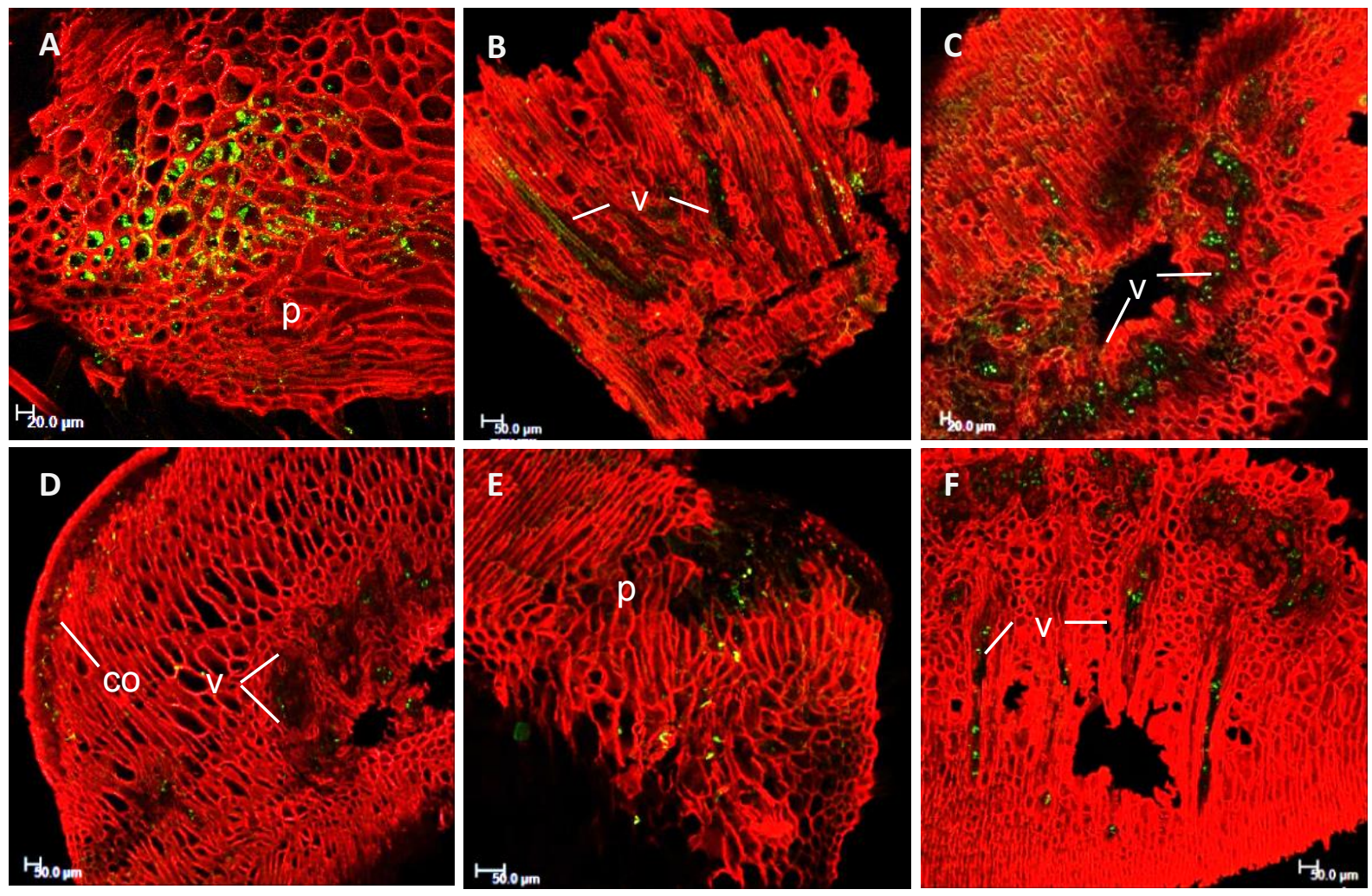

Fig. 28. Confocal overlay images of the progression of $F$. graminearum in the rachilla of wheat cvs. Milan and Sumai 3 at initial stages of infection (36-60 hpi). A-C, pathogen development in Milan. A, abaxial cross section of the rachilla at 36 hpi, F. graminearum invaded the parenchyma tissue. B, longitudinal section at $48 \mathrm{hpi}$, vascular bundles were filled with F. graminearum. C, adaxial cross section at $60 \mathrm{hpi}$, showing the infected vascular bundles. D-E, pathogen was growing in Sumai 3. D, abaxial cross section at 36 hpi, pathogen was presented in the subepidermal and vascular bundles. E, infection visible in the hypodermal tissue of a partial cross section at 48 hpi. F, sidelong section of the rachilla at 60 hpi with infected vascular bundles. $\mathrm{V}=$ vascular bundles, $\mathrm{p}=$ parenchyma, $\mathrm{co}=$ cortex.

At 72 hpi, the distinct interactions influenced the F. graminearum colonization in the rachilla. In the susceptible interaction, $F$. graminearum was able to enlarge its biomass and conquer the host tissue. In Milan, the central region of the rachilla was completely occupied, and a massive collapse of tissue structures was observed at 72 hpi (Figure 29 A). On the contrary, $F$. graminearum did not cover the the entire rachilla in Sumai 3 and exhibited a relatively weak filling of vascular bundles with hyphae (Figure 29 B). Around 5 dpi, successful colonization of the entire rachilla was finished in Milan (Figure 29 C), when clear and elongated hyphae spread 
all around the rachilla, and the cellular collapse started in the whole tissue. This process of destruction continued until 7 dpi (Figure 47 B). Besides, F. graminearum tended to infect the epidermal layer (Figure 29 E).

However, in the resistant cultivar Sumai 3, F. graminearum developed slower than in Milan. From 72 hpi to $10 \mathrm{dpi}$, the collapse was focused around the parenchyma cells which neighboured the epidermal tissue (Figure 29 D, F). The eventual colonization of the entire rachilla happened within about 14 days, but the rachilla remained intact, with the exception of some single vascular bundles which were occupied (Figure 29 G, H). 


\section{Results}
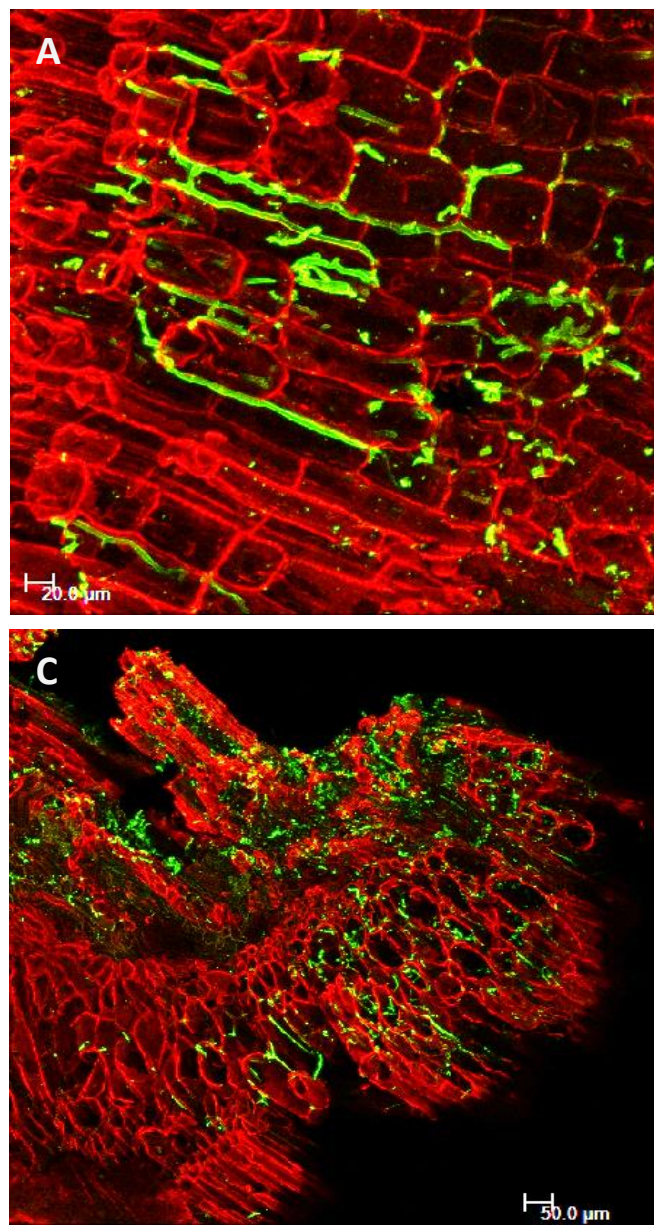

$\longmapsto_{50.0 \mu \mathrm{m}}$
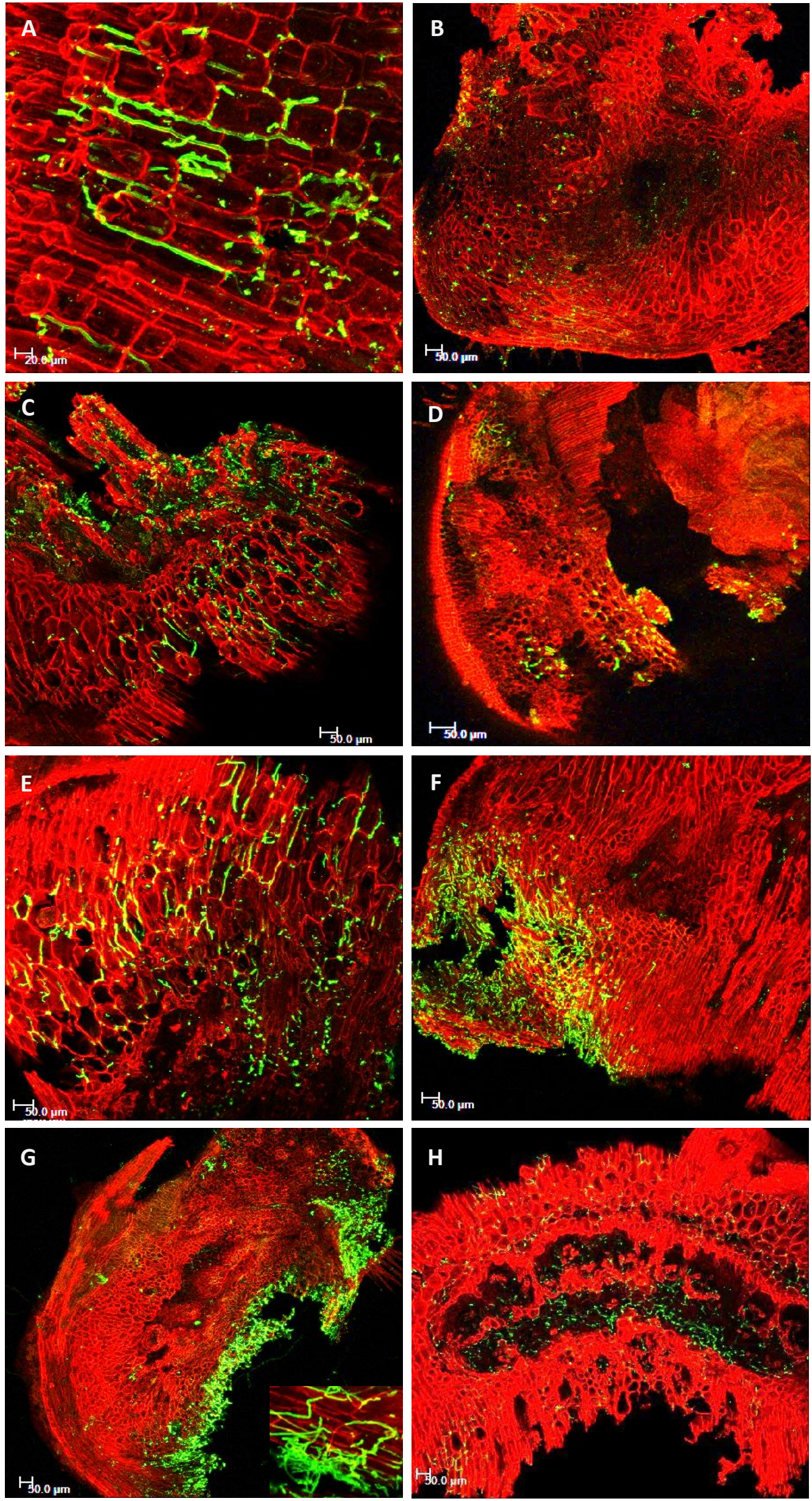
Fig. 29. Confocal images of the evolving colonization of $F$. graminearum in the rachilla of wheat cvs. Milan and Sumai 3 from 3 to 14 dpi. A, abaxial cross section of the rachilla in Milan at 72 hpi, the middle area was colonized and the collapsed cells were shown. B, Sumai 3 at 72 hpi, F. graminearum occured at the edge of the cross section on the parenchyma tissue which near the epidermal and vascular bundles. C, massive hyphal colonization of rachilla, cross section of Milan at 5 dpi. D, Sumai 3 at 5 dpi, a few hyphae were visible in the parenchyma cells in developing areas and the hypodermis. E, fully colonized and collapsed tissues on cross section in Milan implied entire colonization of the rachilla by F. graminearum at 7 dpi. F, Sumai 3 at 7 dpi showing aggressive pathogen invasion. G and H, F. graminearum infection in Sumai 3 at 10 and 14 dpi respectively; in $\mathrm{G}$ severe infection was initiated from the adaxial epidermis, and in $\mathrm{H}$ hyphae were obviously extensively distributed, especially in the vascular bundles.

\subsection{Biochemical analyses of diseased ears}

\subsubsection{ROS production in infected tissue}

\section{Superoxide}

Rapid and strong $\mathrm{O}_{2}^{-}$accumulations were detected in all compatible and incompatible interactions along with the controls at 12 hpi (Figure 30 and 31), especially in the highly susceptible interaction Milan-F. graminearum. However, the resistant interaction MilanM. grisea resulted in a relatively lower $\mathrm{O}_{2}{ }^{-}$formation. $\mathrm{O}_{2}{ }^{-}$accumulation from $F$. graminearum and M. grisea infections on Milan displayed similar characteristics at 12 hpi and were different to the Milan control. At 24 and 48 hpi, $\mathrm{O}_{2}{ }^{-}$accumulation in both interactions became dissimilar and decreased. At 60 hpi, $\mathrm{O}_{2}{ }^{-}$accumulation in Milan-F. graminearum was notably higher than in Milan-M. grisea (Figure 30). 
For both F. graminearum and M. grisea interactions on Sumai 3, there was an initial increase of $\mathrm{O}_{2}{ }^{-}$accumulation at $12 \mathrm{hpi}$ (Figure 31). At $24 \mathrm{hpi}$, these accumulations in the two interactions dropped, especially in the resistant interaction Sumai 3-F. graminearum. However, the control of Sumai 3 markedly increased at $36 \mathrm{hpi}$, in comparison to both interactions which had a relatively weaker increase. At $48 \mathrm{hpi}$, Sumai 3-M. grisea and the control gave a similar undulating pattern of $\mathrm{O}_{2}{ }^{-}$accumulation. At 60 hpi, a subdued increase of $\mathrm{O}_{2}{ }^{-}$accumulation occurred in Sumai 3-F. graminearum.

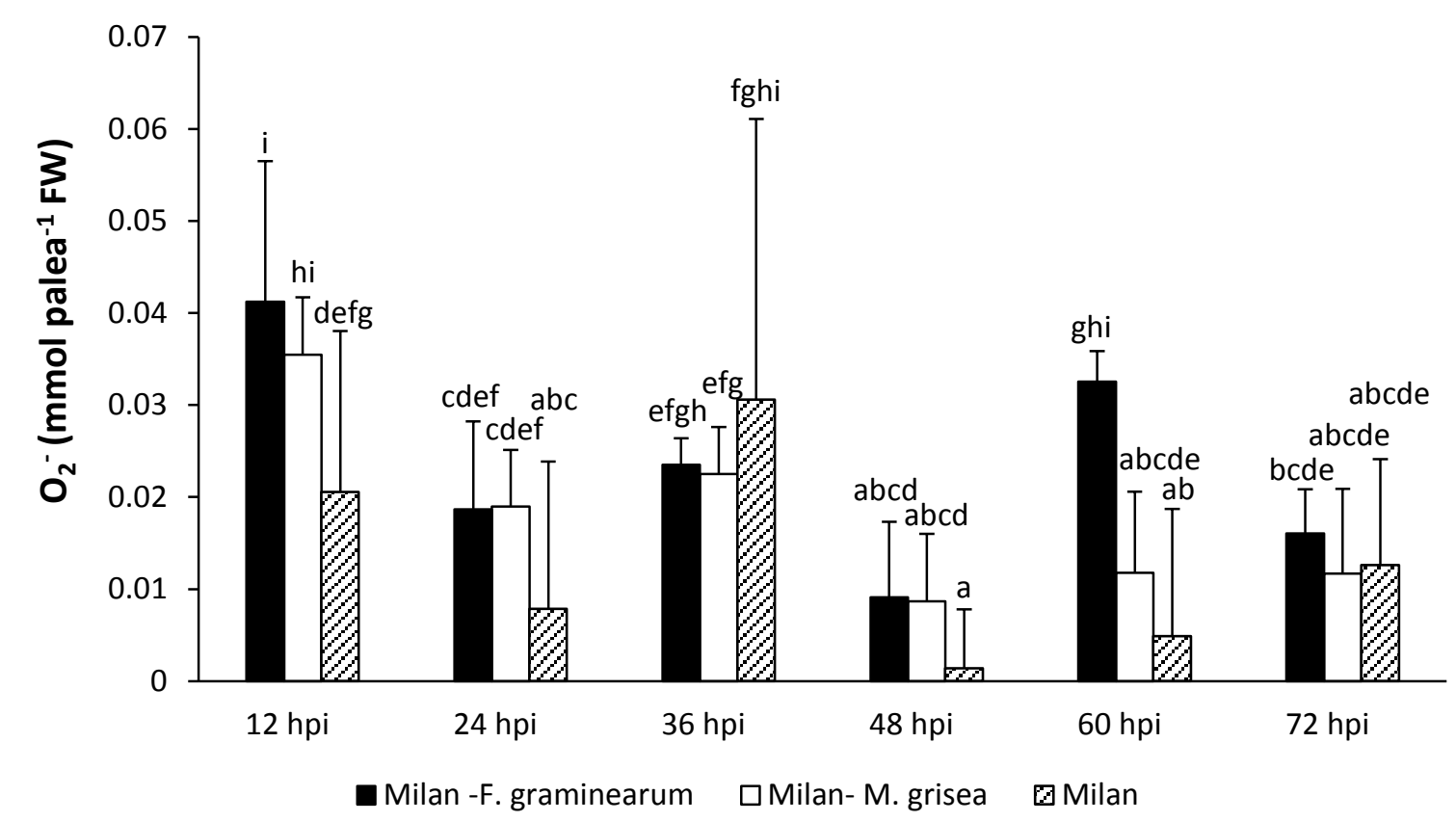

Fig. 30. $\mathrm{O}_{2}^{-}$accumulation in the palea of cv. Milan at different time points after inoculation with F. graminearum and M. grisea. Each value indicates the mean $\pm \mathrm{SD}$ of disease severity for each interaction. $\mathrm{O}_{2}^{-}$accumulation levels followed by the same letter are not significant different according to LSD test $(\mathrm{P} \leq 0.05)$. At 12 hpi, $\mathrm{O}_{2}{ }^{-}$accumulation of Milan-M. grisea and MilanF. graminearum significantly differed from the control, and at 60 hpi, Milan-M. grisea were significantly differentsfrom Milan-F. graminearum. 


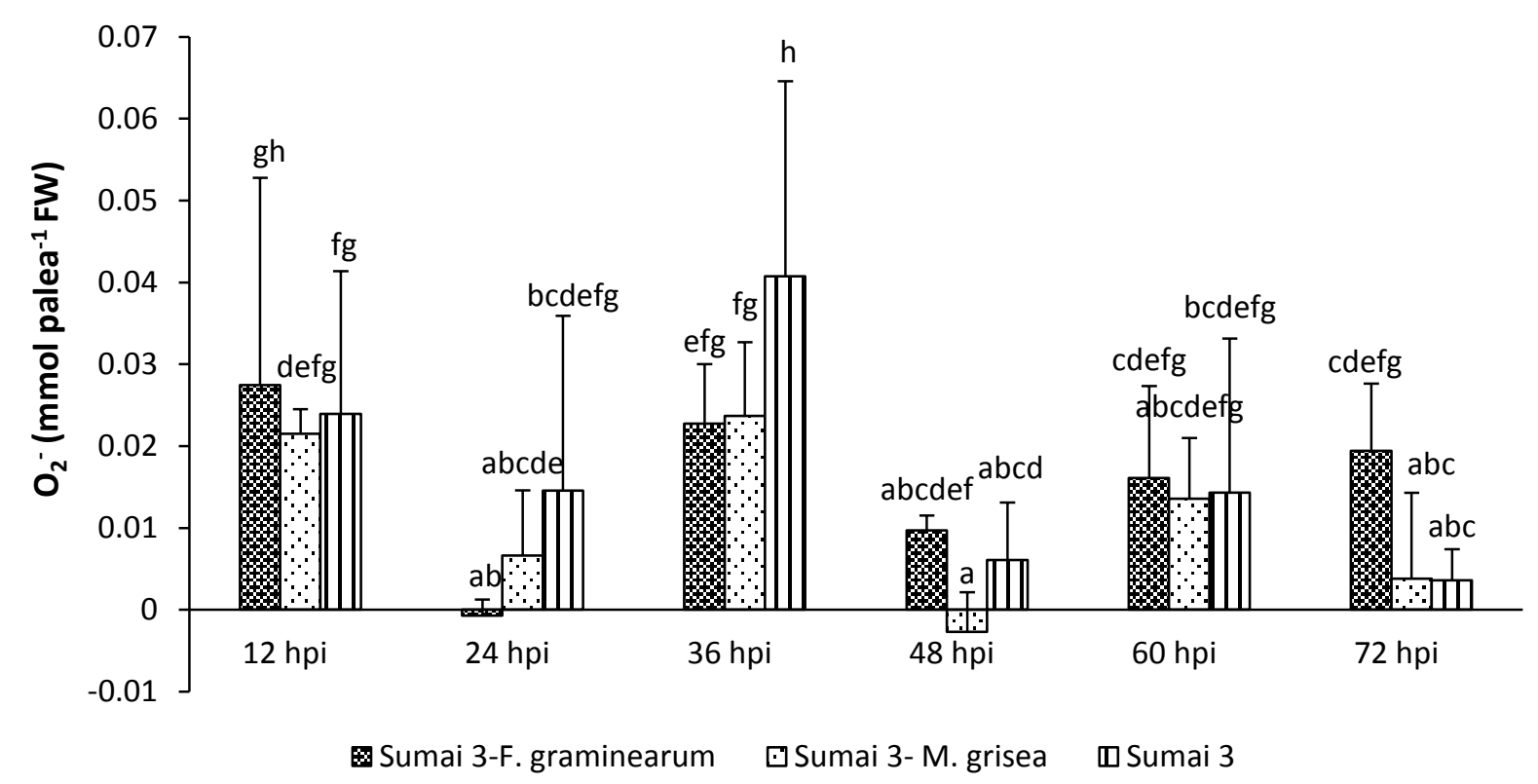

Fig. 31. $\mathrm{O}_{2}{ }^{-}$accumulation in the palea of cv. Sumai 3 at different time points after inoculation with F. graminearum and M. grisea. Each value indicates the mean \pm SD of disease severity for each interaction. $\mathrm{O}_{2}^{-}$accumulation levels followed by the same letter are not significant different according to LSD test $(\mathrm{P} \leq 0.05)$. At 36 hpi, $\mathrm{O}_{2}{ }^{-}$accumulation of Sumai 3-M. grisea and Sumai 3-F. graminearum was significantly different from the control.

Hydrogen peroxide production inquiry

Within 72 hpi in different interactions and the controls, $\mathrm{H}_{2} \mathrm{O}_{2}$ levels were relatively stable (Figure 32 and 33). At 36 hpi, a transient faint rise of $\mathrm{H}_{2} \mathrm{O}_{2}$ accumulation was found in the incompatible interaction Milan-M. grisea (Figure 32). Subsequently, a strong increment at 48 hpi was recorded. At 48 hpi, $\mathrm{H}_{2} \mathrm{O}_{2}$ accumulation in Milan-F. graminearum was significantly different to Milan-M. grisea. 


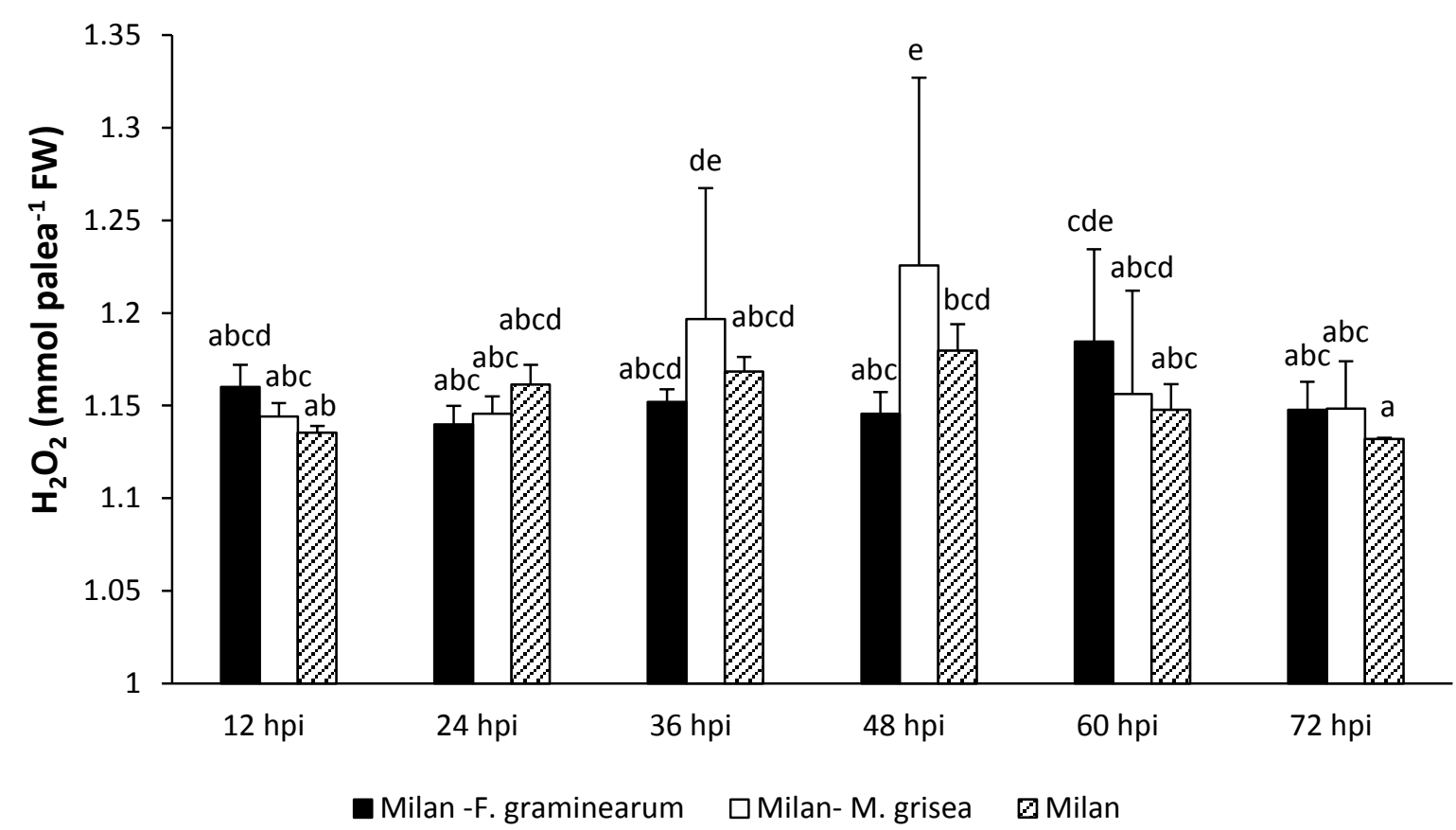

Fig. 32. $\mathrm{H}_{2} \mathrm{O}_{2}$ accumulations in the palea of $\mathrm{cv}$. Milan at different time points after inoculation with F. graminearum and M. grisea. Each value indicates the mean $\pm \mathrm{SD}$ of disease severity for each interaction. $\mathrm{H}_{2} \mathrm{O}_{2}$ accumulation levels followed by the same letter are not significant different according to LSD test $(\mathrm{P} \leq 0.05)$. At 48 hpi, $\mathrm{H}_{2} \mathrm{O}_{2}$ accumulation of Milan-M. grisea and Milan-F. graminearum significantly differed.

An increase of $\mathrm{H}_{2} \mathrm{O}_{2}$ accumulation happened in the Sumai 3 control and the compatible interaction Sumai 3-M. grisea at 48 hpi (Figure 33), while $\mathrm{H}_{2} \mathrm{O}_{2}$ accumulation kept quiet in the compatible interaction Sumai 3-F. graminearum, which went up slightly at 72 hpi. 


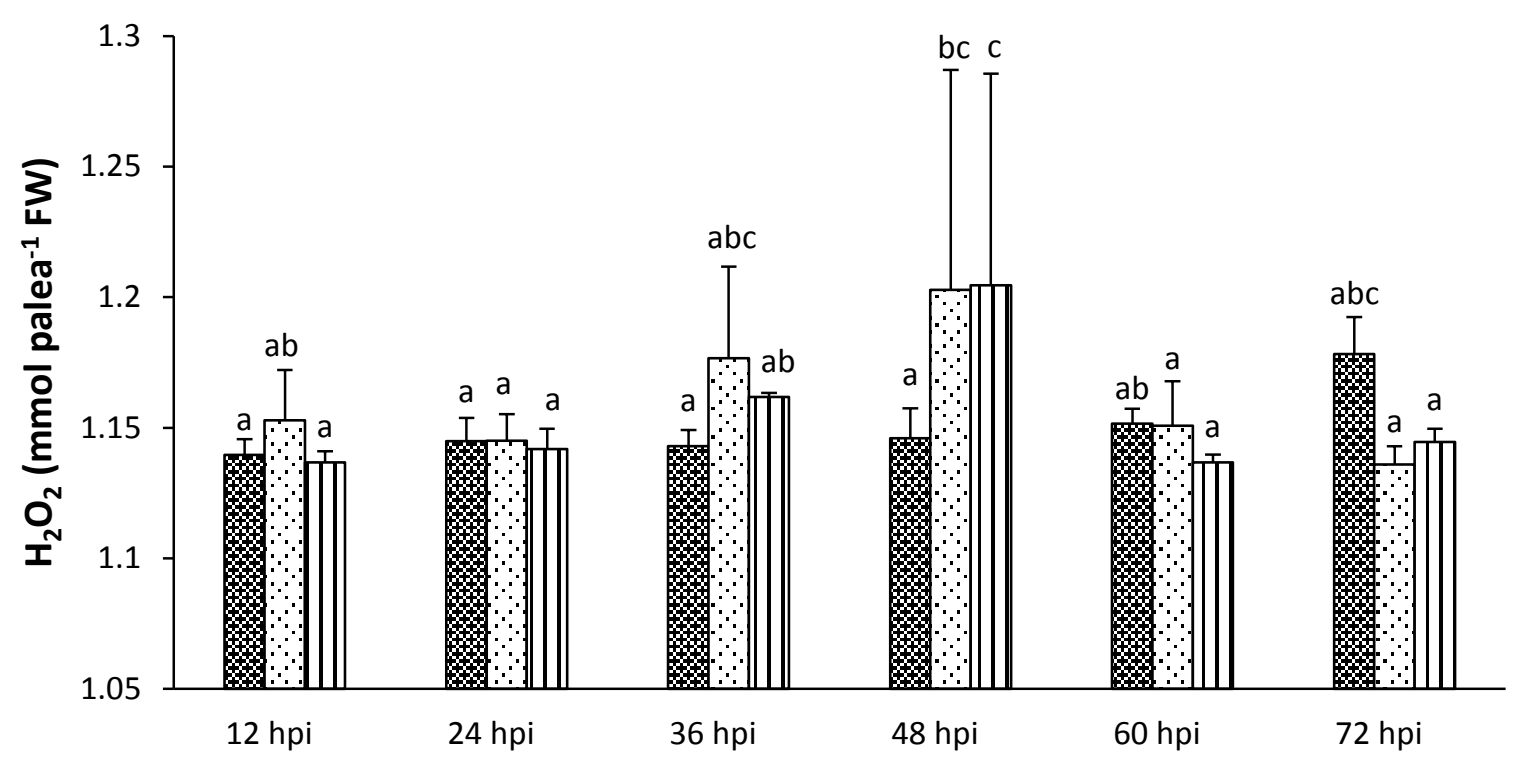

⿴囗大 Sumai 3-F. graminearum $\square$ Sumai 3- M. grisea $\square$ Sumai 3

Fig. 33. $\mathrm{H}_{2} \mathrm{O}_{2}$ accumulations in the palea of cv. Sumai 3 at different time points after inoculation with F. graminearum and $M$. grisea. Each value indicates the mean $\pm \mathrm{SD}$ of disease severity for each interaction. $\mathrm{H}_{2} \mathrm{O}_{2}$ accumulation levels followed by the same letter are not significant different according to LSD test $(\mathrm{P} \leq 0.05)$. At 48 hpi, $\mathrm{H}_{2} \mathrm{O}_{2}$ accumulation of Sumai 3-M. grisea and Sumai 3-F. graminearum differed significantly.

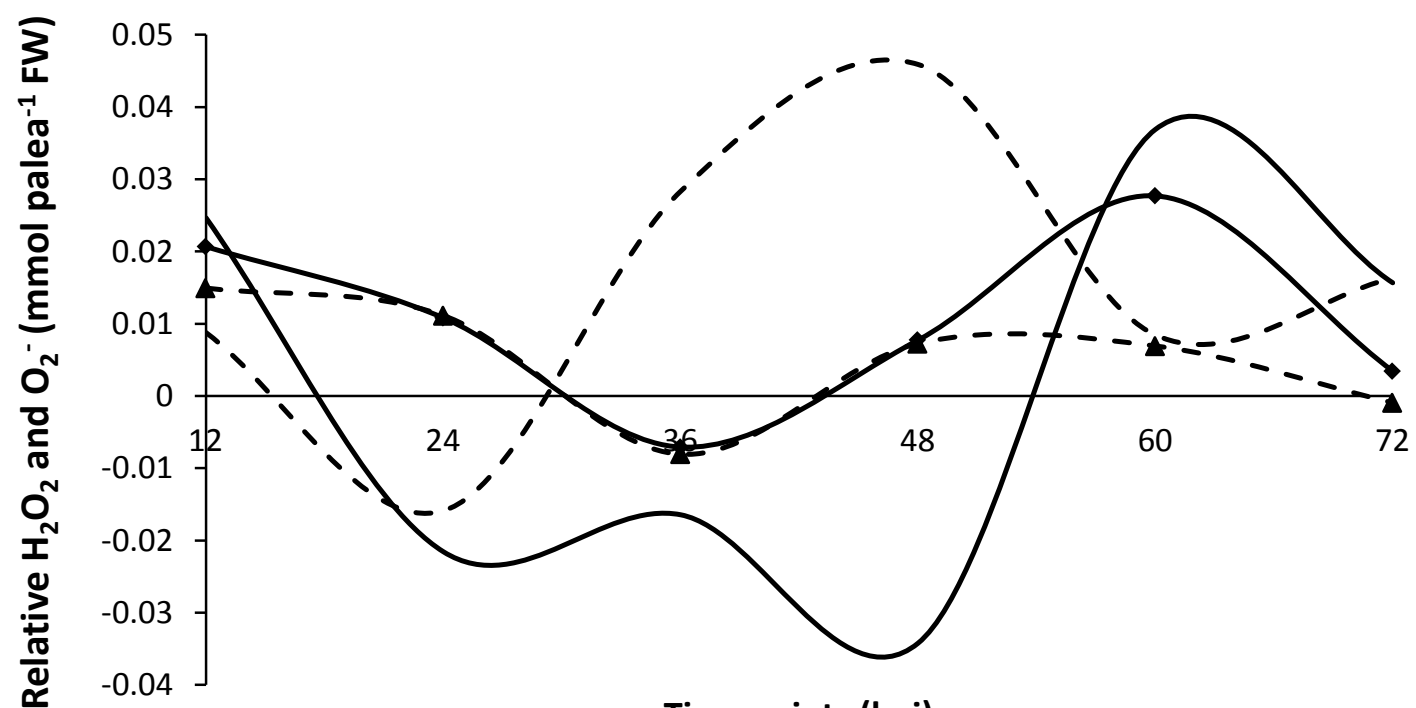

Time points (hpi)

$\longrightarrow$ O2-Milan -F. graminearum

- \pm - 02-Milan- M. grisea

H2O2-Milan -F. graminearum

- - - H2O2-Milan- M. grisea 
Fig. 34. Trend lines show time course of $\mathrm{H}_{2} \mathrm{O}_{2}$ and $\mathrm{O}_{2}{ }^{-}$accumulation relative to the control in the palea tissue of wheat cv. Milan after inoculation with M. grisea and F. graminearum.

In the resistant interaction Milan-M. grisea, $\mathrm{O}_{2}{ }^{-}$accumulation decreased from the initial stage until 36 hpi, while $\mathrm{H}_{2} \mathrm{O}_{2}$ accumulation increased after 24 hpi (Figure 34). The increase may be caused by conversion of $\mathrm{O}_{2}{ }^{-}$to $\mathrm{H}_{2} \mathrm{O}_{2}$. However, this would not explain the increase of $\mathrm{H}_{2} \mathrm{O}_{2}$ accumulation in Milan-M. F. graminearum at $60 \mathrm{hpi}$, since both ROS had an increase then.

In the susceptible interaction Sumai 3-M. grisea (Figure 35), both $\mathrm{H}_{2} \mathrm{O}_{2}$ and $\mathrm{O}_{2}{ }^{-}$accumulations were low. A small drop in $\mathrm{O}_{2}{ }^{-}$occurred at 36 hpi while $\mathrm{H}_{2} \mathrm{O}_{2}$ experienced a small increment, which could be related to the conversion between the two ROS. However, this explanation is applicable in the incompatible interaction of Sumai 3-F. graminearum, because $\mathrm{H}_{2} \mathrm{O}_{2}$ accumulation underwent a sharp fall at $48 \mathrm{hpi}$, while the $\mathrm{O}_{2}{ }^{-}$production was positive (Figure $35)$.

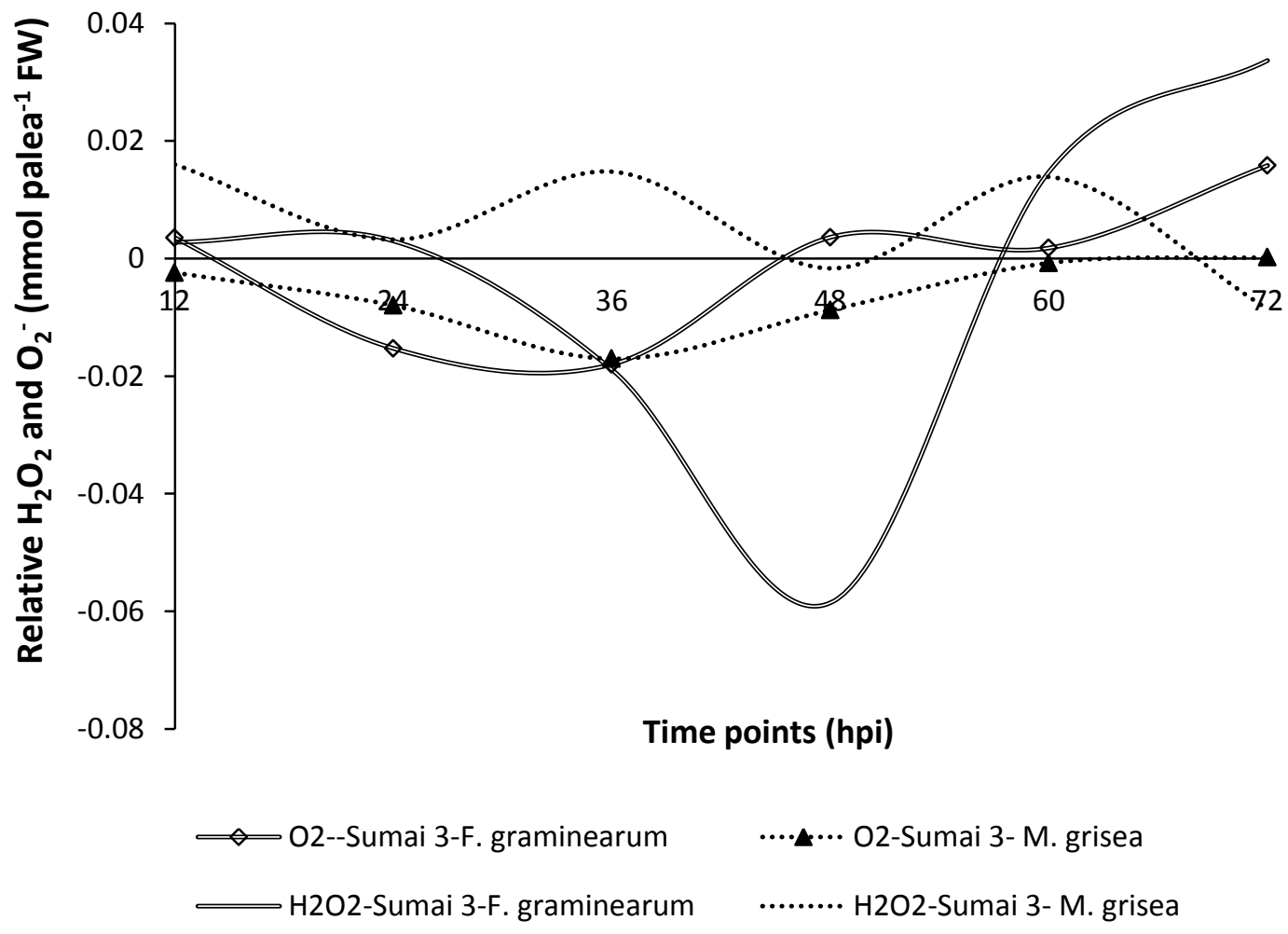

Fig. 35. Trend lines show time course of $\mathrm{H}_{2} \mathrm{O}_{2}$ and $\mathrm{O}_{2}{ }^{-}$accumulation relative to the control in the palea tissue of wheat cv. Sumai 3 after inoculation with M. grisea and F. graminearum. 


\subsubsection{Histochemical localization of ROS}

Superoxide generation detected by NBT staining

Typical blue discolorations on the palea were observed in $3.5 \mathrm{~h}$ after infiltration with a NBT staining solution, suggesting $\mathrm{O}_{2}{ }^{-}$were accumulated in the palea tissue during initial stages of plant defense. By histological analysis, assorted blue lesions were formed along the pathogenesis. These blue lesions were formed in varieties of shape and size, and mostly occurred in the compatible interactions.

At $12 \mathrm{hpi}$, various small blue dots spread along with cells on the palea in the compatible interaction Milan-F. graminearum, these blue marks connected together occasionally (Figure 36 B). At 24 hpi, some blue lesions appeared as a central circle with a surrounding scattered area of lesions corresponding with the pathogenesis development and $\mathrm{O}_{2}{ }^{-}$accumulation. The lesions were also dispersed along the cells which were adjacent to the location of the hyphae.

In another relatively compatible interaction, Sumai 3-M. grisea, at $24 \mathrm{hpi}, \mathrm{O}_{2}{ }^{-}$accumulation was demonstrated albeit not as clearly. The expression of $\mathrm{O}_{2}{ }^{-}$accumulation was shown in limited size and with blurry edges, mostly like pale blue lesions (Figure 36 E, F). Some unclear blue marks also occurred in two incompatible interactions: Sumai 3-F. graminearum and MilanM. grisea. Strong evidence of NBT was difficult to find besides a few very weak dots or stained cells in these two interactions (Figure $36 \mathrm{G}, \mathrm{H}$ ). Interestingly, in the subsequent infection period, the blue staining was not seen in the same place where the cell death took place, but rather in nearby cells instead. From Figure $34 \mathrm{I}-\mathrm{L}, \mathrm{O}_{2}{ }^{-}$accumulation (with clear scale and levels) spreads in the cells which neighbor the dead cells. In Figure 34-L, stronge NBT reaction was observed in the mesophyll cells close to the infection site. 


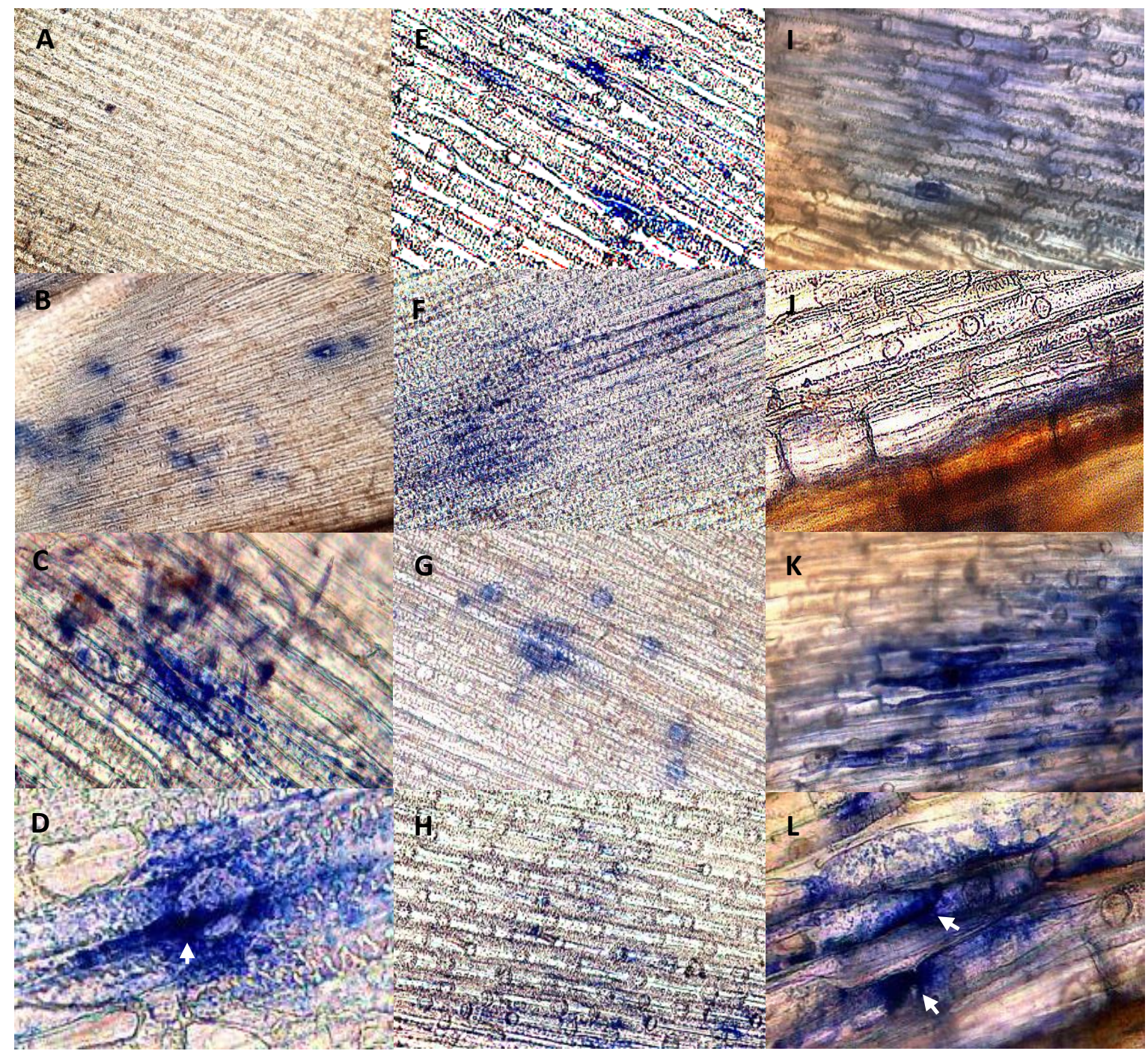

Fig. 36. Microscopic views of superoxide accumulations on the palea of the two wheat cvs. Milan and Sumai 3 inoculated with M. grisea and F. graminearum, after staining with NBT. A, non-inoculated palea of Milan stained with NBT (x100). B-D, $\mathrm{O}_{2}{ }^{-}$traces on the palea from Milan-F. graminearum interaction. B, at 12 hpi, $\mathrm{O}_{2}{ }^{-}$was presented in the shape of irregular dots (x100). C, at 24 hpi, a clear blue mark emerged at the penetration site, where the hyphae penetrated parenchyma cells (x200). D, stronger NBT reaction at $24 \mathrm{hpi}$, highlighted by the white arrow (x200). E-F, $\mathrm{O}_{2}{ }^{-}$accumulation in the interaction Sumai 3-M. grisea within 24 hpi, with a faint or unclear bordered blue mark along the plant cells (x200). G, small blue dots indicating the presence of $\mathrm{O}_{2}^{-}$at 24 hpi in Sumai 3-F. graminearum (x200). H, obscure blue figures in Milan-M. grisea interaction at 24 hpi indicating low $\mathrm{O}_{2}{ }^{-}$accumulation (x200). $\mathrm{I}-\mathrm{L}, \mathrm{O}_{2}{ }^{-}$ accumulation on the palea from later stages of the interaction Milan-F. graminearum (x200). I, 48 hpi and J-L 72 hpi, on the infected palea, obviously the blue staining did not show dead cells 
(the yellow or brown area), and stronger NBT reaction was observed in L (white arrows).

In situ detection of hydrogen peroxide by DAB staining

After DAB staining, $\mathrm{H}_{2} \mathrm{O}_{2}$ accumulations became visible by a strong dark-brown discoloration in the tissue. DAB staining suggested that establishment of incompatible plant reactions is associated with the production of $\mathrm{H}_{2} \mathrm{O}_{2}$. Results revealed that $\mathrm{H}_{2} \mathrm{O}_{2}$ accumulations displayed a different pattern during the activation of plant defense systems, it had one or two clar brownish sites on the infected palea. Since 24 hpi, the $\mathrm{H}_{2} \mathrm{O}_{2}$ accumulations were shown in two incompatible interactions: Milan-M. grisea and Sumai 3-F. graminearum, and the elevated $\mathrm{H}_{2} \mathrm{O}_{2}$ accumulation appeared in 48 hpi in both interactions (Figure $37 \mathrm{C}-\mathrm{F}$ ).

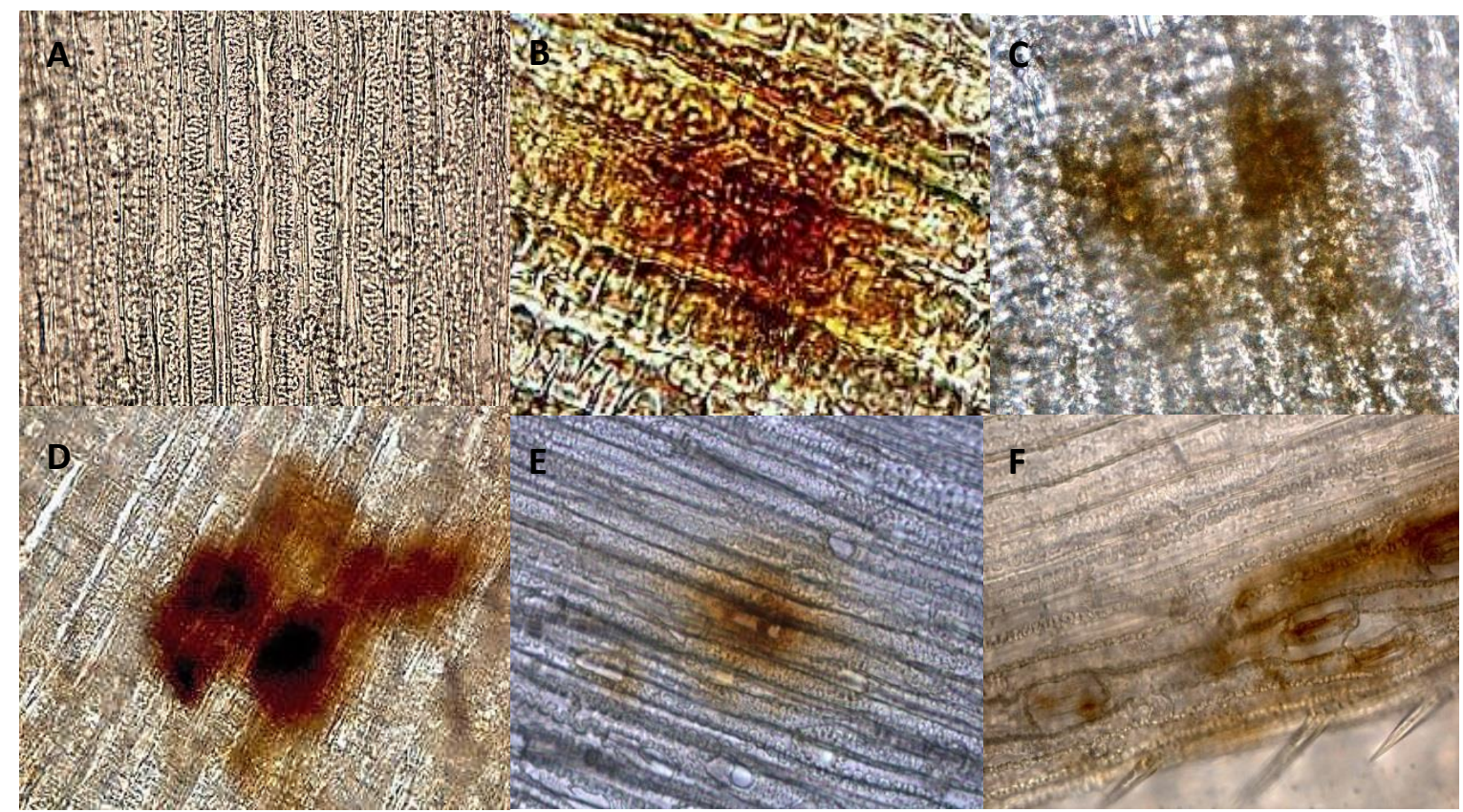

Fig. 37. Microscopic views of hydrogen peroxide accumulations (DAB staining) on the paleae of wheat cvs. Milan and Sumai 3 at different time points post inoculation with M. grisea and F. graminearum (x200). A, non-inoculated palea of Sumai 3 as control. $\mathrm{B}, \mathrm{H}_{2} \mathrm{O}_{2}$ accumulation in Milan-M. grisea at 24 hpi. C-D, $\mathrm{H}_{2} \mathrm{O}_{2}$ traces in Milan-M. grisea at 48 hpi. E-F, $\mathrm{H}_{2} \mathrm{O}_{2}$ accumulation in the interaction Sumai 3-F. graminearum at $48 \mathrm{hpi}$. 


\subsection{Differential gene expression in infected ears}

\subsubsection{Pathogenesis-related (PR) genes}

Gene Chi2, encoding Class VII acidic chitinase, was silent in all interactions at 24 hpi. Similar inductions were displayed in two M. grisea and two F. graminearum interactions at 48 hpi. The highest induction (250 fold) occurred in the susceptible interaction Milan-F. graminearum at 3 dpi, while the second highest induction was in the resistant response Milan-M. grisea at 5 dpi (179 fold). Generally, the Chi2 expression of both M. grisea interactions increased over time, especially in the resistant interaction at 5 dpi. However, Chi2 levels in the two F. graminearum interactions were stable, except for the resistant response with Sumai 3 at 3 dpi. The activation of Chi2 tended to be in the rachis at the latter time (Figure 38).

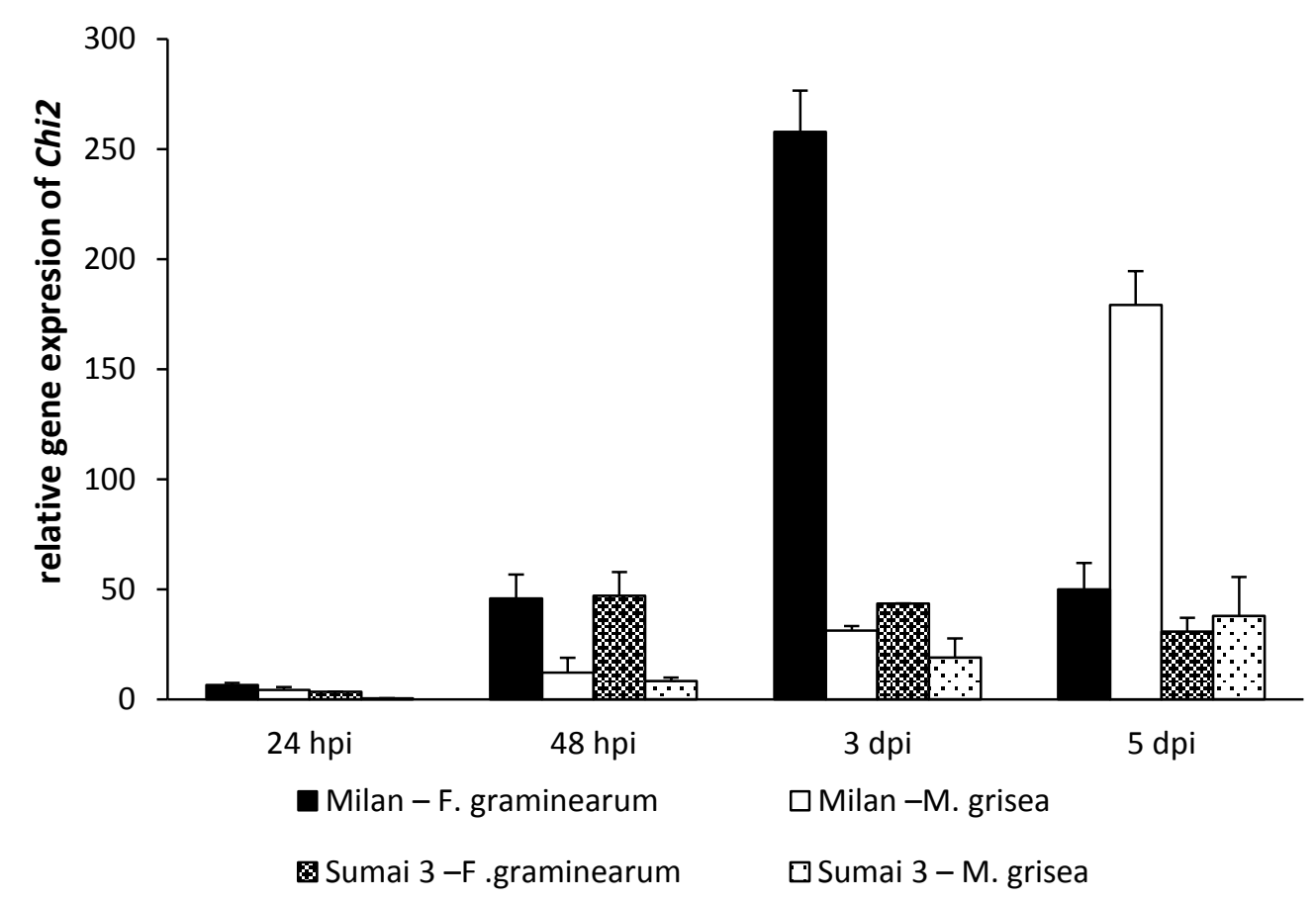

Fig. 38. Expression of Chi2 in wheat cvs. Milan and Sumai 3 inoculated with M. grisea and F. graminearum from 24 hpi to 5 dpi relative to the non-inoculated control. Spikelets and rachillae were analysed at 24 and $48 \mathrm{hpi}$; the rachis was used at 3 and 5 dpi. Each bar represents the mean of three biological replicates in each interaction \pm SD.

$P R 2$ demonstrated a lower but universal expression in various plant tissues of the different interactions. A differential accumulation was found in the initial stages in the spikelet and the 
rachilla, particularly in Milan-M. grisea and Milan-F. graminearum. At 24 hpi, a higher (12fold) induction was detected in the resistant interaction Milan-M. grisea than in the others. At 48 hpi, PR2 was slightly higher induced (17-fold) in the susceptible response of Milan to F. graminearum. Corresponding to different pathogens, the induction of $P R 2$ showed a rise in the susceptible interaction firstly, then a small increase in the resistant response but on a lower level (less than 10-fold).

From 24 to 48 hpi, in the Milan-M. grisea interactions it showed increases in inductions in the spikelet and the rachilla, but the Sumai 3-M. grisea interaction revealed increases in induction in the rachis from 3 to 5 dpi (Figure 39).

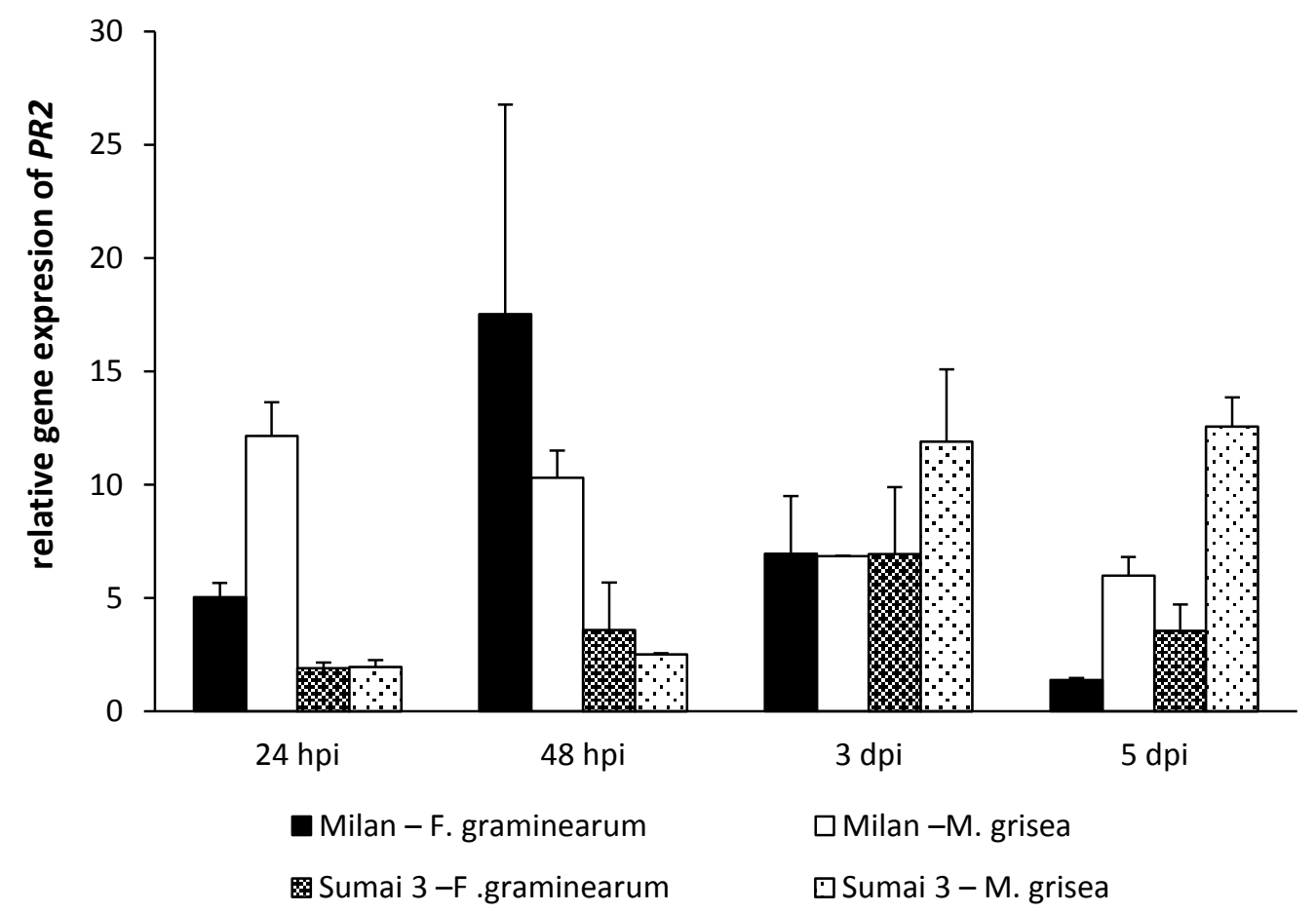

Fig. 39. Expression of $P R 2$ in wheat cvs. Milan and Sumai 3 inoculated with M. grisea and F. graminearum from 24 hpi to 5 dpi relative to the non-inoculated control. 
Another PR related gene, PR5, which refers to a thaumatin-like protein, showed a noticeable result in the rachis at 3 and 5 dpi. Both M. grisea interactions achieved a high, up to 265-fold induction in the resistant and susceptible interaction at 3 dpi and 5 dpi. Besides, MilanF. graminearum showed a particular 156-fold rise at 3 dpi (Figure 40).

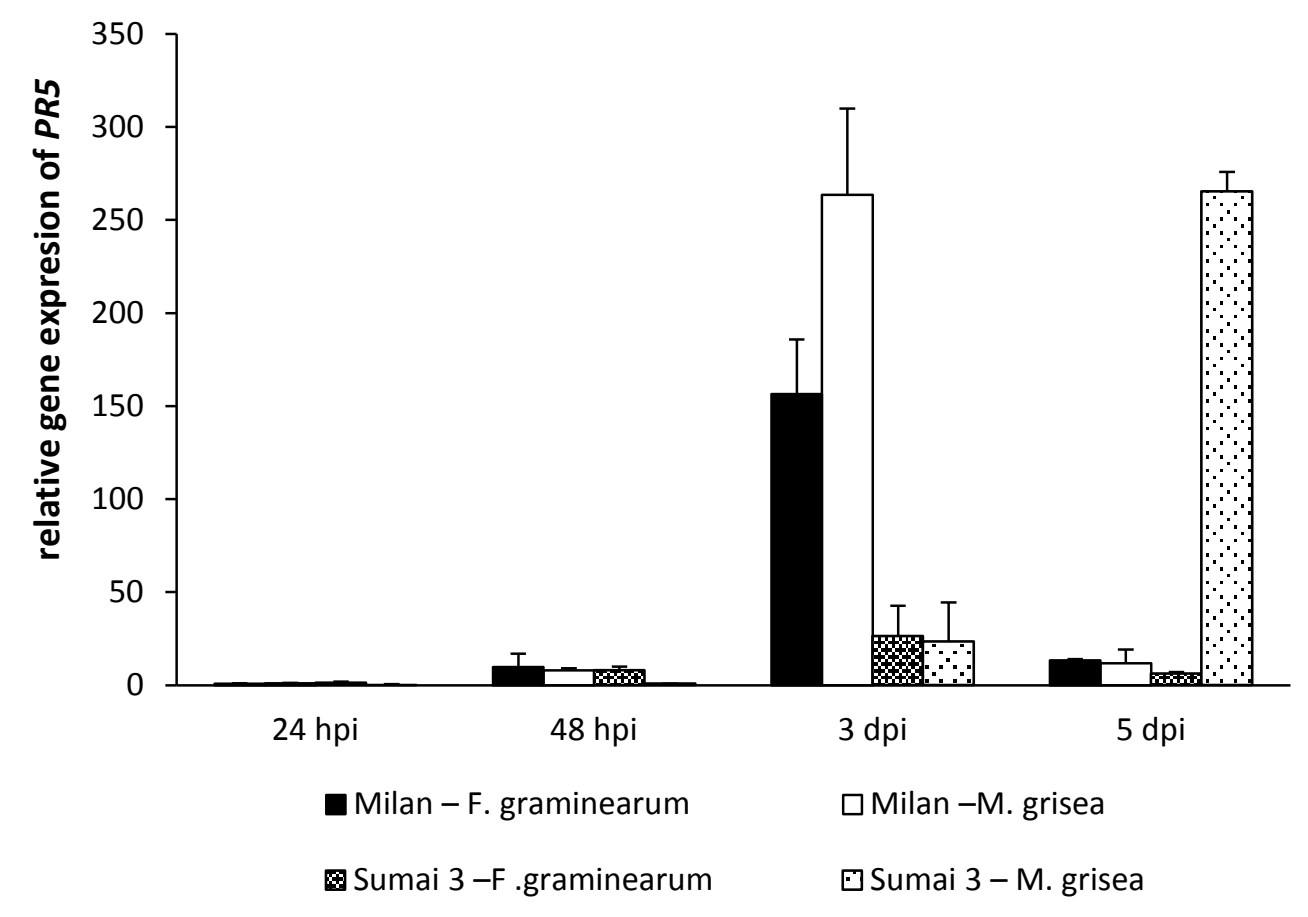

Fig. 40. Expression of $P R 5$ in wheat cvs. Milan and Sumai 3 inoculated with M. grisea and F. graminearum from 24 hpi to 5 dpi relative to the non-inoculated control.

\subsubsection{Peroxidase, lignification and signaling concerned genes}

Pox2 was observed to have abundant expression in the cultivar Milan when infected with both pathogens. At 24 hpi, Pox 2 experienced a direct increment in the compatible interaction MilanF. graminearum and the incompatible interaction Milan-M. grisea, with up to 1086- and 729fold changes, respectively. At 48 hpi, the extreme increase continued in Pox 2 was observed in the cultivar Milan when infected by F. graminearum, with 2600-fold changes, while the lowest Pox2 expression (186-fold) occurred in Milan-M. grisea. Subsequently, expression of Pox2 in Milan-F. graminearum kept dropping while showing an increase in Milan-M. grisea, both ending at similar levels at 5 dpi. Conversely, the induction of Pox2 in two interactions on Sumai 3 were confined to 70-fold changes through all time courses, while for Sumai 3-M. grisea, the susceptible response at 5 dpi reached a 100-fold induction (Figure 41). 


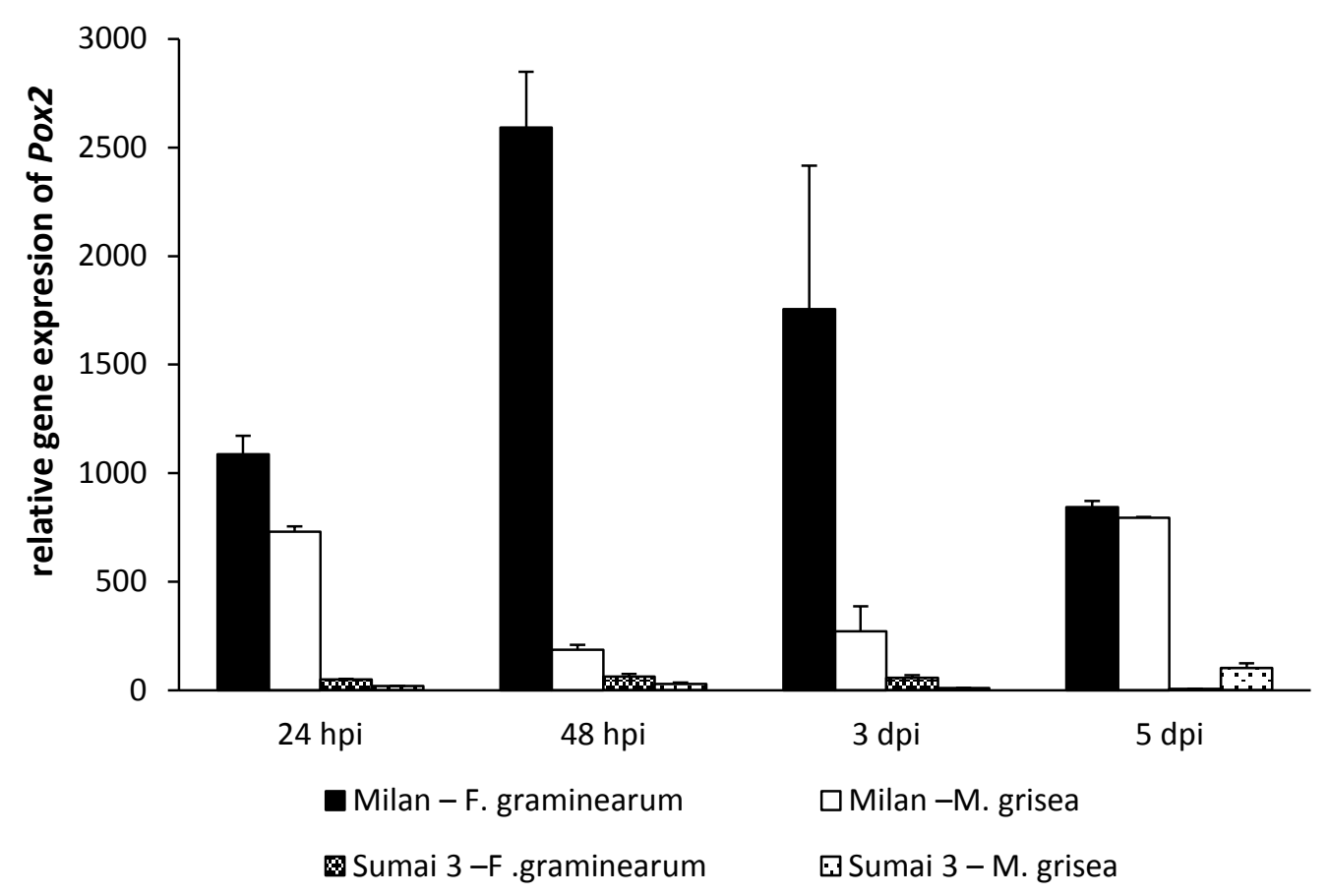

Fig. 41. Expression of Pox 2 in wheat cvs. Milan and Sumai 3 inoculated with M. grisea and F. graminearum from 24 hpi to 5 dpi relative to the non-inoculated control.

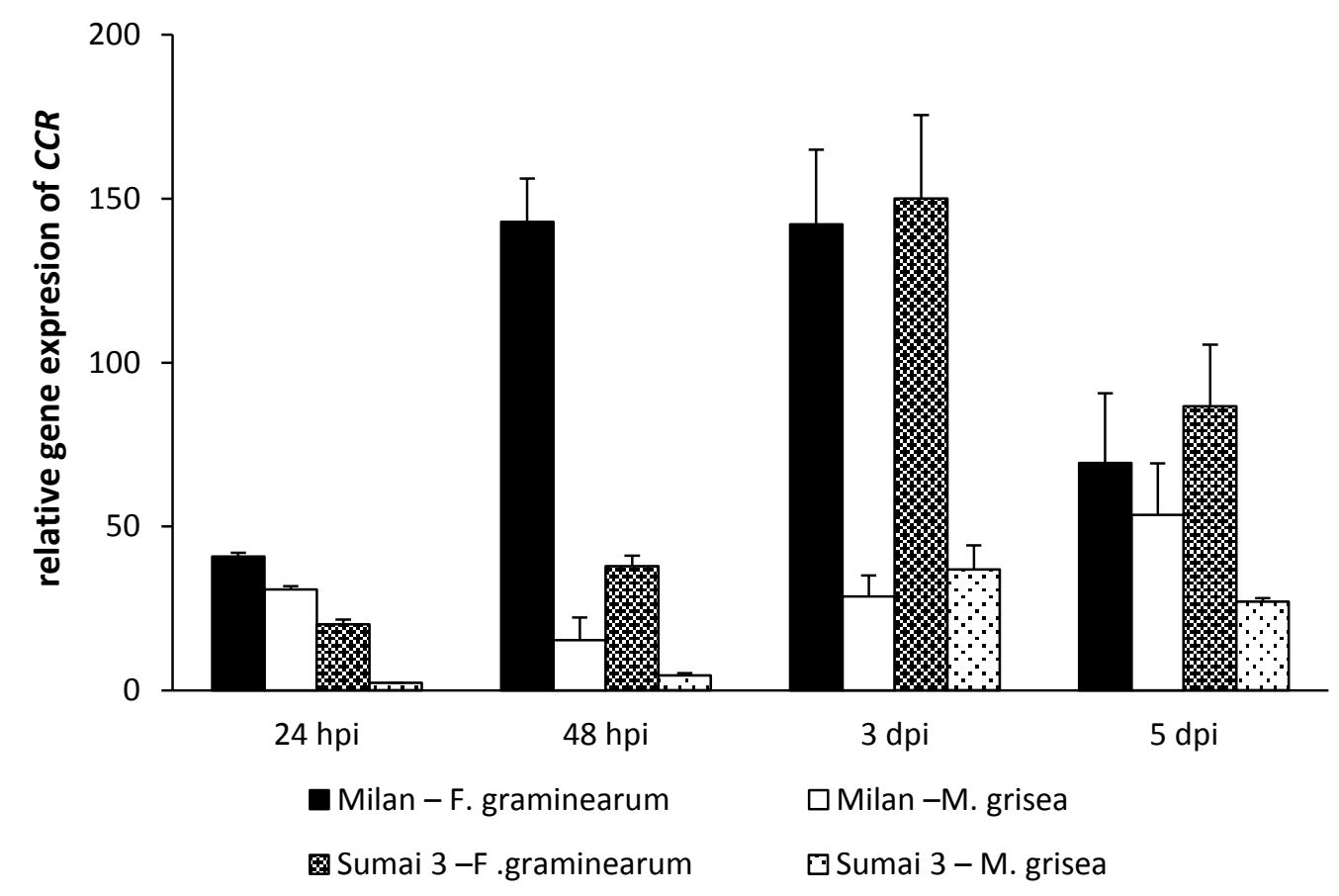

Fig. 42. Expression of $C C R$ in wheat cvs. Milan and Sumai 3 inoculated with M. grisea and F. graminearum from 24 hpi to 5 dpi relative to the non-inoculated control. 
In the compatible interaction Milan- $F$. graminearum, $C C R$ expression reached its highest levels of around 142-fold changes at 48 and 3 dpi. However, there were different tissues at the two time points which may suggest that the $C C R$ gene was activated systemically. The time point-3 dpi seems to be a critical stage for the plant to react to $F$. graminearum since infections induced $C C R$ expression in both cultivars to a similar extent. The resistance of interaction regulated the gene expression at $5 \mathrm{dpi}$, thus the incompatible interaction Milan-M. grisea and Sumai 3F. graminearum showed weaker inductions than compatible interactions (Figure 42).

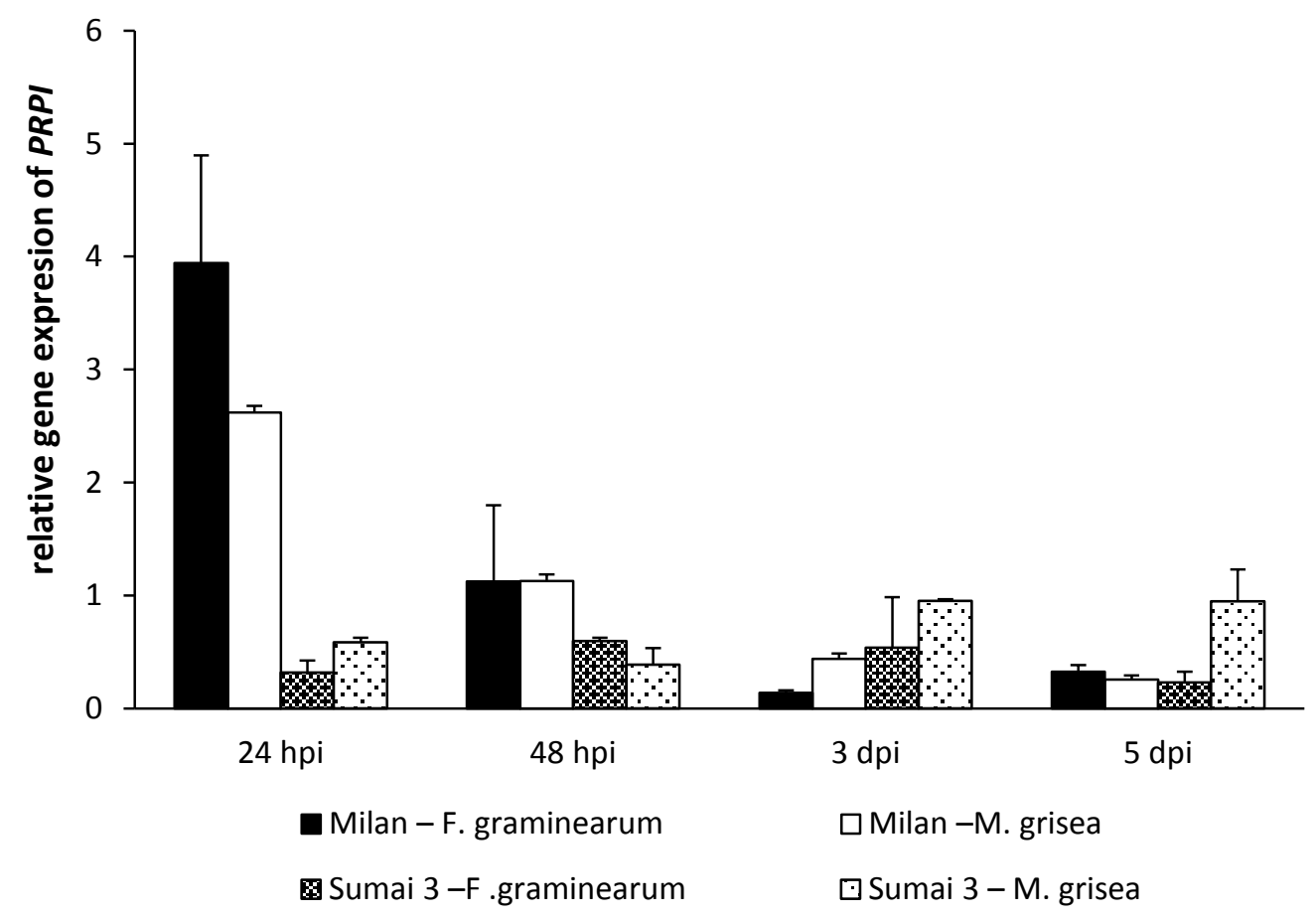

Fig. 43. Expression of PRPI in wheat cvs. Milan and Sumai 3 inoculated with M. grisea and F. graminearum from 24 hpi to 5 dpi relative to the non-inoculated control.

All interactions had quite low induction levels of PRPI. Only the interactions Milan-M. grisea and Milan-F. graminearum demonstrated some elevated expression in the rachilla and spikelet tissue in the initial infection stage. In all other interactions PRPI remained quiet, particular in the rachis at later stages (Figure 43).

\subsubsection{Genes related to mycotoxin detoxification}

CYP709C1 was continuously expressed in the two F. graminearum interactions starting from 48 hpi, and mainly focused on the rachis at 3 and 5 dpi. At 48 hpi, CYP709Cl displayed a low 
accumulation in both $F$. graminearum interactions. At 3 dpi, the resistant interaction of Sumai 3-F. graminearum was associated with a higher transcription level, which achieved 31-fold changes, but was dropped to 7-fold changes at 5 dpi. Moreover, a constant induction of around 15 was demonstrated at the two later time points in the compatible interaction MilanF. graminearum (Figure 44).

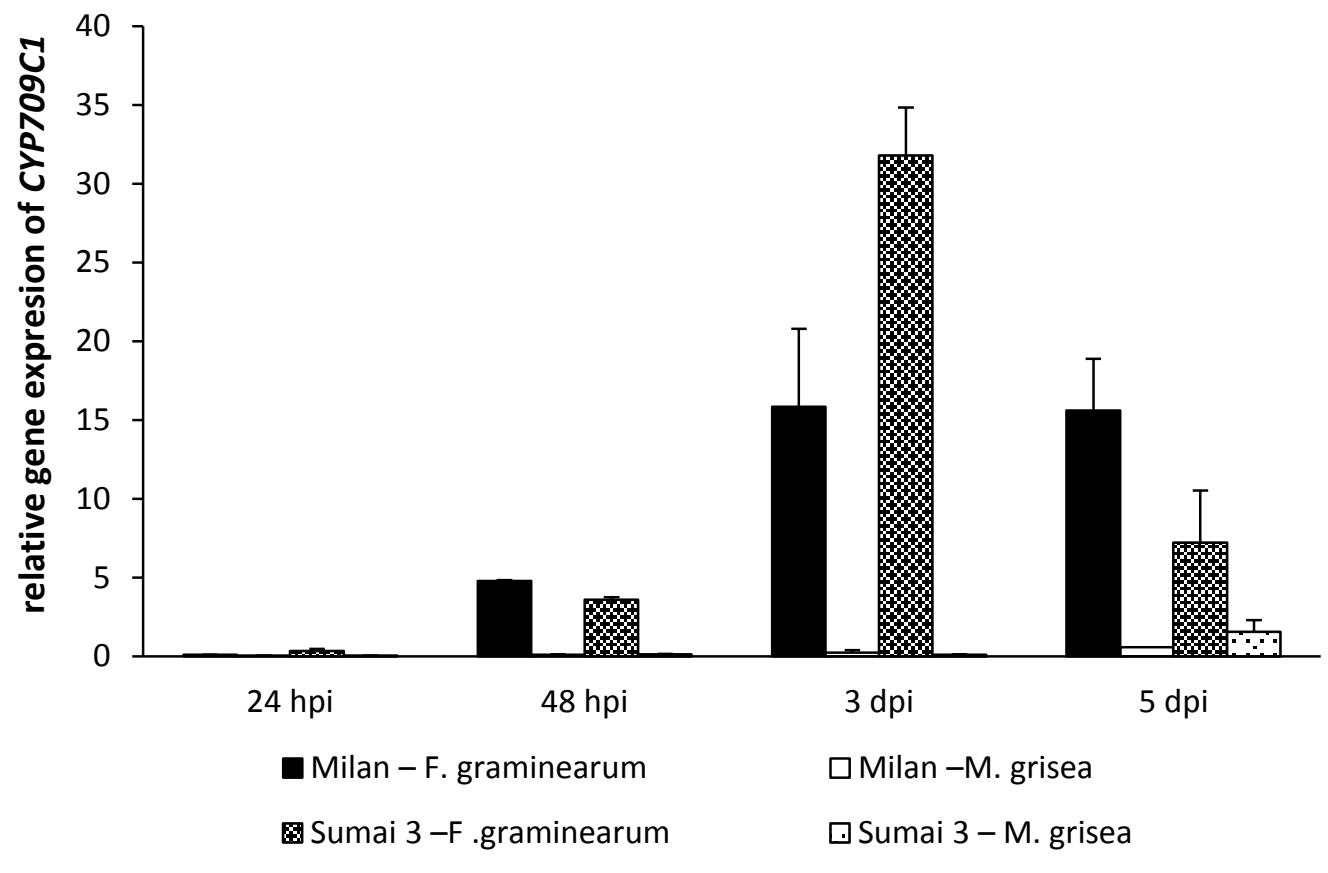

Fig. 44. Expression of CYP709C1 in wheat cvs. Milan and Sumai 3 inoculated with M. grisea and F. graminearum from 24 hpi to 5 dpi relative to the non-inoculated control. 


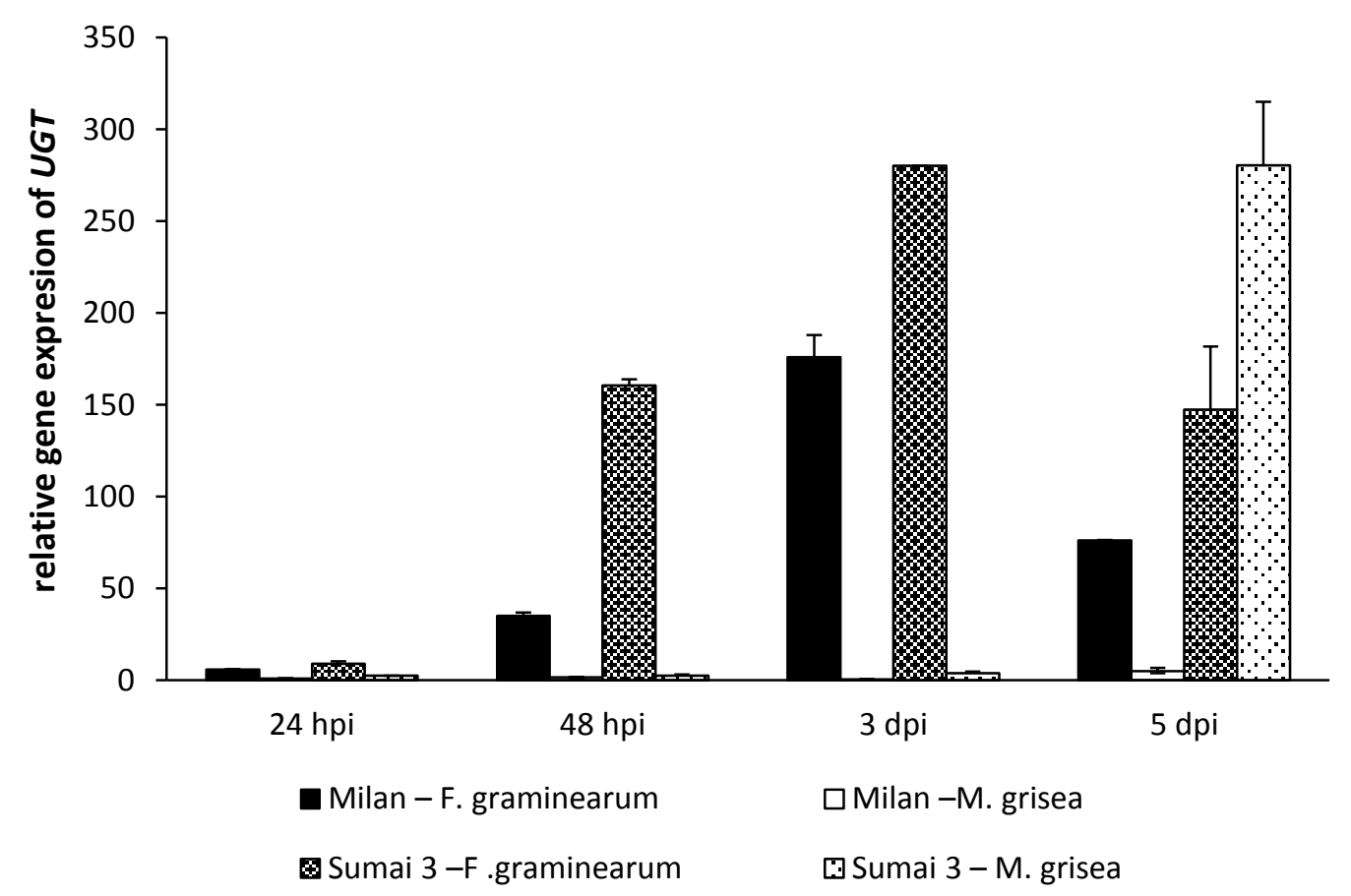

Fig. 45. Expression of detoxification related gene $U G T$ in cvs. Milan and Sumai 3 inoculated by M. grisea and F. graminearum from 24 hpi-5 dpi, relative to non-inoculated control.

$U G T$ was expressed clearly in the two $F$. graminearum interactions and a distinct pattern was seen associated with resistance during pathogenesis. Differential accumulation of UGT transcripts started at $48 \mathrm{hpi}$, inductions in the incompatible response Sumai 3-F. graminearum and compatible Milan-F. graminearum were 160 and 35 fold, respectively. An enhancement was detected in both $F$. graminearum interactions at 3 dpi; the incompatible response gained a particular spurt with almost 280 fold changes whereas the induction in the compatible response reached 176-fold changes. At 5 dpi, a reduction in expression levels was observed in both interactions. Surprisingly, the relatively susceptible interaction Sumai 3-M. grisea reached a dramatically high rise at $5 \mathrm{dpi}$, similar to the resistant interaction Sumai 3-F. graminearum at 3 dpi, which reached up to 280 -fold changes. Besides that, there was no clear gene induction discovered during the whole time course of pathogenesis in the resistant Milan-M. grisea interaction (Figure 45). 


\section{Discussion}

\subsection{Differential resistance of cultivars to wheat blast and FHB}

Resistance genetically mechanisms in plants against pathogens can be divided into monogenic resistance and polygenic resistance. Monogenic resistance is the $\mathrm{R}$ gene resistance, can be recognized by the HR response in plant-pathogen interaction. It is the result of gene for gene systems in which an avirulence (avr) gene in the pathogen corresponds to an $\mathrm{R}$ gene in the host plant (Agrios, 2005). On cultivar Milan during the attack of $M$. grisea, the clear HR response was observed around $48 \mathrm{hpi}$, which indicates this resistance belongs to the monogenic resistance. Furthermore, the monogenic resistance of host can inhibit the initial establishment of pathogens and the evelopment of epidemics (Agrios, 2005). It was noticeable that blast symptoms developed slowly on the ear of Milan, and the microscopic investigation of the infected rachilla also indicated a slow type of $M$. grisea colonization. These features indicate that Milan inhibits the initial establishment of $M$. grisea and restrict the spreading of $M$. grisea, suggesting the defense system of Milan is activated since $M$. grisea initial infection, and strengthened to restrict fungal expansion, also proved it is the monogenic resistance.

Cultivar Milan is not completely immune to M. grisea, but obviously exhibits a high resistance. It is considered as an ideal candidate against wheat blast, and other reports have confirmed its high resistance under artificial conditions (Kohli et al., 2011). In the present study, the cultivar Milan is from a CIMMYT line, it is a spring genotype with a short height and late heading time. The surface of Milan is covered with a waxy and water-proof substance such as cutin leading it to being called 'blue wheat', because it looks a little blue under light due to these surface protections. Effective protection by the cuticle and a later heading time might be for the benefit of the plant aiding it to escape from a pathogen. This might suggest that this stringently structured cuticle can hinder the landing of spores or conidia, while the postponed anthesis could help the plant to avoid massive spore or conidia invasion.

Moreover, Milan or its cross lines also provides a broader resistance to more pathogens. Milan/Shanghai \#7 was described as having a single dominant $\mathrm{R}$ gene resistance to spot blotch 
caused by Cochliobolus sativus in some areas of South Asia (Neupane et al., 2007). Further research was carried out on three leaf spot diseases on wheat: Tan spot (caused by Pyrenophora tritici-repentis (Died.) Drechs.), Stagonospora nodorum blotch (SNB) [(teleomorph: Phaeosphaeria nodorum (E.Müller) Hedjarroude)] and Septoria tritici blotch (STB) [(teleomorph: Mycosphaerella graminicola (Fückl) J. Schröt. in Cohn)]. After testing of 164 lines, four wheat cultivars showed strong resistance to the three diseases, and Milan was the common parent of three of the four varieties (Ali et al., 2008). Although no clear information regarding to the existence of $\mathrm{R}$ genes in Milan is so far available and based on a comprehensive understanding of the physical traits from Milan and active response, we conclude that Milan provides monogenic resistance toward $M$. grisea. It is speculated that the R gene expression take the responsibility of the high resistance.

Another form of resistance was revealed when we examined the seed infected by wheat blast alongside with healthy seeds from Milan. The weight of the infected seed was reduced by $56.1 \%$, while two other susceptible cultivars, Sumai 3 and Gondo/CBRD, lost $87.4 \%$ and $89.2 \%$ in seed weight (Table A 1), respectively. Recently, cultivars such as Sausal CIAT, CD 116 and Caninde 1, which descend from Milan, have been planted in some countries in South America (Kohli et al., 2011). The final results from field trials on the resistance of Milan are still awaited. Additionally, different geographical sources of the fungal isolates should be considered for Milan as it is necessary to obtain more information about the durability and robustness of this resistance.

Although cultivar Milan exhibited a striking resistance to M. grisea, it demonstrated a strong susceptibility to F. graminearum. Generally, this may result by the $\mathrm{R}$ gene from cultivar Milan loses the target in F. graminearum that cause the compatible interaction. Although a diverse and clear ROS accumulation was displayed in the Milan-F. graminearum interaction, even some defense related genes activated, suggesting the defense system in Milan is activated but failed to be established during the F. graminearum infection. Moreover, spores from F. graminearum easily germinate in the anther of Milan. Presumably, some substances in the anther can provide nutrition or stimulation for germination. Strange et al. (1974) reported two major components in anthers and wheat germ that could stimulate Fusarium growth in vitro. Another report stated the 
choline content in susceptible spikes was twice as high as in a resistant cultivar during anthesis ( $\mathrm{Li}$ and $\mathrm{Wu}, 1994$ ), which may be an explanation why more spores germinated in the anther of Milan in our study. In addition, the rapid symptoms on the ear and a fast and intense progress of F. graminearum in rachilla infection in Milan, indicating that Milan has little resistance to the spreading of this pathogen. In general, Milan lacks effective resistance to F. graminearum, both passively and actively.

Sumai 3 is considered as one of the most resistant cultivars to FHB. It has been used worldwide as a major resistance source against FHB for a long time (Bai and Shaner, 1994; Frohberg et al., 2004). Sumai 3 is a Chinese spring cultivar, well-known by its type II resistance to F. graminearum. The definition of type II resistance is to 'restrict the spreading of the pathogen in the head' (Schroeder and Christensen, 1963). In several decades, numerous studies have extensively investigated this resistance and the molecular basis behind it. It is revealed that Sumai 3 resistance is polygenic resistance controlled by two or three major dominant genes and several minor genes, with additive effects of resistance to F. graminearum (Ban and Suenaga 2000), resulting the type II resistance (Buerstmayr et al., 2002). In the genome of Sumai 3, several quantitative trait loci (QTLs) related to FHB resistance have been identified and analyzed (Buerstmayr et al., 2009; Li et al., 2010). In total, 52 QTLs were reported from different resource and were mapped on the wheat chromosome. Of the QTLs, Fusarium head blight 1 (Fhb1) from Sumai 3 was considered to be the most effective, stable QTL that is located on the chromosome arm 3BS (Buerstmayr et al., 2002; Somers et al., 2003), Fhbl could explain the $60 \%$ phenotypic variation in resistance and it contribute to reducing susceptibitily of FHB resistance in the first 60 h (Buerstmayr et al., 2009; Zhuang et al., 2013). Zhuang et al. (2013) also reported another gene, $W F h b 1 \_c 1$, was functionally associated with and physically located within Fhb1 may function together on the resistance.

The bleached ears from Sumai 3-M. grisea interaction were appered after 15 dpi, and microscopic checking of the diseased rachillae revealed that Sumai 3 cannot restrict the fungal spreading. This indicates the polygenic resistance from Sumai 3 was not effective under the M. grisea infection. This major and minor genes controlled resistance slows down the spread of the disease and the 
development of epidemics (Agrios, 2005). In the present study, Sumai 3 is moderate resistant to M. grisea in the artificial inoculation test, the defense system of Sumai 3 was not reacting when the pathogen started invasion, which may be caused by the absence of effective resistance or fungal effectors resulting in a postponed or suppressed defense related signaling or enzyme activation. Some studies considered that this susceptibility can be induced by multiple interactions between QTLs, linkage drag and related genes cross mediated on Fhbl (Pumphrey et al., 2007; Cuthbert et al., 2007; Zhuang et al., 2013). Furthermore, this susceptibility may be associated with physical features like the long and thin ear, the tight space between spikelets, the plant height or the thickness of the epidermis (Zhuang et al., 2013). These physical traits might increase the possibility of spreading and invasion of M. grisea. It was found a M. grisea spore infecting the palea of Sumai 3 at 48 hpi, something which was rarely found in Milan towards to M. grisea.

However, Sumai 3 possess some unbeneficial physical traits like low yield, high stem $(110 \mathrm{~cm})$, susceptible to other disease such as powerdey mildew, leaf rust (Wilde et al., 2007) and wheat blast. This poses a big challenge, especially since Sumai 3 became the major source of FHB resistance.

Resistant cultivars to wheat blast and FHB is an important question for the farmer, since both wheat blast and FHB are destructive to wheat production, and it was found to occur together in some areas in mountain region (Cerrado) in South America due to the suitable temperature zone $\left(20-25^{\circ} \mathrm{C}\right)$. The yield would not be guaranteed if Milan was chosen, likewise for Sumai 3 . Therefore Milan and Sumai 3 have to be combined with other resistance sources to reduce these diseases and economic losses. The cross line from cultivar Milan/Sumai 3 and other resistant genotype or related species could contribute to further study. Furthermore, cultivar BR 18 was mentioned in previous studies as a moderately resistant cultivar against $M$. grisea in the field. It is widely cultured in South America (Prestes et al., 2007). However, according to our screening results, it was one of the most susceptible cultivars to F. graminearum. An effective resistant cultivar to both diseases still needs more research and development time along with the integration of a disease controlling scheme. This would be essential for the management of wheat 
blast and FHB.

\subsection{Differential development of both pathogens on wheat ears}

Examing the pathogenic development is necessary to understand the disease progression on the ear and to establish a disease control scheme. In this study, wheat blast and FHB symptoms on ears are considered independently. For M. grisea, the partially bleached ear is the typical and critical symptom (Urashima et al., 2004), whereas leaf infection caused by M. grisea is only occasionally observed under high humidity and temperature conditions. Correlation analysis revealed that sensitivity of wheat lines to leaf infection is independent from head bleaching.

F. graminearum may infect the plant head, stem or root under favorable conditions (Strausbaugh et al., 1986; Guenther et al., 2005). The diverse infection sites increase the likelihood of survival of the pathogen during winter and allow for the preparation of the inoculum for the next season (Guenther et al., 2005). F. graminearum infection initiated at the stem failed to infect the head (Clement et al., 1998), thus the symptoms of the head are independent with the other symptoms.

Both types of fungal colonization were influenced by the resistance in the different wheat cultivars. M. grisea demonstrated rapid development in the susceptible cultivar Sumai 3, and exhibited a tendency of downward growth on the ear upon point inoculation. However, typical symptoms of blast failed to develop on the resistant cultivar Milan until 21 dpi. Progression of F. graminearum into the upper rachis was confined in the resistant cultivar Sumai 3. However, F. graminearum did not show differential distribution in the lower rachis of resistant and susceptible varieties, suggesting that $F$. graminearum possesses a highly downwards oriented growth property.

Microscopic investigation on detached spikelets and rachillae showed differences in the progress of both ear diseases. The spikelet is an important exterior tissue of the ear and determines the grain production. More importantly, the spikelet is considered as the entry point for pathogens. Several previous reports have shown that the flowering stage favours the pathogen invasion, spores of $F$. graminearum deposit on or in the floral tissue for germination 
and then initiate infection during the anthesis period (Sutton, 1982; Bai and Shaner, 1996).

The conidia of $M$. grisea have been reported to only remain active for a short time and hence have to attach themselves to the host surface for a quick infection. Once the landing and adhesion to the surface of the plant has succeeded, germination and germ tube elongation will follow quickly (Talbot, 1995; Thines et al., 2000). By following the germiantion, a specialized structure named the appressorium is produced (Figure A 2), and a penetration peg then is developed and pushed into the plant tissue for invasion by physical pressure (Thines et al., 2000). Since conidial germination relies on the energy source of the spore (Howard et al., 1991; de Jong et al., 1997), germinating hyphae of M. grisea can consequently be discovered in suspension or at different locations on the host instead of the specific infection sites. This perspective was proved in the present investigation, the germinated spores of M. grisea were observed on the anther, palea, and stigma at early stages of 12 hpi in both cultivars, implying the extensive germination increases the infection chance of $M$. grisea, and leads to the scattered spreading of $M$. grisea in the spikelet. Furthermore, resistance of varieties had no clear impact on conidia germination.

Conversely, F. graminearum invades the plant directly through the stomata or via wounds (Pritsch et al., 2000; Trail et al., 2002; Bushnell et al., 2003). Germinated spores develop hyphae to colonize the exterior surfaces of the spikelet such as florets and glumes, or directly penetrate the epidermal tissue through stomata (Ribichich et al., 2000). The first infection step on the ear is the anther. In this study, germinated spores were only found on the anther at 12 hpi, this might be due to the choline or other contents in the anther. Also the anther is the first mature tissue which is exposed and comes into contact with $F$. graminearum inoculum (Strange et al., 1978; Ribichich et al., 2000). Additionally, the susceptible variety Milan improved the opportunity for germination and advanced the development of F. graminearum in the spikelet. Some researchers pointed to the expansion strategy of $F$. graminearum inside the floret: hyphae colonized the filament and the stigma, penetrated the ovary and colonized the floret bracts including the glume, palea and lemma (Esau et al., 1965; Pritsch et al., 2000; Gilbert et al., 2004). Presently, this strategy was verified since the colonization of the filament and stigma 
was observed after 24 hpi in both cultivars, following the mycelia were found to be thriving around the glume and lemma after 48 hpi. Resistance of cultivar played a role once again after 48 hpi when F. graminearum was seen to occupy the whole spikelet. The susceptible cultivar Milan was infected far more rapidly than the resistant one Sumai 3. Nevertheless, due to the fast growth of F. graminearum, hyphae were distributed all over the spikelet in both cultivars after 72 hpi.

The rachilla connects the rachis and spikelet. It is a key point for the systemic pathogen progress in planta. The vascular bundles inside the rachilla are linked to the ones in the rachis and stem, which forms a path for the fungal expansion in planta. Pathogens may reach the rachilla through the spikelet or penetrate through the epidermal tissue. Initially, M. grisea was detected in the vascular bundles of the susceptible cultivar Sumai 3 from 12 hpi to 24 hpi, whereas in resistant Milan, M. grisea was found in vascular bundle only at 36 hpi. M. grisea clearly spreads fast both intra- and inter-cellularly in the susceptible cultivar Sumai 3. The rachis of Sumai 3 between the inoculated sites became bleached around $10 \mathrm{dpi}$, which is associated with the fact that the rachilla of Sumai 3 was colonized after 7 dpi, suggesting M. grisea can grow in and occlude the vascular bundles in rachis. Additionally, it can be deduced that M. grisea colonizes the rachilla first, then occludes the xylem in the rachis to block the transport of water or nutrients, thus the typical partial bleached ear was shown. On the other hand, up until $14 \mathrm{dpi}$, under the microscopy checking, the whole rachilla of resistant cultivar Milan was filled with M. grisea, particularly in the xylem. However, at $14 \mathrm{dpi}$, the rachis in Milan between the inoculated sites was not bleached. In detail, it was found that M. grisea expansion was restricted by some amorphous substances or thickened cells in the resistant cultivar Milan. This may suggest that the resistance in Milan inhibits the fungal development and spreading in rachis, which indicate $M$. grisea is hard to grow or occlude the vascular bundles in rachis of Milan.

F. graminearum showed a similar invasion as $M$. grisea in cultivar Sumai 3, the pathogen was presented in vessels and vascular bundles around 12 and 24 hpi, respectively. This may due to some physical traits of cultivar Sumai 3, indicating it is easier infected by both pathogens. Until 14 dpi, in the resistant cultivar Sumai 3, the collapsed tissues were limited but some vascular 
bundles have been destroyed. F. graminearum tends to destroy the vascular bundles to spread vertically-along the ear (Strausbaugh et al., 1986; Guenther et al., 2005). Moreover, only a short region of the rachis was bleached in Sumai 3 after 15 dpi, although F. graminearum exhibits a downward spreading tendency, which may suggest that the spreading of F. graminearum was restricted by Sumai 3 in rachis. Besides, F. graminearum was observed the infection in the epidermal surface of rachis (Figure A 3). On the contrary, towards the susceptible cultivar Milan, F. graminearum was presented in the vascular bundles after 24 hpi. The susceptible cultivar slightly improved F. graminearum expansion in the rachilla at the initial stages. Reviewing the inoculation results, two thirds of ears from Milan were bleached at 5 dpi, which corresponded to the fact that the examined rachilla were completely colonized around $5 \mathrm{dpi}$.

Overall, F. graminearum was growing faster than M. grisea in both cultivars, but developments of both pathogens were restricted in the resistant varieties in the macro- and microscopic examinations. During the disease progression inside a spikelet, resistant or susceptible traits had a weak effect on the development of M. grisea, but they worked successfully with the F. graminearum invasion, especially within $12 \mathrm{hpi}$. The anther is clearly an essential and critical factor for F. graminearum. Whereas, M. grisea is not limited to the anther and thus free to expand on diverse tissues within the spikelet. F. graminearum followed a certain strategy of expansion in the spikelet. In the rachilla, M. grisea was influenced by the different resistance properties of cultivars. Both pathogens aim at colonizing the vascular bundles.

Furthermore, for disease development on ears, there were horizontal and vertical pathways available for fungal spreading. Fungal spread can be inside the plant tissue through vascular bundles to colonize the rachis and reach other spikelets vertically. Alternatively, after one spikelet was infected, the hyphae colonized the whole spikelet, grew over the palea, lemma and glume, and expanded to an adjacent spikelet horizontally (Ribichich et al. 2000). In this study, M. grisea and F. graminearum were observed spreading through vertical pathways, since both pathogens colonizations were found in different sites near the inoculation point. Especially, F. graminearum spread more distance than M. grisea. Another point is F. graminearum spread in a clear horizontal pathway in cultivar Milan, and the mycelium was obvious on the spikelets. Generally, 
F. graminearum displayed a clearer pattern in spreading compared with M. grisea.

\subsection{Defense responses in wheat ears to $M$. grisea and $F$. graminearum}

\subsubsection{ROS in ears}

Although plenty of studies about the role of ROS in plant-pathogen interactions have been reported (Torres et al., 2006; Schützendübel et al., 2002; Chamnongpol et al., 1998), few studies on ROS accumulation in wheat ear have been conducted. Here we are going to discuss the differential role of ROS in the ears upon infection with $M$. grisea and F. graminearum, with special emphasis on the resistance of interactions.

$\mathrm{O}_{2}{ }^{-}$, the main product of ROS, is extensively produced during pathogenesis. In our study, at 12 hpi, $\mathrm{O}_{2}^{-}$accumulation was simultaneously activated in all compatible and incompatible interactions with different induction levels. A similar situation is reported by Trujillo et al. (2004). They found that ROS accumulated in both compatible and incompatible interactions of barley infected with powdery mildew (Blumeria graminis). Another example where $\mathrm{O}_{2}^{-}$is produced was in alfalfa nodules responding to Sinorhizobium meliloti infection (Santos et al., 2001). In present study, there were significant increases of $\mathrm{O}_{2}{ }^{-}$accumulation in cultivar Milan against the two pathogens when compared to a non-inoculated plant at $12 \mathrm{hpi}$. These increases can be considered as a recognization between plant and pathogen invasion and is a signal that plant will react to the infection, suggesting the initiation of defense. Moreover, the differential $\mathrm{O}_{2}{ }^{-}$accumulations may be caused by the distinct surface structure of plant, epidermal physical features or plant pattern recognition receptors (PRR) (Molloy, 2010).

$\mathrm{O}_{2}{ }^{-}$accumulation in all interactions decreased after 12 hpi until 36 hpi compared to the control plant. This was particularly noticeable in the moderately susceptible interaction Sumai 3-M. grisea and resistant one Sumai 3-F. graminearum at 36 hpi: both had significant decreases compared with Sumai 3 control. It seems that the drop of $\mathrm{O}_{2}{ }^{-}$accumulation in all interactions was regulated by the pathogens as they tried to reduce the ROS level to avoid or eliminate the possibility of defense reactions. Certain enzymes and related gene expression networks from the pathogen can be involved in this reduction. A global gene expression analysis was conducted in 
the research of wheat coleoptiles against a F. graminearum invasion. During the infection, extracellular $\mathrm{O}_{2}{ }^{-}$scavenging enzyme related genes in F. graminearum underwent a significant increase between 0 and 16 hpi, after which the expression level of these genes was stable until 64 hpi. Accordingly, the extracellular ROS producing enzyme related genes were expressed at a lower rate prior to 40 hpi (Zhang et al., 2012).

$\mathrm{O}_{2}{ }^{-}$accumulations in Milan/Sumai 3-F. graminearum interactions were observed to increase again at 48 hpi which may due to the plant defense system struggling with pathogen infection. Followed it also underwent a prominent increase in the susceptible interaction MilanF. graminearum at 60 hpi. It is speculated that the rising $\mathrm{O}_{2}{ }^{-}$accumulations may be resulted by the enzyme work from plant, more ROS was evoked to try to contend against the pathogen, but the plant defense in Milan was failed to establish since the $\mathrm{O}_{2}{ }^{-}$accumulation sharply dropped at 72 hpi, which may caused by the enzyme work from pathogen. Meanwhile, a rise of $\mathrm{O}_{2}{ }^{-}$ accumulation was detected in the resistant interaction Sumai 3-F. graminearum, suggesting that the $\mathrm{O}_{2}{ }^{-}$accumulation was modified by plant to enhance the resistance. $\mathrm{O}_{2}{ }^{-}$accumulation in the resistant interaction Milan-M. grisea was exhibited positive and similar situations from 48-60 hpi, then a drop occurred in 72 hpi which may result from the successful plant defense establishment. However, $\mathrm{O}_{2}{ }^{-}$accumulation increased in the susceptible interaction of Sumai 3M. grisea from 48-60 hpi, indicating that the plant was continuously trying to promote plant resistance. Generally, in comparison with M. grisea, it is assumed that F. graminearum has a potential to induce more intense reactions in the host plant during infection.

In the histochemical investigation, $\mathrm{NaN}_{3}$ is used to avoid unspecific NBT reduction. This prevents the production of superoxide radicals by peroxidase and the mitochondrial respiration chain (Hückelhoven and Kogel, 1998). By the NBT staining, blue lesions were found in various shapes and sizes in the compatible interactions, especially in Milan-F. graminearum, normally indicating that the pathogen has successfully penetrated (Hückelhoven and Kogel, 1998). NBT staining was visible throughout the cells which neighbored the dead cells in the susceptible interaction Milan-F. graminearum. This may indicate that $\mathrm{O}_{2}{ }^{-}$accumulation is involved in cell death and has a restrictive role in the spreading of lesions (Jabs et al., 1996; Epple et al., 2003). 
$\mathrm{O}_{2}{ }^{-}$is considered to be a cell death-inducing signal in some plant-pathogen interactions which are related to the production of jasmonic acid (JA). JA is a signal compound which may induce $\mathrm{O}_{2}{ }^{-}$under stress and pathogen development (Overmyer, 2003; Turner et al., 2002). Thus, the increased $\mathrm{O}_{2}{ }^{-}$accumulation which was occured in the susceptible interaction Sumai 3-M. grisea may be due, in part, to serious cell death during pathogenesis in the later stages of infection.

$\mathrm{H}_{2} \mathrm{O}_{2}$ accumulation was weakly expressed in the first oxidative burst stage. In the present study, at $12 \mathrm{hpi}, \mathrm{H}_{2} \mathrm{O}_{2}$ accumulation was similar in all the interactions as in the controls. However, $\mathrm{H}_{2} \mathrm{O}_{2}$ high accumulation always accompanies the second phase of oxidative burst which corresponds to the $\mathrm{R}$ gene function in the plant, recognizing an avirulence factor of pathogens (Torres, 2010). This process induces strong ROS accumulation and normally displays the HR response associated with cell death during infection (Jones and Dangl, 2006). In the present study, the $\mathrm{H}_{2} \mathrm{O}_{2}$ concentration underwent a significant rise at 48 hpi in the incompatible interaction Milan-M. grisea. This may indicate that $48 \mathrm{hpi}$ is critical for M. grisea to be recognized by the $\mathrm{R}$ gene from Milan. Furthermore, during the blast symptom evaluation on Milan inoculated with M. grisea, intense necrotic lesions were found on ears at 48 hpi implying that $\mathrm{HR}$ reactions were activated, accompanied by $\mathrm{H}_{2} \mathrm{O}_{2}$ accumulation. However, there was no clear increase happening in another incompatible interaction: Sumai 3-F. graminearum. It should consider that Sumai 3 is based on a polygenic resistance to F. graminearum. Under this resistance mechanism regulation, type II resistance is obvious but no HR response. As we mentioned before, the $F h b 1$, function on the resistance of Sumai 3 to F. graminearum, it is estimated seven genes were functionally asscioated with each other and responsible for the resistance ( $\mathrm{Li}$ and Yen 2008; Zhuang et al., 2013), whereas the resistance of Milan may be contributed by the major resistant gene. Additionally, at 48 hpi, a sharp drop was recorded in another incompatible interaction: Sumai 3-F. graminearum. This represented the lowest values in all interactions during the whole procedure. It may demonstrate how a compromise between the plant and pathogen, also partly due to the polygenic resistance from Sumai 3. Baptista et al. (2007) reported that $\mathrm{H}_{2} \mathrm{O}_{2}$ accumulation had three peaks within 15 hpi for the ectomycorrhizal fungus Pisolithus tinctorius interacting with the roots of Castanea sativa (chestnut tree). This may be due to the inhibition by ROS-scavenging enzymes from fungus. 
Clear histological evidences from DAB staining were shown in the Milan-M. grisea interaction at 48 hpi, with a very strong brown colour. This coincided with the burst of $\mathrm{H}_{2} \mathrm{O}_{2}$ accumulation in Milan-M. grisea. However, some weaker DAB stainings were found in the resistant interaction Sumai 3-F. graminearum at $48 \mathrm{hpi}$, but no corresponding accumulation was shown in the $\mathrm{H}_{2} \mathrm{O}_{2}$ concentration investigation. Nevertheless, this histochemical phenomenon may suggest that a recognition response or enzyme activities happened in the two incompatible interactions. In 2002, Torres reported the accumulation of a significant oxidative burst which was positively related to the HR reaction in the $d S p m$ insertions for highly expressed AtrbohD and AtrbohF genes during the resistance interaction of tomato against the avirulent bacteria DC3000 (avrRpm1). Furthermore, an increase of $\mathrm{H}_{2} \mathrm{O}_{2}$ accumulation was detected in barley with $m l o$ resistance compared with the wild type Mlo (Hückelhoven, 1999, 2000).

In DAB and NBT study, the cell wall apposition (CWA) was not clear, and only the drak brown or blue stainings were found. However, CWAs are produced by crosslinks of phenolics and are regarded as a physical barrier to pathogen infection. Normally, $\mathrm{H}_{2} \mathrm{O}_{2}$ can be located in the CWAs and is regarded as the substance employed for lignification-like processes (McLusky et al., 1999; Hückelhoven and Kogel, 2003). CWAs can be found in both compatible and incompatible interactions (Hückelhoven, 2007). In the present study, strong staining caused by the presence of $\mathrm{O}_{2}{ }^{-}$was only exhibited in the compatible interaction Milan- $F$. graminearum, if it is considered to be the CWAs, probably indicating that part of the $\mathrm{O}_{2}^{-}$may have been converted to $\mathrm{H}_{2} \mathrm{O}_{2}$ and be involved in cell wall strengthening. In the DAB staining, strong staining occurred in Milan-M. grisea, which may thought as the CWAs due to $\mathrm{H}_{2} \mathrm{O}_{2}$ accumulation.

Both $\mathrm{O}_{2}{ }^{-}$and $\mathrm{H}_{2} \mathrm{O}_{2}$ accumulation appeared different in resistant and susceptible interactions. The clear rising and drop was found in Milan-M. grisea/F. graminearum interactions. These changes may be correlated with pathogen infection, plant defense activation, cell death or imbalance of the ROS regulation system (Hückelhoven and Kogel, 2003; Huang et al., 2011a). From the symptom observations of the four interactions, it appears that rapid colonization of F. graminearum finished in a short time on Milan, which might be a reason for the relatively high induction of both $\mathrm{H}_{2} \mathrm{O}_{2}$ and $\mathrm{O}_{2}{ }^{-}$in the early infection stage. Hückelhoven (2000a) reported a 
strong $\mathrm{O}_{2}^{-}$accumulation and very faint $\mathrm{H}_{2} \mathrm{O}_{2}$ accumulation were detected around the pathogen invasion site and adjacent cell walls. Wang et al. (2010) observed that both $\mathrm{H}_{2} \mathrm{O}_{2}$ and $\mathrm{O}_{2}^{-}$emerged in the tissue or cells which were in contact with cells killed during the HR response by plant mesophyll cells around the infection site.

Although ROS is considered as a significant marker for plant of pathogenesis with important signaling and regulation functions, pathogens have developed a counter defense mechanism to antagonize ROS accumulation. For instance, a conserved effector HopAI1 from Pseudomonas syringae inhibited the activation of two mitogen-activated protein kinases (MAPKs) from Arabidopsis by dephosphorylation. This consequently suppressed a flagellin-derived peptide flg22 gene expression along with $\mathrm{H}_{2} \mathrm{O}_{2}$ production and cell wall reinforcement in the compatible interaction to promote pathogenesis (Zhang et al., 2007). A pattern for reprogramming the metabolism was discovered in rice infected with Brachypodium distachyon in the early stages. The pathogen triggered the suppression or delay of $\mathrm{H}_{2} \mathrm{O}_{2}$ synthesis in different hosts, therefore impacting the plant defense system and colonizing the plant tissue successfully (Parker et al., 2009).

Normally $\mathrm{O}_{2}{ }^{-}$has been considered as one of the sources of $\mathrm{H}_{2} \mathrm{O}_{2}$ production. The related enzyme superoxide dismutase (SOD) refers to the dismutation function of the $\mathrm{O}_{2}{ }^{-}$radical to $\mathrm{H}_{2} \mathrm{O}_{2}$ (Giannopolitis and Ries, 1977; Bowler et al., 1992), and the catalase (CAT) and peroxidase (POX) are mainly responsible for the removal of $\mathrm{H}_{2} \mathrm{O}_{2}$ production (Arora et al., 2002; Hiraga et al., 2001; Mittler, 2002). In the present results, in the resistant interaction Milan-M. grisea, some conversion between $\mathrm{O}_{2}{ }^{-}$to $\mathrm{H}_{2} \mathrm{O}_{2}$ was displayed between 24 and 48 hpi, which implies that $\mathrm{H}_{2} \mathrm{O}_{2}$ accumulation might be generated partly from $\mathrm{O}_{2}{ }^{-}$, which could be explained by $\mathrm{O}_{2}{ }^{-}$ scavenging enzymes like, for example, SOD may join the conversion (Hückelhoven and Kogel, 2003). But after 48 hpi, $\mathrm{H}_{2} \mathrm{O}_{2}$ was decreased while $\mathrm{O}_{2}{ }^{-}$stayed stable. This reduction of $\mathrm{H}_{2} \mathrm{O}_{2}$ and stable $\mathrm{O}_{2}{ }^{-}$accumulation after 48 hpi may be caused by POX, which may consume and detoxify $\mathrm{H}_{2} \mathrm{O}_{2}$ with various substrates, while also producing ROS such as $\mathrm{O}_{2}^{-}$(Gechev et al., 2006). While in this study the gene expression data demonstrated that the POX related gene turned to high expression levels in Milan-M. grisea after $48 \mathrm{hpi}$, it has been proved that POX is 
negatively associated with $\mathrm{H}_{2} \mathrm{O}_{2}$ accumulation. A recent detection of biochemical changes in the leaves of the wheat-Pyricularia oryzae interaction revealed that POX accumulation at 48 hpi increased until 96 hpi in both resistant and susceptible interactions (Debona et al., 2012). However, in the susceptible interaction Sumai 3-M. grisea, both ROS accumulations were low until 72 hpi, perhaps because no strong defense reaction was activated in the interaction. There was a small drop in $\mathrm{O}_{2}{ }^{-}$at 36 hpi while $\mathrm{H}_{2} \mathrm{O}_{2}$ experienced a small increment. This conversion may relate to the $\mathrm{O}_{2}{ }^{-}$scavenging enzyme.

In the incompatible interaction Sumai 3-F. graminearum, the enzymatic mechanism of the plant defense system may contribute to the drop in $\mathrm{H}_{2} \mathrm{O}_{2}$ accumulation. According to the gene expression data, POX related genes were only slightly induced in Sumai 3-F. graminearum at 48 hpi, so probably another remover eliminated the $\mathrm{H}_{2} \mathrm{O}_{2}$ at 48 hpi to relieve the toxic stress. Meanwhile, the rise of $\mathrm{O}_{2}{ }^{-}$accumulation may be due to the imbalance of ROS. Additionally, ROS accumulation went up in Sumai 3-F. graminearum after $60 \mathrm{hpi}$, while it decreased in Milan-F. graminearum after $60 \mathrm{hpi}$, a phenomenon which may be caused by regulation from different resistance mechanisms.

The current work shows the diverse performance of $\mathrm{O}_{2}{ }^{-}$and $\mathrm{H}_{2} \mathrm{O}_{2}$ in the incompatible and compatible interactions of wheat ears infected with M. grisea and F. graminearum. However, while $\mathrm{H}_{2} \mathrm{O}_{2}$ had a more evident pattern and would be a clear indication of resistance in plantpathogen interactions, which is regulated by the recognition between pathogen and $\mathrm{R}$ gene. $\mathrm{O}_{2}{ }^{-}$ tends to serve as more of a signal of plant reaction, defense activation, JA pathway or resistance recognition (Overmyer, 2003; Gechev et al., 2006). Different rates of $\mathrm{O}_{2}{ }^{-}$production in the continuous time courses are co-regulated by the enzyme works from plant and pathogen, resulting from the competition between plant and pathogen. But the idea behind the different ROS accumulation is the different resistance mechanisms, the polygenic and mongenic resistance can lead to different defense reactions and chemical pathways that induce the different accumulations of ROS. Based on the resistance mechnisms, the gene expression and regulation is the only part to determine all the reactions and defense. Therefore, ROS is a comprehensive signal action and the gene expression analysis will be critical to understand the 
plant resistance mechnisms during the colonization by pathogens.

\subsubsection{Differential gene expression in infected ears}

A number of gene studies were performed on ears to discover the different reaction patterns of the tissues with pathogens. But limited reports were shown about the wheat ears and M. grisea and F. graminearum. However, we have presented a new report on the reaction from various structures of the wheat ear against $F$. graminearum and $M$. grisea, to better recognize the plant defense underlying the different resistance, the gene expression analysis is applied. And according to fungal expansion during the pathogenesis under the microscopy work, two major parts were used in the gene study. The first part is the exterior spikelet tissue and the connected rachilla in 24 and $48 \mathrm{hpi}$; the second is the rachis in 3 and 5 dpi.

Pritsch (2001) examined the transcript accumulation of four PR genes in colonized and noncolonized areas of wheat ears, and the results demonstrated that the PR genes are systemic expressed and were not specifically induced in resistance or susceptible interactions. The PRproteins which are encoded by the PR genes represent a critical and necessary group and were expressed in the compatible and incompatible procedure to play important roles in plant defense. Normally they function together with the plant immune system and defense activation system (Antoniw et al., 1980; Dixon et al., 1994). However, most of the PR related proteins have been identified to exist in non-infected plants in certain tissues or developmental stages. Based on the immunological reactivity and bio-information of the proteins, 14 different groups of PR-proteins have been established (Van Loon and Van Strien, 1999), and many of the PRproteins exhibit antimicrobial or antifungal activity (Dixon et al., 1994; Sels et al., 2002).

Chitinases are antifungal proteins which belong to the PR3 group and work to catalyze the $\beta-1$, 4-glycoside bond in chitin, a substrate that mainly exists in fungal cell walls, insect exoskeletons and the shells of crustaceans (Wally et al., 1992; Flach et al., 1992). The PR2 group ( $\beta$-1, 3-glucanases) preferentially hydrolyzes the $\beta$-1,3-glucan linker in the cell wall of many pathogenic fungi (Liu et al., 2009). Both chitinases and $\beta-1,3$-glucanases are combined to enhance antifungal activity and show an ability to inhibit fungal growth (Mauch et al., 1988; Kirubakaran et al., 2007). When a fungal cell wall contains $\beta$-1, 3-glucans or chitin (Bartnicki- 
Garcia, 1968) and comes across these hydrolytic enzymes, cell wall fragments which contain oligosaccharides could be released and can activate defense responses in a variety of plants (Mauch et al., 1989; Ham et al., 1997). Moreover, chitin and $\beta$-1, 3- glucan synthase could be hindered during the cell wall assembling process, causing additional cell wall dissolution (Muthukrishnan et al., 2001).

In the present study, the genes Chi2 and PR2 represent diverse accumulation levels in the incompatible and compatible interactions with $M$. grisea and F. graminearum, and both seem to be served as a pathogenesis related gene. However, gene Chi2 was predominant in the rachis of cultivar Milan infected by M. grisea and F. graminearum. It is known that F. graminearum transferred from one or two spikelets to more on the ear in Milan at $3 \mathrm{dpi}$, at which point Chi2 accumulation was noted to increase. In the Milan-M. grisea response, the initial expansion stage of $M$. grisea in the rachis was at $5 \mathrm{dpi}$ when Chi2 had higher expression. This may imply that Chi2 expression was associated with fungal expansion inside the rachis, and the accumulation level of Chi2 was enhanced in cultivar Milan to confine the development of F. graminearum and M. grisea. However, in Sumai 3-F. graminearum interaction, the expression of Chi2 was found to be stable but relatively low at $3 \mathrm{dpi}$, potentially because the gene was less activated in Sumai 3. It also may explain why there was a much lower expression of Chi2 in the Sumai 3M. grisea interaction although at 5 dpi there was still a severe infection point for $M$. grisea colonization.

PR2 was differentially low expressed in various tissues in both compatible and incompatible interactions. However, $P R 2$ accumulation levels in the resistant response of Milan-M. grisea was influenced in the beginning whereas in the susceptible response of Sumai 3- M. grisea levels were influenced in the later stages. The first period 24 hpi was essential for PR2 accumulation in both Milan interactions, while $P R 2$ accumulations were slightly lifting in Sumai 3 interactions at the later stages, which may indicate that the $P R 2$ gene regulation was activated during the pathogens initial invasion of Milan, and the further fungal development in Sumai 3. With these responses, it seems that the $P R 2$ gene may not be essential to build certain defenses in host plant. 
PR5 encodes for thaumatin-like proteins (TLPs) which are polypeptides and occur universally in plants (van Loon et al., 2006). The PR5 family includes the closely related proteins permatin, osmotin and zeamatin (Vigers et al., 1992; Skadsen et al., 2000). Many PR5 proteins have been identified as antifungal compounds. A PR5 protein from rice overexpressed in transgenic tobacco plants exhibited an enhanced resistance to Alternaria alternata (Velazhahan and Muthukrishnan, 2003). And the RT-qPCR analysis revealed that TaPR5 transcription level was significantly increased and up-regulated in the incompatible interaction (Wang et al., 2010).

In the present work, high transcript accumulations of PR5 were induced in the resistant response of Milan-M. grisea and susceptible Sumai 3-M. grisea interaction at 3 and 5 dpi, respectively. In another susceptible interaction Milan-F. graminearum, a relatively high transcript accumulation was exhibited at $3 \mathrm{dpi}$ as well, but the gene PR5 was mainly expressed in the $M$. grisea interactions in the rachis at later stages. It is difficult to judge whether PR5 is an indicator of more resistance or not, but these expressions may suggest that PR5 is involved in plant defense of cultivar Milan against pathogen invasion rather than Sumai 3. Furthermore, the enhanced induction of Chi2, PR2 and PR5 in Milan (but not in Sumai 3) to F. graminearum may be led by defense mechanism in Milan, which tried to activate the three $P R$ genes to associate with the resistance to combat the pathogen.

Pathogens, elicitors, stresses and some phytohormones can induce POX related genes during the activation of the plant defense system (Van Loon et al., 1999; Muthukrishnan et al., 2001). POX has multiple functions which are hard to define. Generally, POX are a group of plantspecific oxido-reductases and can be involved in lignification, suberization, cross-linking of cell wall structural proteins, auxin catabolism, and defense against pathogen infection (Hiraga et al., 2001; Whetten et al., 1998; Lagrimini et al., 1997). In rice, two Pox genes were reported and were predominantly expressed in the resistant interaction against Xanthomonas oryzae (Chittoor et al., 1997). Li et al. (2010) detected that one of the POX related genes, Pox2, was induced in both compatible and incompatible interactions of wheat against F. graminearum infection without any significant difference. Additionally, some studies suggested that several Pox genes are induced via different signal transduction pathways from known defense-related genes 
(Hiraga et al., 2001).

A previous report demonstrated that the wheat anionic peroxidases can bind to chitins, and the ionically binding peroxidases appeared in the cell walls of infected wheat calli. This indicated that these peroxidases might be involved in the reinforcement of cell walls (Maksimov et al., 2004). In this study, the Pox2 gene was high expressed in the two Milan-pathogen interactions from 24 hpi to 5 dpi. It is speculated that the Pox2 gene regulated the lignin or cell wall reinforcement process in cultivar Milan to manage the initial defense response. It also indicates that the enzyme and signal transductions related to lignin and cell wall reinforcement are the early and mian defense responses in Milan. Moreover, the gene Pox2 regulates the ROS accumulations in plant since it encodes the POX that may contribute to detoxify $\mathrm{H}_{2} \mathrm{O}_{2}$ with various substrates, which can also produce ROS such as $\mathrm{O}_{2}^{-}$(Gechev et al., 2006). With regards to the previous result of $\mathrm{H}_{2} \mathrm{O}_{2}$ accumulation, it is assumed that the high accumulation of $\mathrm{H}_{2} \mathrm{O}_{2}$ is due to the strong suppression of Pox2 expression, and the Pox2 gene may function as a regulator of $\mathrm{H}_{2} \mathrm{O}_{2}$ levels in the oxidative burst. In pepper leaves infected by Xanthomonas campestris, three peroxidase-like genes showed correlation with $\mathrm{H}_{2} \mathrm{O}_{2}$ accumulation. POX activity declined at 24 and $30 \mathrm{hpi}$, while the accumulation level of $\mathrm{H}_{2} \mathrm{O}_{2}$ reached its peak, and two peroxidase-like genes were induced $1 \mathrm{~h}$ after exogenous treatment with $\mathrm{H}_{2} \mathrm{O}_{2}$, while other peroxidase-like gene transcripts accumulated $12 \mathrm{~h}$ after $\mathrm{H}_{2} \mathrm{O}_{2}$ treatment (Do et al., 2003).

In the present study, remarkably strong transcript accumulations of the Pox2 gene were obtained in the compatible interaction Milan-F. graminearum that exhibited extensive and extremely high induction levels, especially at 48 hpi in the spikelet and rachilla, reaching up to 2600 fold changes. This was coupled with the rising $\mathrm{O}_{2}{ }^{-}$accumulation at $48 \mathrm{hpi}$, where the lowest $\mathrm{H}_{2} \mathrm{O}_{2}$ levels were recorded in the same interaction. Additionally, the expression of Pox2 also coincided with decreased $\mathrm{H}_{2} \mathrm{O}_{2}$ level at 24 hpi in the spikelet and the rachilla in MilanF. graminearum interaction. However at 3 dpi, the accumulation of $\mathrm{H}_{2} \mathrm{O}_{2}$ was not concordant with Pox2 expression may due to the rachis was used in gene analysis but the palea was used in the ROS detection. Relatively high transcript induction of Pox2 also occurred in the incompatible response Milan- $M$. grisea from 24 hpi to 5 dpi. The expression peaks emerged at 
24 hpi and 5 dpi with 730 and 795 fold changes, respectively. The minimum suppression was shown at 48 hpi and 3 dpi. The unstable expression of Pox2 in Milan-M. grisea was also considered to be connected with the ROS accumulation.

Inversely, the Pox 2 transcript accumulation in Sumai 3 interactions was far below that seen in Milan interactions. This may suggest that the lignin or cell wall reinforcing process is not critical defense reaction for Sumai 3 to the pathogen, it may be consequenced by the resistance of Sumai 3 which are controlled by several genes. And the ROS reactions in Sumai 3 interactions were not activated as in Milan interaction, indicating the related signal transduction was not the main contribution to the defense of Sumai 3.

The accumulation of $C C R$ gene was evaluated in a similar manner as the Pox2 in MilanF. graminearum and Milan-M. grisea interactions from 24 hpi to 5 dpi. $C C R$ was activated in a lower expression level in the Milan-M. grisea interaction. The close accumulations of the two genes demonstrate that $C C R$ gene corresponded to Pox2 gene take responsible for lignification in Milan defense response. Moreover, transcript accumulation of $C C R$ was elevated in interactions Sumai 3-F. graminearum and Sumai 3-M. grisea at a later period, whereas the higher induction of the incompatible interaction Sumai 3-F. graminearum compared with the $C C R$ expression in the compatible interaction Sumai 3-M. grisea. This may suggest that lignification related pathway was activated in Sumai 3 against pathogen at later stages, being more relevant in plants infected by F. graminearum than $M$. grisea.

Expression of defense gene PRPI was quite weak. The highest induction recorded was only 4 fold at the beginning time course of the susceptible interaction Milan-F. graminearum. Just 2.6fold changes were induced in the resistant interaction Milan-M. grisea. This may suggest the defensin concerning gene was not activated in wheat ear during the pathogenesis. Moreover, the PRPI gene was found to be only activated directly in the spikelet and rachilla of cultivar Milan, at 24 and 48 hpi. As Kovalchuk et al. (2010) mentioned, PRPI is predominately expressed in soft plant tissues such as the leaf, lemma, palea and anther. The defensin gene PRPI is considered to be regulated by the jasmonate pathway (Manners et al., 1998; Kovalchuk et al., 2010). 
$U G T$ and $C Y P$ genes have been described in numerous studies of various crops in response to Fusarium infection. UGTs are encoded by a very large gene family in plants and expression levels of most $U G T$ candidates vary under the resistance response to Fusarium spp. (Schweiger et al., 2010). UGT genes have been identified to carry out a potential function in DON detoxification in wheat with an up-regulation in response to Fusarium spp. (Desmond et al., 2008; Steiner et al., 2009). In recent investigations on the relationship between gene transcript expression and DON accumulation performed on wheat against Fusarium culmorum, the results elucidated that $U G T$ and $C Y P$ genes were positively correlated to DON accumulation in the stem basis (Winter et al., 2013). Li et al. (2010) demonstrated that a plant cytochrome P450 gene, $C Y P 709 C 1$, was expressed in resistance reactions in both the seedling and the ear reacting to F. graminearum, which was triggered by DON in a resistance-dependent manner. However, when testing the expression levels of four $U G T$ genes from barley in Arabidopsis that displayed a high accumulation of DON, a HvUGT13248 gene conferring DON resistance in barley was confirmed by heterologous expression in yeast (Schweiger et al., 2010). This implied that not all $U G T$ genes are definitely associated with DON detoxification.

In the present study, certain expected expressions of the $U G T$ and $C Y P 709 C 1$ genes were exhibited in the wheat ear response to F. graminearum in both compatible and incompatible interactions. In the plant host, $U G T$ gene transcript accumulation resembled the $C Y P 709 C 1$ gene against $F$. graminearum in the rachis at 3 dpi. Consequently, $U G T$ and $C Y P 709 C 1$ gene transcript accumulation rapidly arrived at a peak at 3 dpi in both $F$. graminearum interactions. At 3 dpi, the expression of $U G T$ in the resistant response with Sumai 3-F. graminearum and the susceptible interaction with Milan-F. graminearum was 280-and 176-fold, respectively. CYP709C1 reached 32-and 16-fold changes. Cultivar resistance to F. graminearum influenced the induction of both genes and led to a stronger expression in resistant interactions Sumai 3F. graminearum. This result illustrates that $U G T$ and $C Y P$ gene transcript expressions were reacted to the resistance of wheat cultivars to F. graminearum. While information about DON accumulation could not be determined in the present study, it is well known that it plays a role in the expression of both genes during pathogenesis (Gardiner et al., 2010; Schweiger et al., 2010). However, a surprising burst of UGT transcript expression occurred in the compatible 
interaction Sumai 3-M. grisea at $5 \mathrm{dpi}$, which reached 280-fold induction and more or less equalled the highest level in Sumai 3-F. graminearum at 5 dpi. This phenomenon may either be due to the stress caused by M. grisea invasion or is due to some unknown compounds were produced by pathogen in the later pathogenesis stages, requiring further analysis to reveal this question. 


\section{Summary}

The hemi-biotrophic fungus Magnaporthe grisea has recently developed into a potential threat to wheat production in South America. Continuously warm and humid weather after ear emergence favours the disease. However, knowledge about the control of this disease is relatively insufficient as compared to rice blast. Wheat blast can attack all above-ground parts of the wheat plant, but the typical symptom is head infection, which is commonly found together with Fusarium Head Blight. Fusarium Head Blight (FHB) induced by Fusarium graminearum produces similar symptoms as wheat blast, and is another threat to wheat production. Both diseases can cause partially or entirely bleached ears, which may result in high yield losses. This study therefore aimed to determine the differential resistance of wheat cultivars and to understand the infection process of wheat blast and FHB. The findings of this study have unraveled the differences between the susceptible and resistant plant-pathogen interactions between the diverse wheat genotypes and the two pathogens.

Initially, the inoculation system for $M$. grisea and F. graminearum was optimized in a controlled environment. A set of twenty-seven wheat cultivars was used to establish a suitable inoculation protocol,, and a disease scoring and evaluation system. Cultivar Milan exhibited the highest resistance to $M$. grisea but showed a susceptible reaction towards F. graminearum, whereas cultivar Sumai 3 displayed opposite responses to both pathogens. These results were confirmed with point inoculations on the ears. Distinct patterns of spreading and colonizing ears were found for the two pathogens. M. grisea generally grew at a slower speed than F. graminearum on the host. Upon point inoculation in the center of the ear, downward growth along the ear axis was shown for both pathogens, especailly in the susceptible interactions. However, upward spreading on the ears was dependent on the type of interaction.

Further, the differential spreading of M. grisea and F. graminearum was determined on the ear and within a spikelet. Staining methods and GFP-labelled strains were employed with confocal laser scanning microscopy (CLSM). Infection on spikelets was followed in a time course in three days with $12 \mathrm{~h}$ sampling intervals. $M$. grisea spores germinated extensively in the spikelet within 
12 hpi, and initial fungal development was not influenced by the cultivar, whereas F. graminearum colonized only the anthers, most probably prior to 12 hpi. After 12 hpi, the development of F. graminearum in the susceptible cultivar Milan was both faster and highly invasive when compared to the resistant Sumai 3. Moreover, the spikelet colonization was more pronounced at 72 hpi than at initial time points. On the other hand, we observed a reduced growth rate of M. grisea on the spikelet after $12 \mathrm{hpi}$, when compared to F. graminearum. The growth rate of M. grisea was consistently similar in Milan and Sumai 3 until 72 hpi. Cultivar resistance had an impact on fungal growth and expansion on the rachilla. At 7 dpi, an extensive colonization of the rachilla of Sumai 3 by $M$. grisea was observed, whereas the pathogen growth in Milan was slow at first but grew extensively at $14 \mathrm{dpi}$. This indicates that Milan restricted the growth of $M$. grisea at the initial stages earlier than Sumai 3. However, the extensive colonization of rachilla, not of the rachis, in Milan by $M$. grisea is intriguing and may suggest that resistance restricts the pathogen development in a small scale. A similar explanation may apply for F. graminearum colonization of Sumai 3. Both pathogens seem to grow more rapidly after entering the vascular system and spread systemically downwards in the rachis, but more profusely for F. graminearum compared to $M$. grisea. The successfulness of infection by $M$. grisea may depend in part upon the tissue in which the infection begins. Furthermore, F. graminearum may exhibit horizontal and vertical spreading during host colonization.

The further aim of this work was to identify the contribution of plant defense responses, including ROS metabolism and gene expression levels of a set of 8 selected genes. Firstly, we determined superoxide radical accumulation using in situ NBT staining, while hydrogen peroxide was detected in situ using DAB staining and by spectrophotometric analysis for the four interactions. ROS accumulation was distinct in these interactions. At 12 hpi, $\mathrm{O}_{2}^{-}$ accumulation in Milan-M. grisea and Milan-F. graminearum significantly differed from the control. At $60 \mathrm{hpi}, \mathrm{O}_{2}^{-}$accumulation was significantly higher in Milan-F. graminearum compared to Milan-M. grisea. This might suggest that the two pathogens elicit a general plant response at the early time point but the amount of superoxide production is plant-pathogen specific. In contrast, $\mathrm{O}_{2}{ }^{-}$accumulation in Sumai 3-M. grisea and Sumai 3-F. graminearum was similar but significantly different from the control, at $36 \mathrm{hpi}$, indicating that ROS accumulation 
is both pathogen and cultivar specific. A clear burst of hydrogen peroxide in the resistant interaction Milan-M. grisea coincided with an HR reaction on the ears. However, no such accumulation was found in Sumai 3-F. graminearum, which would support the involvement of different defense mechanisms of the two cultivars. The transcript analysis also demonstrated a differential induction of defense related genes in the plant under pathogen attack. Three pathogenesis-related genes $(P R 2, C h i 2, P R 5)$ did not show any clear response patterns, either in the resistant or susceptible interaction. Two genes encoding for enzymes involved in lignin biosynthesis, peroxidase (Pox2) and CCR, were highly induced in Milan interaction with both pathogens, indicating the lignin reaction and signal transduction being a significant defense response in Milan. Moreover, an extremly high expression of Pox2 was detected in the MilanF. graminearum susceptible interaction. The Pox2 gene may function as a regulator of $\mathrm{H}_{2} \mathrm{O}_{2}$ levels upon oxidative burst. Two mycotoxin detoxification related genes, UGT and CYP709C1, were more expressed in the resistant Sumai 3-F. graminearum interaction than MilanF. graminearum, indicating that both genes may play a critical role in wheat resistance response. In the Sumai 3-M. grisea susceptible interaction, a higher expression of UGT occurred at later times ( $5 \mathrm{dpi}$ ), suggesting that either the stress caused by M. grisea invasion or some unknown secondary metabolites or an artefact were responsible.

Based on these studies, it is assumed that resistance in Milan to M. grisea is monogenic whereas Sumai 3 exhibits polygenic resistance to F. graminearum. Although the R gene in Milan has not been clarified it is assumed that lignification and signal transduction, especially related to pathways towards ROS production are important for establishment of defense in Milan, in particular at 48 hpi. However, these reactions do not seem to be critical for resistance in Sumai 3 which is controlled by several genes. Resistance in Sumai 3 is useful for restricting or slowing down the pathogen development, which is exhibited as type II resistance. Further studies should aim at verifying and identifying the major R gene in Milan, and further unveil the role of ROS related enzymes and defense hormones, lignin biosynthesis and fungal metabolites in order to understand the genetic regulation of the different types of resistance in wheat, which is important knowledge to create the new resistant wheat genotypes. 


\section{References}

Adam, A., Farkas, T., Somlyai, G., Hevesi, M., and Kiraly, Z. (1989) Consequence of $\mathrm{O}_{2}^{-}$ generation during a bacterially induced hypersensitive reaction in tobacco: deterioration of membrane lipids. Physiological and Molecular Plant Pathology 34, 13-26.

Agrios, G.N. (2005) Plant Pathology. 5th eds.

Ali, S., Singh, P.K., McMullen, M.P., Mergoum, M., and Adhikari, T.B. (2008) Resistance to multiple leaf spot diseases in wheat. Euphytica 159, 167-179.

Anand, A., Zhou, T., Trick, H.N., Gill, B.S., Bockus, W.W., and Muthukrishnan, S. (2003) Greenhouse and field testing of transgenic wheat plants stably expressing genes for thaumatinlike protein, chitinase and glucanase against Fusarium graminearum. Journal of Experimental Botany 54, 1101-1111.

Antoniw, J.F., Ritter, C.E., Pierpoint, W.S., and Van Loon, L.C. (1980) Comparison of three pathogenesis-related proteins from plants of two cultivars of tobacco infected with TMV. Journal of General Virology 47, 79-87.

Arora, A., Sairam, R.K., and Srivastava, G.C. (2002) Oxidative stress and antioxidative system in plants. Current Science 82, 1227-1238.

Asselbergh, B., Curvers, K., França, S.C., Audenaert, K., Vuylsteke, M., Van Breusegem, F., and Höfte, M. (2007) Resistance to Botrytis cinerea in sitiens, an abscisic acid-deficient tomato mutant, involves timely production of hydrogen peroxide and cell wall modifications in the epidermis. Plant Physiology 144, 1863-1877.

Båga, M., Chibbar, R.N., and Kartha, K.K. (1995) Molecular cloning and expression analysis of peroxidase genes from wheat. Plant Molecular Biology 29, 647-662.

Bai, G., Shaner, G. (1994) Scab of wheat: prospects for control. Plant Disease 78, 760-766.

Bai, G. and Shaner, G. (1996) Variation in Fusarium graminearum and cultivar resistance to wheat scab. Plant Disease 80, 975-979.

Bai, G., Shaner, G., Ohm, H. (2000) Inheritance of resistance to Fusarium graminearum in wheat. Theoretical and Applied Genetics 100, 1-8.

Bai, G., Shaner, G. (2004) Management and resistance in wheat and barley to Fusarium head blight. Annual Review of Phytopathology 42, 135-161. 
Bak, S., and Feyereisen, R. (2001) The involvement of two P450 enzymes, CYP83B1 and CYP83A1, in auxin homeostasis and glucosinolate biosynthesis. Plant Physiology 127, 108118.

Baldwin, T.K., Urban, M., Brown, N., and Hammond-Kosack, K.E. (2010) A role for topoisomerase $\mathrm{I}$ in Fusarium graminearum and $F$. culmorum pathogenesis and sporulation. Molecular Plant-Microbe Interactions 23, 566-577.

Ban, T., and Suenaga, K. (2000) Genetic analysis of resistance to Fusarium head blight caused by Fusarium graminearum in Chinese wheat cultivar Sumai 3 and the Japanese cultivar Saikai 165. Euphytica 113, 87-99.

Baptista, P., Martins, A., Pais, M.S., Tavares, R.M., and Lino-Neto, T. (2007) Involvement of reactive oxygen species during early stages of ectomycorrhiza establishment between Castanea sativa and Pisolithus tinctorius. Mycorrhiza 17, 185-193.

Barlier, I., Kowalczyk, M., Marchant, A., Ljung, K., Bhalerao, R., Bennett, M., Sandberg, G., Bellini, C., and Bellini, C. (2000) The SUR2 gene of Arabidopsis thaliana encodes the cytochrome P450 CYP83B1, a modulator of auxin homeostasis. Proceedings of the National Academy of Sciences 97, 14819-14824.

Bartnicki-Garcia, S. (1968) Cell wall chemistry, morphogenesis, and taxonomy of fungi. Annual Reviews in Microbiology 22, 87-108.

Bernardo, A., Bai, G., Guo, P., Xiao, K., Guenzi, A.C., and Ayoubi, P. (2007) Fusarium graminearum-induced changes in gene expression between Fusarium head blight-resistant and susceptible wheat cultivars. Functional and Integrative Genomics 7, 69-77.

Bohlmann, H., Vignutelli, A., Hilpert, B., Miersch, O., Wasternack, C., and Apel, K. (1998) Wounding and chemicals induce expression of the Arabidopsis thaliana gene Thi2.1, encoding a fungal defense thionin, via the octadecanoid pathway. Febs Letters 437, 281-286.

Bolwell, G.P., Davies, D.R., Gerrish, C., Auh, C.K., and Murphy, T.M. (1998) Comparative biochemistry of the oxidative burst produced by rose and French bean cells reveals two distinct mechanisms. Plant Physiology 116, 1379-1385.

Bowler, C., Montagu, M.V., and Inze, D. (1992) Superoxide dismutase and stress tolerance. Annual Review of Plant Biology 43, 83-116.

Bowles, D., Lim, E.K., Poppenberger, B., and Vaistij, F.E. (2006) Glycosyltransferases of lipophilic small molecules. Annual Review of Plant Biology 57, 567-597. 
Bradley, D.J., Kjellbom, P., and Lamb, C.J. (1992) Elicitor-and wound-induced oxidative crosslinking of a proline-rich plant cell wall protein: a novel, rapid defense response. Cell 70, 21-30.

Brennan, J.M., Fagan, B., Maanen, A. van Cooke, B.M., Doohan, F.M. (2003) Studies on in vitro growth and pathogenicity of European Fusarium fungi. European Journal of Plant Pathology $109,577-587$.

Briggle, L.W., and Curtis, B.C. (1987). Wheat worldwide. Wheat and wheat improvement, 1-32.

Buerstmayr, H., Ban, T., and Anderson, J.A. (2009) QTL mapping and marker-assisted selection for Fusarium head blight resistance in wheat: a review. Plant Breeding 128, 1-26.

Buerstmayr, H., Lemmens, M., Hartl, L., Doldi, L., Steiner, B., Stierschneider, M., and Ruckenbauer, P. (2002) Molecular mapping of QTLs for Fusarium head blight resistance in spring wheat. I. Resistance to fungal spread (Type II resistance). Theoretical and Applied Genetics 104, 84-91.

Bushnell WR, Hazen BE, Pritsch C. 2003. Histology and physiology of Fusarium head blight. In: Leonard KJ, Bushnell WR, eds. Fusarium head blight of wheat and barley. St Paul, MN, USA: APS Press, 44-83.

Madden, L.V., \& Campbell, C.L. (1990) Nonlinear disease progress curves. In: Epidemics of plant diseases. Springer Berlin Heidelberg (S), 181-229.

Cardoso, C.A.D.A., Reis, E.M., and Moreira, E.N. (2008) Development of a warning system for wheat blast caused by Pyricularia grisea. Summa Phytopathologica 34, 216-221.

Chamnongpol, S., Willekens, H., Moeder, W., Langebartels, C., Sandermann, H., Van Montagu, M., D. Inzé and Van Camp, W. (1998) Defense activation and enhanced pathogen tolerance induced by $\mathrm{H}_{2} \mathrm{O}_{2}$ in transgenic tobacco. Proceedings of the National Academy of Sciences 95, 5818-5823.

Chittoor, J.M., Leach, J.E., and White, F.F. (1997) Differential induction of a peroxidase gene family during infection of rice by Xanthomonas oryzae pv. oryzae. Molecular Plant-Microbe Interactions 10, 861-871.

Chittoor, J.M., Leach, J.E., and White, F.F. (1999) Induction of peroxidase during defense against pathogens. Pathogenesis-Related Proteins in Plants, 171-193.

Cho, W.K., Yu, J., Lee, K.M., Son, M., Min, K., Lee, Y.W., and Kim, K.H. (2012) Genomewide expression profiling shows transcriptional reprogramming in Fusarium graminearum by Fusarium graminearum virus 1-DK21 infection. BMC Genomics 13, 173. 
Clear, R.M. and Patrick, S.K. (2000) Fusarium head blight pathogens isolated from Fusariumdamaged kernels of wheat in western Canada, 1993 to 1998. Canadian Journal of Plant Pathology 22, 51-60.

Clement, J.A., Parry, D.W. (1998) Stem-base disease and fungal colonization of winter wheat grown in compost inoculated with Fusarium culmorum, F. graminearum and Microdochium nivale. European Journal of Plant Pathology 104, 323-330.

Collins, N.C., Thordal-Christensen, H., Lipka, V., Bau, S., Kombrink, E., Qiu, J.L., Hückelhoven, R., Stein, M., Freialdenhoven, A., Somerville, S.C., and Schulze-Lefert, P. (2003) SNAREprotein-mediated disease resistance at the plant cell wall. Nature 425, 973-977.

Couch, B.C., Kohn, L.M. (2002) A multilocus gene genealogy concordant with host preference indicates segregation of a new species, Magnaporthe oryzae, from M. grisea. Mycologia 94, 683693.

Creelman, R.A., Tierney, M.L., and Mullet, J.E. (1992) Jasmonic acid/methyl jasmonate accumulate in wounded soybean hypocotyls and modulate wound gene expression. Proceedings of the National Academy of Sciences 89, 4938-4941.

Cuthbert, P.A., Somers, D.J., and Brulé-Babel, A. (2007) Mapping of Fhb2 on chromosome 6BS: a gene controlling Fusarium head blight field resistance in bread wheat (Triticum aestivum L.). Theoretical and Applied Genetics 114, 429-437.

Dangl, J.L., and Jones, J.D. (2001) Plant pathogens and integrated defence responses to infection. Nature 411, 826-833.

de Jong, J.C., McCormack, B.J., Smirnoff, N., and Talbot, N.J. (1997) Glycerol generates turgor in rice blast. Nature 389, 244-244.

Dean, R.A., Talbot, N.J., Ebbole, D.J., Farman, M.L., Mitchell, T.K., Orbach, M.J., et al. and Birren, B. W. (2005) The genome sequence of the rice blast fungus Magnaporthe grisea. Nature 434, 980-986.

Debona, D., Rodrigues, F.Á., Rios, J.A., and Nascimento, K.J.T. (2012) Biochemical changes in the leaves of wheat plants infected by Pyricularia oryzae. Phytopathology 102, 1121-1129.

Desmond, O. J., Manners, J. M., Stephens, A. E., Maclean, D. J., Schenk, P. M., Gardiner, D. M., Munn, A.L., and Kazan, K. (2008). The Fusarium mycotoxin deoxynivalenol elicits hydrogen peroxide production, programmed cell death and defence responses in wheat. Molecular Plant Pathology 9, 435-445. 
Dexter, J.E., Nowicki, T.W., Leonard, K.J., Bushnell, W.R. (2003) Safety assurance and quality assurance issues associated with Fusarium head blight in wheat. Fusarium head blight of wheat and barley. St Paul, MN, USA: APS Press, 420-460.

Dixon, R.A., Harrison, M.J., and Lamb, C.J. (1994) Early events in the activation of plant defense responses. Annual Review of Phytopathology 32, 479-501.

Do, H.M., Hong, J.K., Jung, H.W., Kim, S.H., Ham, J.H., and Hwang, B.K. (2003) Expression of peroxidase-like genes, $\mathrm{H}_{2} \mathrm{O}_{2}$ production, and peroxidase activity during the hypersensitive response to Xanthomonas campestris pv. vesicatoria in Capsicum annuum. Molecular PlantMicrobe Interactions 16, 196-205.

Draper, J. (1997) Salicylate, superoxide synthesis and cell suicide in plant defence. Trends in Plant Science 2, 162-165.

Engel, J.S., Lipps, P.E., and Mills, D. (2003) Fusarium head blight severity scale for winter wheat. Published online by The Ohio State University, Colombus, OH. ohioline. osu. edu/acfact/0049. html.

Epple, P., Mack, A.A., Morris, V.R., and Dangl, J.L. (2003) Antagonistic control of oxidative stress-induced cell death in Arabidopsis by two related, plant-specific zinc finger proteins. Proceedings of the National Academy of Sciences 100, 6831-6836.

Esau, K. (1965). Plant anatomy. Plant anatomy (2nd Edition).

Fernando, W.G., Miller, J.D., Seaman, W.L., Seifert, K., and Paulitz, T.C. (2000) Daily and seasonal dynamics of airborne spores of Fusarium graminearum and other Fusarium species sampled over wheat plots. Canadian Journal of Botany 78, 497-505.

Flach, J., Pilet, P.E., and Jolles, P. (1992) What's new in chitinase research? Experientia 48, 701-716

Frohberg, R.C., Stack, R.W., Mergoum, M. (2004) Registration of spring wheat germplasm ND2710 resistant to Fusarium head blight. Crop Science 44, 1498-a.

Galletti, R., Denoux, C., Gambetta, S., Dewdney, J., Ausubel, F.M., De Lorenzo, G., and Ferrari, S. (2008) The AtrbohD-mediated oxidative burst elicited by oligogalacturonides in Arabidopsis is dispensable for the activation of defense responses effective against Botrytis cinerea. Plant Physiology 148, 1695-1706. 
Gardiner, D.M., Kazan, K., Praud, S., Torney, F.J., Rusu, A., and Manners, J.M. (2010) Early activation of wheat polyamine biosynthesis during Fusarium head blight implicates putrescine as an inducer of trichothecene mycotoxin production. BMC Plant Biology 10, 289.

Gechev, T.S., Van Breusegem, F., Stone, J.M., Denev, I., and Laloi, C. (2006) Reactive oxygen species as signals that modulate plant stress responses and programmed cell death. Bioessays 28, 1091-1101.

Giannopolitis, C.N., and Ries, S.K. (1977) Superoxide dismutases I. Occurrence in higher plants. Plant Physiology 59, 309-314.

Gilbert, J., Fernando, W.G.D. (2004) Epidemiology and biological control of Gibberella zeae/Fusarium graminearum. Canadian Journal of Plant Pathology 26, 464-472.

Glazebrook, J. (2005) Contrasting mechanisms of defense against biotrophic and necrotrophic pathogens. Annual Review of Phytopathology 43, 205-227.

Glazener, J.A., Orlandi, E.W., and Baker, C.J. (1996) The active oxygen response of cell suspensions to incompatible bacteria is not sufficient to cause hypersensitive cell death. Plant Physiology 110, 759-763.

Gottwald, S., Samans, B., Lück, S., and Friedt, W. (2012) Jasmonate and ethylene dependent defence gene expression and suppression of fungal virulence factors: two essential mechanisms of Fusarium head blight resistance in wheat? BMC Genomics 13, 369.

Goulart, A.C.P., and Paiva, F.A. (2000). Perdas no rendimento de grãos de trigo causadas por Pyricularia grisea, nos anos de 1991 e 1992, no Mato Grosso do Sul. Summa Phytopathologica 26, 279-282.

Govrin, E.M., and Levine, A. (2000) The hypersensitive response facilitates plant infection by the necrotrophic pathogen Botrytis cinerea. Current Biology 10, 751-757.

Grant, J.J., and Loake, G.J. (2000) Role of reactive oxygen intermediates and cognate redox signaling in disease resistance. Plant Physiology 124, 21-30.

Grant, J.J., Yun, B.W., and Loake, G.J. (2000a) Oxidative burst and cognate redox signalling reported by luciferase imaging: identification of a signal network that functions independently of ethylene, SA and Me-JA but is dependent on MAPKK activity. The Plant Journal 24, 569-582.

Green, S., Mazur, A., and Shorr, E. (1956) Mechanism of the catalytic oxidation of adrenaline by ferritin. Journal of Biological Chemistry 220, 237-255. 
Guenther, J.C., and Trail, F. (2005) The development and differentiation of Gibberella zeae (anamorph: Fusarium graminearum) during colonization of wheat. Mycologia 97, 229-237.

Gundlach, H., Müller, M.J., Kutchan, T. M., and Zenk, M.H. (1992) Jasmonic acid is a signal transducer in elicitor-induced plant cell cultures. Proceedings of the National Academy of Sciences 89, 2389-2393.

Haidukowski, M., Visconti, A., Perrone, G., Vanadia, S., Pancaldi, D., Covarelli, L., Balestrazzi, R., and Pascale, M. (2012) Effect of prothioconazole-based fungicides on Fusarium head blight, grain yield and deoxynivalenol accumulation in wheat under field conditions. Phytopathologia Mediterranea 51, 236-246.

Ham, K.S., Wu, S.C., Darvill, A.G., and Albersheim, P. (1997) Fungal pathogens secrete an inhibitor protein that distinguishes isoforms of plant pathogenesis-related endo- $\beta-1,3-$ glucanases. The Plant Journal 11, 169-179.

Harmon, P.F., and Latin, R. (2005) Winter survival of the perennial ryegrass pathogen Magnaporthe oryzae in north central Indiana. Plant Disease 89, 412-418.

Hill-Ambroz, K., Webb, C.A., Matthews, A.R., Li, W., Gill, B.S., and Fellers, J.P. (2006) Expression analysis and physical mapping of a cDNA library of Fusarium head blight infected wheat ears. Crop Science 46, S-15.

Hiraga, S., Sasaki, K., Ito, H., Ohashi, Y., and Matsui, H. (2001) A large family of class III plant peroxidases. Plant and Cell Physiology 42, 462-468.

Howard, R.J., Ferrari, M.A., Roach, D.H., and Money, N.P. (1991) Penetration of hard substrates by a fungus employing enormous turgor pressures. Proceedings of the National Academy of Sciences 88, 11281-11284.

Huang, K., Czymmek, K.J., Caplan, J.L., Sweigard, J.A., and Donofrio, N.M. (2011) HYR1mediated detoxification of reactive oxygen species is required for full virulence in the rice blast fungus. PLoS Pathogens 7, e1001335.

Huang, K., Czymmek, K.J., Caplan, J.L., Sweigard, J.A., and Donofrio, N.M. (2011a) Suppression of plant-generated reactive oxygen species is required for successful infection by the rice blast fungus. Virulence 2, 559-562.

Huang, N., Agrawal, V., Giacomini, K.M., and Miller, W.L. (2008) Genetics of P450 oxidoreductase: sequence variation in 842 individuals of four ethnicities and activities of 15 missense mutations. Proceedings of the National Academy of Sciences 105, 1733-1738. 
Hückelhoven, R., and Kogel, K. H. (1998) Tissue-specific superoxide generation at interaction sites in resistant and susceptible near-isogenic barley lines attacked by the powdery mildew fungus (Erysiphe graminis f. sp. hordei). Molecular Plant-Microbe Interactions 11, 292-300.

Hückelhoven, R., Fodor, J., Preis, C., and Kogel, K.H. (1999) Hypersensitive cell death and papilla formation in barley attacked by the powdery mildew fungus are associated with hydrogen peroxide but not with salicylic acid accumulation. Plant Physiology 119, 1251-1260.

Hückelhoven, R., Trujillo, M., and Kogel, K.H. (2000) Mutations in Ror1 and Ror2 genes cause modification of hydrogen peroxide accumulation in mlo-barley under attack from the powdery mildew fungus. Molecular Plant Pathology 1, 287-292.

Hückelhoven, R., Fodor, J., Trujillo, M., and Kogel, K.H. (2000a) Barley Mla and Rar mutants compromised in the hypersensitive cell death response against Blumeria graminis f. sp. hordei are modified in their ability to accumulate reactive oxygen intermediates at sites of fungal invasion. Planta 212, 16-24.

Hückelhoven, R., and Kogel, K.H. (2003) Reactive oxygen intermediates in plant-microbe interactions: Who is who in powdery mildew resistance? Planta 216, 891-902.

Hückelhoven, R. (2007) Cell wall-associated mechanisms of disease resistance and susceptibility. Annual Review of Phytopathology 45, 101-127.

Hutcheon, J.A. and Jordan, V.W.L. (1990) Glasshouse evaluation of fungicides for control of Fusarium spp. on ears of winter wheat. Annals of Applied Biology 116, 50-51.

Igarashi, S. (1990) Update on wheat blast (Pyricularia oryzae) in Brazil. In Wheat for nontraditional warm areas: a proceedings of the International Conference, Foz do Iguaçu, Brazil, 480-483.

Igarashi, S., Utiamada, C.M., Igarashi, L.C., Kazuma, A.H., \& Lopes, R.S. (1986) Pyricularia em trigo. 1. Ocorrência de Pyricularia sp. no estado do Paraná. Fitopatologia Brasileira 11, 351-352.

Jabs, T., Dietrich, R.A., and Dangl, J.L. (1996) Initiation of runaway cell death in an Arabidopsis mutant by extracellular superoxide. Science 273, 1853-1856.

Jarosch, B., Jansen, M., and Schaffrath, U. (2003) Acquired resistance functions in mlo barley, which is hypersusceptible to Magnaporthe grisea. Molecular Plant-Microbe Interactions 16, 107-114. 
Jia, H., Cho, S., and Muehlbauer, G.J. (2009) Transcriptome analysis of a wheat near-isogenic line pair carrying Fusarium head blight-resistant and-susceptible alleles. Molecular PlantMicrobe Interactions 22, 1366-1378.

Jones, J.D., and Dangl, J.L. (2006) The plant immune system. Nature 444, 323-329.

Kandel, S., Sauveplane, V., Compagnon, V., Franke, R., Millet, Y., Schreiber, L., WerckReichhart, D., and Pinot, F. (2007) Characterization of a methyl jasmonate and woundingresponsive cytochrome $\mathrm{P} 450$ of Arabidopsis thaliana catalyzing dicarboxylic fatty acid formation in vitro. FEBS journal 274, 5116-5127.

Karpinski, S., Gabrys, H., Mateo, A., Karpinska, B., and Mullineaux, P.M. (2003) Light perception in plant disease defence signalling. Current Opinion in Plant Biology 6, 390-396.

Kirubakaran, S.I., and Sakthivel, N. (2007) Cloning and overexpression of antifungal barley chitinase gene in Escherichia coli. Protein Expression and Purification 52, 159-166.

Kobayashi, M., Kawakita, K., Maeshima, M., Doke, N., and Yoshioka, H. (2006) Subcellular localization of Strboh proteins and NADPH-dependent O2--generating activity in potato tuber tissues. Journal of Experimental Botany 57, 1373-1379.

Kohli, M.M., Mehta, Y.R., Guzman, E., Viedma, L.D., Cubilla, L.E. (2011) Pyricularia blast-a threat to wheat cultivation. In Czech Journal of Genetics and Plant Breeding 47, S130-S134.

Kovalchuk, N., Li, M., Wittek, F., Reid, N., Singh, R., Shirley, N., et al. and Lopato, S. (2010) Defensin promoters as potential tools for engineering disease resistance in cereal grains. Plant Biotechnology Journal 8, 47-64.

Kovtun, Y., Chiu, W. L., Tena, G., and Sheen, J. (2000) Functional analysis of oxidative stressactivated mitogen-activated protein kinase cascade in plants. Proceedings of the National Academy of Sciences 97, 2940-2945.

Kunkel, B.N., and Brooks, D.M. (2002) Cross talk between signaling pathways in pathogen defense. Current Opinion in Plant Biology 5, 325-331.

Lacombe, E., Hawkins, S., Doorsselaere, J., Piquemal, J., Goffner, D., Poeydomenge, O., Boudet, A.M., and Grima-Pettenati, J. (1997) Cinnamoyl CoA reductase, the first committed enzyme of the lignin branch biosynthetic pathway: cloning, expression and phylogenetic relationships. The Plant Journal 11, 429-441. 
Lagrimini, L.M., Gingas, V., Finger, F., Rothstein, S., and Liu, T.T.Y. (1997) Characterization of antisense transformed plants deficient in the tobacco anionic peroxidase. Plant Physiology 114, 1187-1196.

Lamb, C., Dixon, R.A. (1997) The oxidative burst in plant disease resistance. Annual Review of Plant Physiology and Plant Molecular Biology 48, 251-275.

Langebartels, C., Wohlgemuth, H., Kschieschan, S., Grün, S., and Sandermann, H. (2002) Oxidative burst and cell death in ozone-exposed plants. Plant Physiology and Biochemistry 40, 567-575.

Levine, A., Tenhaken, R., Dixon, R., and Lamb, C. (1994) $\mathrm{H}_{2} \mathrm{O}_{2}$ from the oxidative burst orchestrates the plant hypersensitive disease resistance response. Cell 79, 583-593.

Li, G., and Yen, Y. (2008) Jasmonate and ethylene signaling pathway may mediate Fusarium head blight resistance in wheat. Crop Science 48, 1888-1896.

Li, X., Zhang, J.B., Song, B., Li, H.P., Xu, H.Q., Qu, B., Dang, F. J., and Liao, Y. C. (2010) Resistance to Fusarium head blight and seedling blight in wheat is associated with activation of a cytochrome P450 gene. Phytopathology 100, 183-191.

Li, X.Y., Wu, Z.S. (1994) Studies on relationship between choline concentration in flowering spikes and resistance to scab among bread wheat varieties. Acta Agronomica Sinica 20, 176-85.

Liu, B., Lu, Y., Xin, Z., and Zhang, Z. (2009) Identification and antifungal assay of a wheat $\beta-1$, 3-glucanase. Biotechnology Letters 31, 1005-1010.

Liu, G., Greenshields, D.L., Sammynaiken, R., Hirji, R.N., Selvaraj, G., and Wei, Y. (2007) Targeted alterations in iron homeostasis underlie plant defense responses. Journal of Cell Science 120, 596-605.

Lu, W.Z., Chen, S.H., and Wang, Y.Z. (2001) Research on wheat scab. Sci. Publ. House, Beijing, China.

Maciel, J.L.N. (2012). Magnaporthe oryzae, the blast pathogen: current status and options for its control. Plant Sciences Reviews 2011, 233.

Maksimov, I.V., Cherepanova, E.A., Surina, O.B., and Sakhabutdinova, A.R. (2004) The effect of salicylic acid on peroxidase activity in wheat calli cocultured with the bunt pathogen Tilletia caries. Russian Journal of Plant Physiology 51, 480-485. 
Manners, J.M., Penninckx, I.A., Vermaere, K., Kazan, K., Brown, R.L., Morgan, A., Maclean D.J., Curtis M.D., Cammue B.P.A., Broekaert W.F, and Broekaert, W.F. (1998) The promoter of the plant defensin gene PDF1. 2 from Arabidopsis is systemically activated by fungal pathogens and responds to methyl jasmonate but not to salicylic acid. Plant Molecular Biology 38, 1071-1080.

Mauch, F., Mauch-Mani, B., and Boller, T. (1988) Antifungal hydrolases in pea tissue II. Inhibition of fungal growth by combinations of chitinase and $\beta$-1, 3-glucanase. Plant Physiology 88, 936-942.

McLusky, S.R., Bennett, M.H., Beale, M.H., Lewis, M.J., Gaskin, P., and Mansfield, J.W. (1999) Cell wall alterations and localized accumulation of feruloyl-3'-methoxytyramine in onion epidermis at sites of attempted penetration by Botrytis allii are associated with actin polarisation, peroxidase activity and suppression of flavonoid biosynthesis. The Plant Journal 17, 523-534.

McMullen, M., Jones, R., Gallenberg, D. (1997) Scab of wheat and barley: A re-emerging disease of devastating impact. Plant Disease 81, 1340-1348.

Mehta, Y.R., \& Baier, A. (1998) Variação patogênica entre isolados de Magnaporthe grisea atacando triticale e trigo no estado do Paraná. Summa Phytopatológica 24, 119-125.

Mesterházy, Á., Leonard, K.J., Bushnell, W.R. (2003) Breeding wheat for Fusarium head blight resistance in Europe. Fusarium head blight of wheat and barley. St Paul, MN, USA: APS Press, 211-240.

Mesterhazy A. 1995. Types and components of resistance to Fusarium head blight of wheat. Plant Breeding 114, 377-86.

Miller, G., Schlauch, K., Tam, R., Cortes, D., Torres, M. A., Shulaev, V., Dangl, J.L. and Mittler, R. (2009). The plant NADPH oxidase RBOHD mediates rapid systemic signaling in response to diverse stimuli. Science Signaling 2, ra45.

Misra, H.P., and Fridovich, I. (1971) The generation of superoxide radical during the autoxidation of ferredoxins. Journal of Biological Chemistry 246, 6886-6890.

Mittler, R. (2002) Oxidative stress, antioxidants and stress tolerance. Trends in Plant Science 7, 405-410.

Mittler, R., Vanderauwera, S., Gollery, M., and Van Breusegem, F. (2004) Reactive oxygen gene network of plants. Trends in Plant Science 9, 490-498.

Molloy, S. (2010) Plant immunity: helping plants to fight back. Nature Reviews Microbiology 8, 


\section{2-313.}

Montillet, J.L., Chamnongpol, S., Rustérucci, C., Dat, J., Van De Cotte, B., Agnel, J.P., Battesti, C., Inze', D., Van Breusegem, F. and Triantaphylidès, C. (2005) Fatty acid hydroperoxides and $\mathrm{H}_{2} \mathrm{O}_{2}$ in the execution of hypersensitive cell death in tobacco leaves. Plant Physiology 138, 15161526.

Morel, J.B., and Dangl, J.L. (1997) The hypersensitive response and the induction of cell death in plants. Cell Death and Differentiation 4, 671-683.

Müller, K., Linkies, A., Vreeburg, R. A., Fry, S. C., Krieger-Liszkay, A., and Leubner-Metzger, G. (2009). In vivo cell wall loosening by hydroxyl radicals during cress seed germination and elongation growth. Plant Physiology 150, 1855-1865.

Mur, L.A., Kenton, P., Lloyd, A.J., Ougham, H., and Prats, E. (2008) The hypersensitive response; the centenary is upon us but how much do we know? Journal of Experimental Botany $59,501-520$.

Murakami, J., Tosa, Y., Kataoka, T., Tomita, R., Kawasaki, J., Chuma, I., Sesumi, Y., Kusaba, M., Nakayashiki, H., and Mayama, S. (2000) Analysis of host species specificity of Magnaporthe grisea toward wheat using a genetic cross between isolates from wheat and foxtail millet. Phytopathology 90, 1060-1067.

Musser, R.O., Farmer, E., Peiffer, M., Williams, S.A., and Felton, G.W. (2006) Ablation of caterpillar labial salivary glands: technique for determining the role of saliva in insect-plant interactions. Journal of Chemical Ecology 32, 981-992.

Muthukrishnan, S., Liang, G.H., Trick, H.N., and Gill, B.S. (2001) Pathogenesis-related proteins and their genes in cereals. Plant Cell, Tissue and Organ Culture 64, 93-114.

Neill, S.J., Desikan, R., Clarke, A., Hurst, R.D., and Hancock, J.T. (2002) Hydrogen peroxide and nitric oxide as signalling molecules in plants. Journal of experimental botany 53, 1237-1247.

Neupane, R. B., Sharma, R. C., Duveiller, E., Ortiz-Ferrara, G., Ojha, B. R., Rosyara, U. R., Bhandari, D., and Bhatta, M. R. (2007) Major gene controls of field resistance to spot blotch in wheat genotypes ' Milan/Shanghai\# 7' and 'Chirya. 3'. Plant Disease 91, 692-697.

Noordermeer, M.A., Veldink, G.A., and Vliegenthart, J.F. (2001) Fatty acid hydroperoxide lyase: a plant cytochrome P450 enzyme involved in wound healing and pest resistance. Chembiochem 2, 494-504.

Oh, H.S., Tosa, Y., Takabayashi, N., Nakagawa, S., Tomita, R., Don, L.D., Kusaba, M., 
Nakayashiki, H., Mayama, S. (2002) Characterization of an Avena isolate of Magnaporthe grisea and identification of a locus conditioning its specificity on oat. Canadian Journal of Botany 80, 1088-1095.

Overmyer, K., Brosché, M., and Kangasjärvi, J. (2003) Reactive oxygen species and hormonal control of cell death. Trends in Plant Science 8, 335-342.

Parker, D., Beckmann, M., Zubair, H., Enot, D.P., Caracuel-Rios, Z., Overy, D.P., Snowdon, S., Talbot, N.J., and Draper, J. (2009) Metabolomic analysis reveals a common pattern of metabolic re-programming during invasion of three host plant species by Magnaporthe grisea. The Plant Journal 59, 723-737.

Parry, D.W., Jenkinson, P., and McLeod, L. (1995) Fusarium ear blight (scab) in small grain cereals-a review. Plant Pathology 44, 207-238.

Pellinen, R.I., Korhonen, M.S., Tauriainen, A.A., Palva, E.T., and Kangasjärvi, J. (2002) Hydrogen peroxide activates cell death and defense gene expression in birch. Plant Physiology 130, 549-560.

Pfaffl, M.W. (2001) A new mathematical model for relative quantification in real-time RTPCR. Nucleic Acids Research 29, e45-e45.

Piccinini, E.C. and Fernandez, J.M.C. (1990) Ocorrência da brusone (Pyricularia oryzae) em lavouras comerciais de trigo (Triticum aestivum) no estado do Rio Grande do Sul. Fitopatología Brasilera 15: 83-84.

Piedras, P., Hammond-Kosack, K.E., Harrison, K., and Jones, J.D. (1998) Rapid, Cf-9-and Avr9dependent production of active oxygen species in tobacco suspension cultures. Molecular PlantMicrobe Interactions 11, 1155-1166.

Piquemal, J., Lapierre, C., Myton, K., O’connell, A., Schuch, W., Grima-pettenati, J., and Boudet, A.M. (1998). Down-regulation of Cinnamoyl-CoA Reductase induces significant changes of lignin profiles in transgenic tobacco plants. The Plant Journal 13, 71-83.

Pirgozliev, S.R., Edwards, S.G., Hare, M.C., Jenkinson, P. (2003) Strategies for the control of Fusarium head blight in cereals. European Journal of Plant Pathology 109, 731-742.

Poppenberger, B., Berthiller, F., Lucyshyn, D., Sieberer, T., Schuhmacher, R., Krska, R., Kuchler, K., Glössl, J., Luschnig, C., and Adam, G. (2003) Detoxification of the Fusarium mycotoxin deoxynivalenol by a UDP-glucosyltransferase from Arabidopsis thaliana. Journal of Biological Chemistry 278, 47905-47914. 
Prabhu, A.S., Filippi, M.C., Castro, N. (1992) Pathogenic variation among isolates of Pyricularia grisea infecting rice, wheat, and grasses in Brazil. Tropical Pest Management 38, 367-371.

Prestes, A.M., Arendt, P.F., Fernandes, J.M.C., and Scheeren, P.L. (2007) Resistance to Magnaporthe grisea among Brazilian wheat genotypes. In Wheat Production in Stressed Environments, 119-123.

Pritsch, C., Muehlbauer, G.J., Bushnell, W.R., Somers, D.A., and Vance, C.P. (2000) Fungal development and induction of defense response genes during early infection of wheat spikes by Fusarium graminearum. Molecular Plant-Microbe Interactions 13, 159-169.

Pritsch, C., Vance, C.P., Bushnell, W.R., Somers, D.A., Hohn, T.M., and Muehlbauer, G.J. (2001) Systemic expression of defense response genes in wheat spikes as a response to Fusarium graminearum infection. Physiological and Molecular Plant Pathology 58, 1-12.

Pumphrey, M.O., Bernardo, R., and Anderson, J.A. (2007) Validating the QTL for Fusarium head blight resistance in near-isogenic wheat lines developed from breeding populations. Crop Science 47, 200-206.

Ren, D., Yang, H., and Zhang, S. (2002) Cell death mediated by MAPK is associated with hydrogen peroxide production in Arabidopsis. Journal of Biological Chemistry 277, 559-565.

Rentel, M.C., Lecourieux, D., Ouaked, F., Usher, S.L., Petersen, L., Okamoto, H., Knight, H., Peck, S.C., Grierson, C.S., Hirt, H., and Knight, M.R. (2004) OXI1 kinase is necessary for oxidative burst-mediated signalling in Arabidopsis. Nature 427, 858-861.

Ribichich, K.F., Lopez, S.E., and Vegetti, A.C. (2000) Histopathological spikelet changes produced by Fusarium graminearum in susceptible and resistant wheat cultivars. Plant Disease 84, 794-802.

Robatzek, S., Chinchilla, D., and Boller, T. (2006) Ligand-induced endocytosis of the pattern recognition receptor FLS2 in Arabidopsis. Genes and Development 20, 537-542.

Rotem, J. (2012) Climatic and Weather Influences on Epidemics. Plant Disease: An Advanced Treatise: How Disease Develops in Populations, 317.

Santos, R., Herouart, D., Sigaud, S., Touati, D., and Puppo, A. (2001) Oxidative burst in alfalfaSinorhizobium meliloti symbiotic interaction. Molecular Plant-Microbe Interactions 14, 86-89.

Schaffrath, U., Freydl, E., and Dudler, R. (1997) Evidence for different signaling pathways activated by inducers of acquired resistance in wheat. Molecular Plant-Microbe Interactions 10, 779-783. 
Schroeder, H.W., and Christensen, J.J. (1963) Factors affecting resistance of wheat to scab caused by Gibberella zeae. Phytopathology 53, 831-838.

Schützendübel, A., and Polle, A. (2002) Plant responses to abiotic stresses: heavy metal-induced oxidative stress and protection by mycorrhization. Journal of Experimental Botany 53, 13511365.

Schweiger, W., Boddu, J., Shin, S., Poppenberger, B., Berthiller, F., Lemmens, M., Muehlbauer, G.J., and Adam, G. (2010) Validation of a candidate deoxynivalenol-inactivating UDPglucosyltransferase from barley by heterologous expression in yeast. Molecular Plant-Microbe Interactions 23, 977-986.

Sels, J., Mathys, J., De Coninck, B., Cammue, B., and De Bolle, M.F. (2008) Plant pathogenesis-related (PR) proteins: a focus on PR peptides. Plant Physiology and Biochemistry 46, 941-950.

Simon-Plas, F., Elmayan, T., and Blein, J.P. (2002) The plasma membrane oxidase NtrbohD is responsible for AOS production in elicited tobacco cells. The Plant Journal 31, 137-147.

Skadsen, R.W., Sathish, P., and Kaeppler, H.F. (2000) Expression of thaumatin-like permatin PR-5 genes switches from the ovary wall to the aleurone in developing barley and oat seeds. Plant Science 156, 11-22.

Somers, D. J., Fedak, G., and Savard, M. (2003) Molecular mapping of novel genes controlling Fusarium head blight resistance and deoxynivalenol accumulation in spring wheat. Genome 46, 555-564.

Stack, R.W., Leonard, K.J., Bushnell, W.R. (2003) History of Fusarium head blight with emphasis on North America. Fusarium head blight of wheat and barley. St Paul, MN, USA: APS Press, 1-34.

Steffenson, B.J., Leonard, K.J., Bushnell, W.R. (2003) Fusarium head blight of barley: impact, epidemics, management, and strategies for identifying and utilizing genetic resistance. Fusarium head blight of wheat and barley. St Paul, MN, USA: APS Press, 241-295.

Steiner, B., Kurz, H., Lemmens, M., and Buerstmayr, H. (2009) Differential gene expression of related wheat lines with contrasting levels of head blight resistance after Fusarium graminearum inoculation. Theoretical and Applied Genetics 118, 753-764.

Strange, R.N., Majer, J.R., Smith, H. (1974) The isolation and identification of choline and betaine as the two major components in anthers and wheat germ that stimulate Fusarium graminearum in vitro. Physiology Plant Pathology 4, 277-90. 
Strange, R.N., Deramo, A., and Smith, H. (1978) Virulence enhancement of Fusarium graminearum by choline and betaine and of Botrytis cinerea by other constituents of wheat germ. Transactions of the British Mycological Society 70, 201-207.

Strausbaugh, C.A., Maloy, O.C. (1986) Fusarium scab of irrigated wheat in central Washington. Plant Disease 70, 1104-1106.

Sutton, J.C. (1982) Epidemiology of wheat head blight and maize ear rot caused by Fusarium graminearum. Canadian Journal of Plant Pathology 4, 195-209.

Talbot, N.J. (1995) Having a blast: exploring the pathogenicity of Magnaporthe grisea. Trends in Microbiology 3, 9-16.

Thines, E., Weber, R.W., and Talbot, N.J. (2000) MAP kinase and protein kinase A-dependent mobilization of triacylglycerol and glycogen during appressorium turgor generation by Magnaporthe grisea. The Plant Cell Online 12, 1703-1718.

Thomma, B.P., Eggermont, K., Penninckx, I.A., Mauch-Mani, B., Vogelsang, R., Cammue, B.P., and Broekaert, W.F. (1998) Separate jasmonate-dependent and salicylate-dependent defense-response pathways in Arabidopsis are essential for resistance to distinct microbial pathogens. Proceedings of the National Academy of Sciences 95, 15107-15111.

Thomson, M.J., Septiningsih, E.M., Suwardjo, F., Santoso, T.J., Silitonga, T.S., and Mccouch, S.R. (2007) Genetic diversity analysis of traditional and improved Indonesian rice (Oryza sativa L.) germplasm using microsatellite markers. Theoretical and Applied Genetics 114, 559-568.

Thordal-Christensen, H., Zhang, Z., Wei, Y., and Collinge, D.B. (1997). Subcellular localization of $\mathrm{H}_{2} \mathrm{O}_{2}$ in plants. $\mathrm{H}_{2} \mathrm{O}_{2}$ accumulation in papillae and hypersensitive response during the barleypowdery mildew interaction. The Plant Journal 11, 1187-1194.

von Tiedemann, A. (1997) Evidence for a primary role of active oxygen species in induction of host cell death during infection of bean leaves with Botrytis cinerea. Physiological and Molecular Plant Pathology 50, 151-166.

Tiwari, B.S., Belenghi, B., and Levine, A. (2002) Oxidative stress increased respiration and generation of reactive oxygen species, resulting in ATP depletion, opening of mitochondrial permeability transition, and programmed cell death. Plant Physiology 128, 1271-1281.

Torres, M.A., and Dangl, J.L. (2005) Functions of the respiratory burst oxidase in biotic interactions, abiotic stress and development. Current Opinion in Plant Biology 8, 397-403.

Torres, M.A., Jones, J.D., and Dangl, J.L. (2006) Reactive oxygen species signaling in response 
to pathogens. Plant Physiology 141, 373-378.

Torres, M.A. (2010) ROS in biotic interactions. Physiologia Plantarum 138, 414-429.

Trail, F., Xu, H.X., Loranger, R., Gadoury, D. (2002) Physiological and environmental aspects of ascospore discharge in Gibberella zeae (anamorph Fusarium graminearum). Mycologia 94, 181-189.

Trujillo, M., Kogel, K.H., and Hückelhoven, R. (2004) Superoxide and hydrogen peroxide play different roles in the nonhost interaction of barley and wheat with inappropriate formae speciales of Blumeria graminis. Molecular Plant-Microbe Interactions 17, 304-312.

Turner, J. G., Ellis, C., and Devoto, A. (2002) The jasmonate signal pathway. The Plant Cell Online 14, S153-S164.

Uddin, W., Viji, G., \& Vincelli, P. (2003) Gray leaf spot (blast) of perennial ryegrass turf: An emerging problem for the turfgrass industry. Plant Disease 87, 880-889.

Uddin, W., Serlemitsos, K., \& Viji, G. (2003a) A temperature and leaf wetness duration-based model for prediction of gray leaf spot of perennial ryegrass turf. Phytopathology 93, 336-343.

Urashima, A.S., Dias Martins, T., Bueno, C.R.N.C., Favaro, D.B., Arruda, M.A., Mehta, Y.R. (2004a) Triticale and barley: new hosts of Magnaporthe grisea in Sa o Paulo, Brazil-Relationship with blast of rice and wheat. In Rice Blast: Interaction with Rice and Control, 251-260.

Urashima, A.S., Grosso, C.R.F., Stabili, A., Freitas, E.G., Silva, C.P., Netto, D.C.S., Franco, I., Me'rola Bottan. J.H. (2009) Effect of Magnaporthe grisea on seed germination, yield and quality of wheat. In Advances in Genetics, Genomics and Control of Rice Blast Disease, 267-277.

Urashima, A.S., Igarashi, S., Kato, H. (1993) Host range, mating type, and fertility of Pyricularia grisea from wheat in Brazil. Plant Disease 12, 11-16.

Urashima, A.S., Kato, H. (1994) Varietal resistance and chemical control of wheat blast fungus. Summa Phytopathologica 20,107-112.

Urashima, A.S., Lavorent, N.A., Goulart, A.C.P., Mehta, Y.R. (2004) Resistance spectra of wheat cultivars and virulence diversity of Magnaporthe grisea isolates in Brazil. Fitopathologia Brasileira 29, 511-518.

Van Camp, W., Van Montagu, M., and Inzé, D. (1998) $\mathrm{H}_{2} \mathrm{O}_{2}$ and NO: redox signals in disease resistance. Trends in Plant Science 3, 330-334.

Van Loon, L.C., and Van Strien, E.A. (1999) The families of pathogenesis-related proteins, their 
activities, and comparative analysis of PR-1 type proteins. Physiological and Molecular Plant Pathology 55, 85-97.

Van Loon, L.C., Rep, M., and Pieterse, C.M.J. (2006) Significance of inducible defense-related proteins in infected plants. Annual Review of Phytopathology 44, 135-162.

Vance, C.P., Kirk, T.K., and Sherwood, R.T. (1980) Lignification as a mechanism of disease resistance. Annual Review of Phytopathology 18, 259-288.

Velazhahan, R., and Muthukrishnan, S. (2003) Transgenic tobacco plants constitutively overexpressing a rice thaumatin-like protein (PR-5) show enhanced resistance to Alternaria alternata. Biologia Plantarum 47, 347-354.

Veronese, P., Ruiz, M. T., Coca, M. A., Hernandez-Lopez, A., Lee, H., Ibeas, J. I., Damsz, B., Pardo, J.M., Hasegawa, P.M., Bressan, R.A., and Narasimhan, M. L. (2003). In defense against pathogens. Both plant sentinels and foot soldiers need to know the enemy. Plant Physiology $131,1580-1590$.

Vidal, G., Ribas-Carbo, M., Garmier, M., Dubertret, G., Rasmusson, A.G., Mathieu, C., Foyer, C. H., and De Paepe, R. (2007) Lack of respiratory chain complex I impairs alternative oxidase engagement and modulates redox signaling during elicitor-induced cell death in tobacco. The Plant Cell Online 19, 640-655.

Viedma, L.Q. (2005) Wheat blast occurrence in Paraguay. Phytopathology 95, S152.

Vigers, A.J., Wiedemann, S., Roberts, W.K., Legrand, M., Selitrennikoff, C.P., and Fritig, B. (1992) Thaumatin-like pathogenesis-related proteins are antifungal. Plant Science 83, 155-161.

Wally, O., Jayaraj, J., and Punja, Z. (2009) Comparative resistance to foliar fungal pathogens in transgenic carrot plants expressing genes encoding for chitinase, $\beta$-1, 3-glucanase and peroxidise. European Journal of Plant Pathology 123, 331-342.

Wang, C.F., Huang, L.L., Zhang, H.C., Han, Q.M., Buchenauer, H., and Kang, Z.S. (2010) Cytochemical localization of reactive oxygen species $\left(\mathrm{O}_{2}{ }^{-}\right.$and $\left.\mathrm{H}_{2} \mathrm{O}_{2}\right)$ and peroxidase in the incompatible and compatible interaction of wheat-Puccinia striiformis f. sp. tritici. Physiological and Molecular Plant Pathology 74, 221-229.

Wang, X., Tang, C., Deng, L., Cai, G., Liu, X., Liu, B., Han, Q., Buchenauer, H.,Wei, G., Han, D., Huang, L., and Kang, Z. (2010). Characterization of a pathogenesis-related thaumatin-like protein gene TaPR5 from wheat induced by stripe rust fungus. Physiologia Plantarum 139, 2738. 
WASDE, (2014) World Agricultural Supply and Demand Estimates Report. http://www.usda.gov/oce/commodity/wasde/latest.pdf

Werck-Reichhart, D., and Feyereisen, R. (2000) Cytochromes P450: a success story. Genome Biology 1, 3003-1.

Whetten, R.W., MacKay, J.J., and Sederoff, R.R. (1998) Recent advances in understanding lignin biosynthesis. Annual Review of Plant Biology 49, 585-609.

Wilde, F., Korzun, V., Ebmeyer, E., Geiger, H.H., and Miedaner, T. (2007) Comparison of phenotypic and marker-based selection for Fusarium head blight resistance and DON content in spring wheat. Molecular Breeding 19, 357-370.

William, A.N.G.U.S., Alain, B.O.N.J.E.A.N., and Maarten, V.G. (2011) The world wheat book: a history of wheat breeding (Vol. 2). Lavoisier.

Winter, M., Koopmann, B., Döll, K., Karlovsky, P., Kropf, U., Schlüter, K., and von Tiedemann, A. (2013) Mechanisms regulating grain contamination with trichothecenes translocated from the stem base of wheat (Triticum aestivum) infected with Fusarium culmorum. Phytopathology 103, 682-689.

Xu, Y.I., Chang, P.F.L., Liu, D., Narasimhan, M.L., Raghothama, K.G., Hasegawa, P.M., and Bressan, R.A. (1994) Plant defense genes are synergistically induced by ethylene and methyl jasmonate. The Plant Cell Online 6, 1077-1085.

Yoshioka H, Numata N, Nakajima K, Katou S, Kawakita K, Rowland O, Jones JD, Doke N (2003) Nicotiana benthamiana gp91z homologs NbrbohA and NbrbohB participate in $\mathrm{H} 2 \mathrm{O} 2$ accumulation and resistance to Phytophthora infestans. Plant Cell 15, 706-718.

Zadoks, J. C., Chang, T.T., and Konzak, C.F. (1974) A decimal code for the growth stages of cereals. Weed Research 14, 415-421.

Zeigler, R.S. (1998) Recombination in Magnaporthe grisea. Annual Review of Phytopathology 36, 249-275.

Zhang, J., Shao, F., Li, Y., Cui, H.T., Chen, L.J., Li, H.T., Zou, Y., Long C.Z., Lan, L.F., Chai, J.J., Chen, S., Tang, X.Y., and Zhou, J.M. (2007) A Pseudomonas syringae effector inactivates MAPKs to suppress PAMP-induced immunity in plants. Cell Host and Microbe 1, 175-185.

Zhang, X.W., Jia, L.J., Zhang, Y., Jiang, G., Li, X., Zhang, D., and Tang, W.H. (2012) In planta stage-specific fungal gene profiling elucidates the molecular strategies of Fusarium graminearum growing inside wheat coleoptiles. The Plant Cell Online 24, 5159-5176. 
Zhuang, Y., Gala, A., and Yen, Y. (2013) Identification of functional genic components of major Fusarium head blight resistance quantitative trait loci in wheat cultivar Sumai 3. Molecular PlantMicrobe Interactions 26, 442-450.

Zurbriggen, M.D., Carrillo, N., Tognetti, V.B., Melzer, M., Peisker, M., Hause, B., and Hajirezaei, M.R. (2009) Chloroplast-generated reactive oxygen species play a major role in localized cell death during the non-host interaction between tobacco and Xanthomonas campestris pv. vesicatoria. The Plant Journal 60, 962-973. 


\section{Appendix}

Table A 1. The weight of the infected seeds of Milan, Sumai 3 and Gondo/CBRD infected by

M. grisea.

\begin{tabular}{ccc}
\hline Cultivars & Control seeds & Infected seeds \\
\hline Milan & 0.19 & 0.10 \\
Milan & 0.25 & 0.11 \\
Milan & 0.23 & 0.11 \\
Milan & 0.25 & 0.09 \\
Milan & 0.20 & 0.09 \\
Milan & 0.20 & 0.08 \\
Sumai 3 & 0.23 & 0.04 \\
Sumai 3 & 0.22 & 0.02 \\
Sumai 3 & 0.24 & 0.03 \\
Sumai 3 & 0.22 & 0.03 \\
Sumai 3 & 0.19 & 0.03 \\
Sumai 3 & 0.25 & 0.02 \\
Gondo-CBRD & 0.25 & 0.03 \\
Gondo-CBRD & 0.25 & 0.03 \\
Gondo-CBRD & 0.26 & 0.03 \\
Gondo-CBRD & 0.24 & 0.02 \\
Gondo-CBRD & 0.21 & 0.03 \\
Gondo-CBRD & 0.27 & 0.02 \\
\hline
\end{tabular}


Table A 2. The decimal codes for the growth stages of cereals (Zadoks et al., 1974)

\begin{tabular}{|c|c|c|c|}
\hline$\overline{G S}$ & General description & GS & General description \\
\hline & Germination & & $\begin{array}{l}\text { Inflorescence (ear/panicle) } \\
\text { emergence }\end{array}$ \\
\hline 00 & Dry seed & 50 & -- \\
\hline 01 & $\begin{array}{l}\text { Start of imbibition (water } \\
\text { absorption) }\end{array}$ & 51 & $\begin{array}{l}\text { First spikelet of inflorescence just } \\
\text { visible }\end{array}$ \\
\hline 02 & -- & 52 & -- \\
\hline 03 & Imbibition complete & 53 & $1 / 4$ of inflorescence emerged \\
\hline 04 & -- & 54 & -- \\
\hline 05 & $\begin{array}{l}\text { Radicle (root) emerged from } \\
\text { caryopsis (seed) }\end{array}$ & 55 & $1 / 2$ of inflorescence emerged \\
\hline 06 & -- & 56 & -- \\
\hline 07 & Coleoptile & 57 & $3 / 4$ of inflorescence emerged \\
\hline 08 & -- & 58 & -- \\
\hline 09 & $\begin{array}{l}\text { Leaf just at coleoptile tip } \\
\text { Seedling growth }\end{array}$ & 59 & $\begin{array}{l}\text { Emergence of inflorescence } \\
\text { Anthesis (flowering) }\end{array}$ \\
\hline 10 & First leaf through coleoptile & 60 & -- \\
\hline 11 & First leaf unfolded & 61 & Beginning of anthesis \\
\hline 12 & 2 leaves unfolded & 62 & -- \\
\hline 13 & 3 leaves unfolded & 63 & -- \\
\hline 14 & 4 leaves unfolded & 64 & -- \\
\hline 15 & 5 leaves unfolded & 65 & Anthesis half-way \\
\hline 16 & 6 leaves unfolded & 66 & -- \\
\hline 17 & 7 leaves unfolded & 67 & -- \\
\hline 18 & 8 leaves unfolded & 68 & -- \\
\hline 19 & $\begin{array}{l}9 \text { or more leaves unfolded } \\
\text { Tillering }\end{array}$ & 69 & $\begin{array}{l}\text { Anthesis complete } \\
\text { Milk development }\end{array}$ \\
\hline 20 & Main shoot only & 70 & -- \\
\hline 21 & Main shoot and 1 tiller & 71 & Caryopsis (kernel) water ripe \\
\hline 22 & Main shoot and 2 tillers & 72 & -- \\
\hline 23 & Main shoot and 3 tillers & 73 & Early milk \\
\hline 24 & Main shoot and 4 tillers & 74 & -- \\
\hline 25 & Main shoot and 5 tillers & 75 & Medium milk \\
\hline 26 & Main shoot and 6 tillers & 76 & -- \\
\hline 27 & Main shoot and 7 tillers & 77 & Late milk \\
\hline 28 & Main shoot and 8 tillers & 78 & -- \\
\hline 29 & Main shoot and 9 or more tillers & 79 & -- \\
\hline & Stem elongation & & Dough development \\
\hline 30 & Pseudostem (leaf sheath) erection & 80 & -- \\
\hline 31 & First node detectable & 81 & -- \\
\hline 32 & 2nd node detectable & 82 & -- \\
\hline 33 & 3rd node detectable & 83 & Early dough \\
\hline 34 & 4th node detectable & 84 & -- \\
\hline
\end{tabular}


35 5th node detectable

36 6th node detectable

$37 \quad$ Flag leaf just visible

$38 \quad--$

39 Flag leaf ligule just visible

\section{Booting}

40 --

$41 \quad$ Flag leaf sheath extending

$42 \quad--$

43 Boots just visibly swollen

$44 \quad-$

45 Boots swollen

46 --

$47 \quad$ Flag leaf sheath opening

$48 \quad--$

49 First awns visible
85 Soft dough

86

87 Hard dough

$88 \quad--$

$89 \quad--$

\section{Ripening}

$90 \quad--$

91 Caryopsis hard (difficult to divide)

92 Caryopsis hard (not dented by thumbnail)

93 Caryopsis loosening in daytime

94 Over-ripe, straw dead and collapsing

95 Seed dormant

96 Viable seed giving 50\% germination

97 Seed not dormant

98 Secondary dormancy induced

99 Secondary dormancy lost 


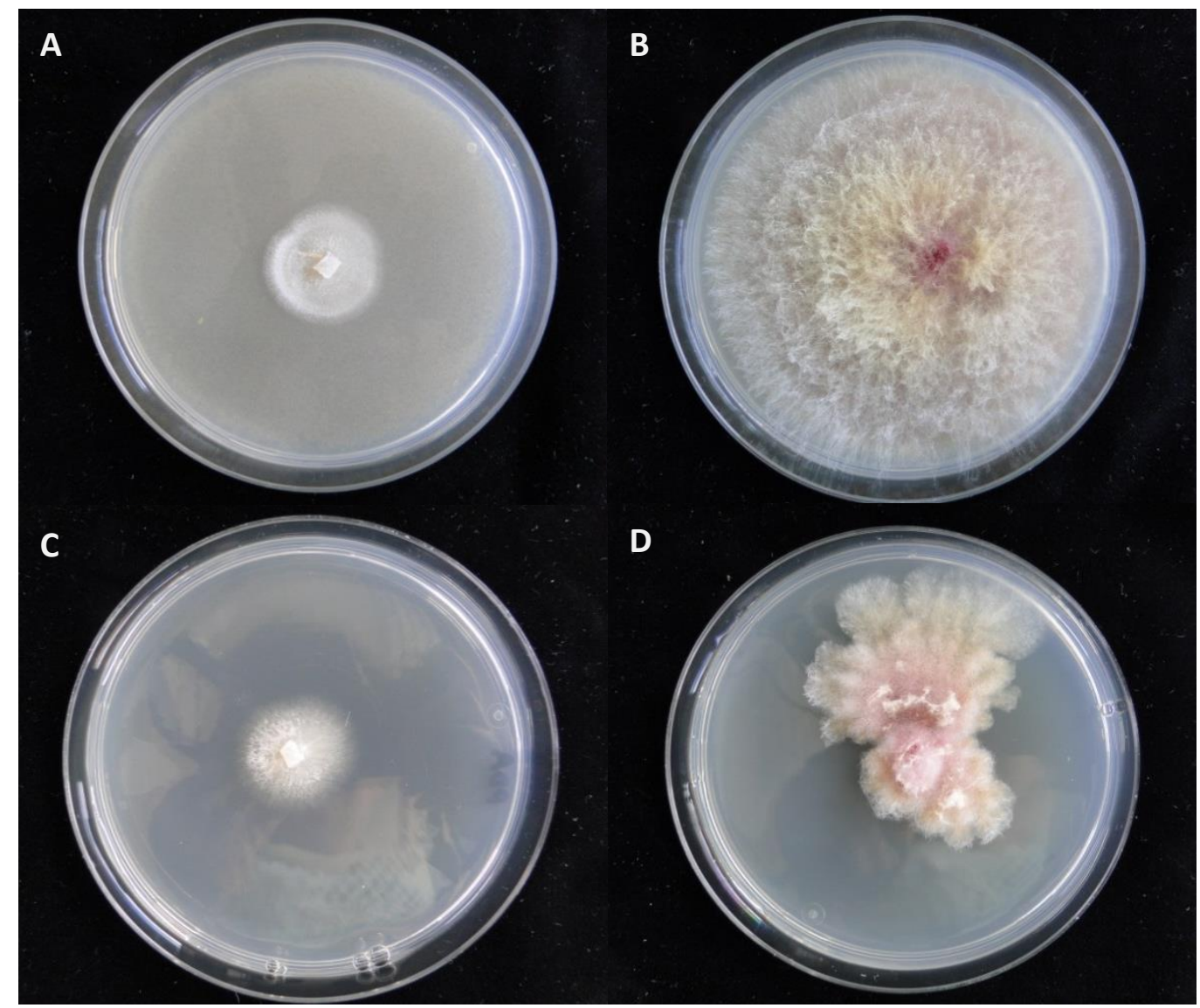

Fig. A 1. Photos of the different cultures of $M$. grisea and F. graminearum at 5 days. A, M. grisea culture on V8 agar plate. B, F. graminearum on V8 agar plate. C, M. grisea culture on PDA plate. B, F. graminearum on PDA plate. 


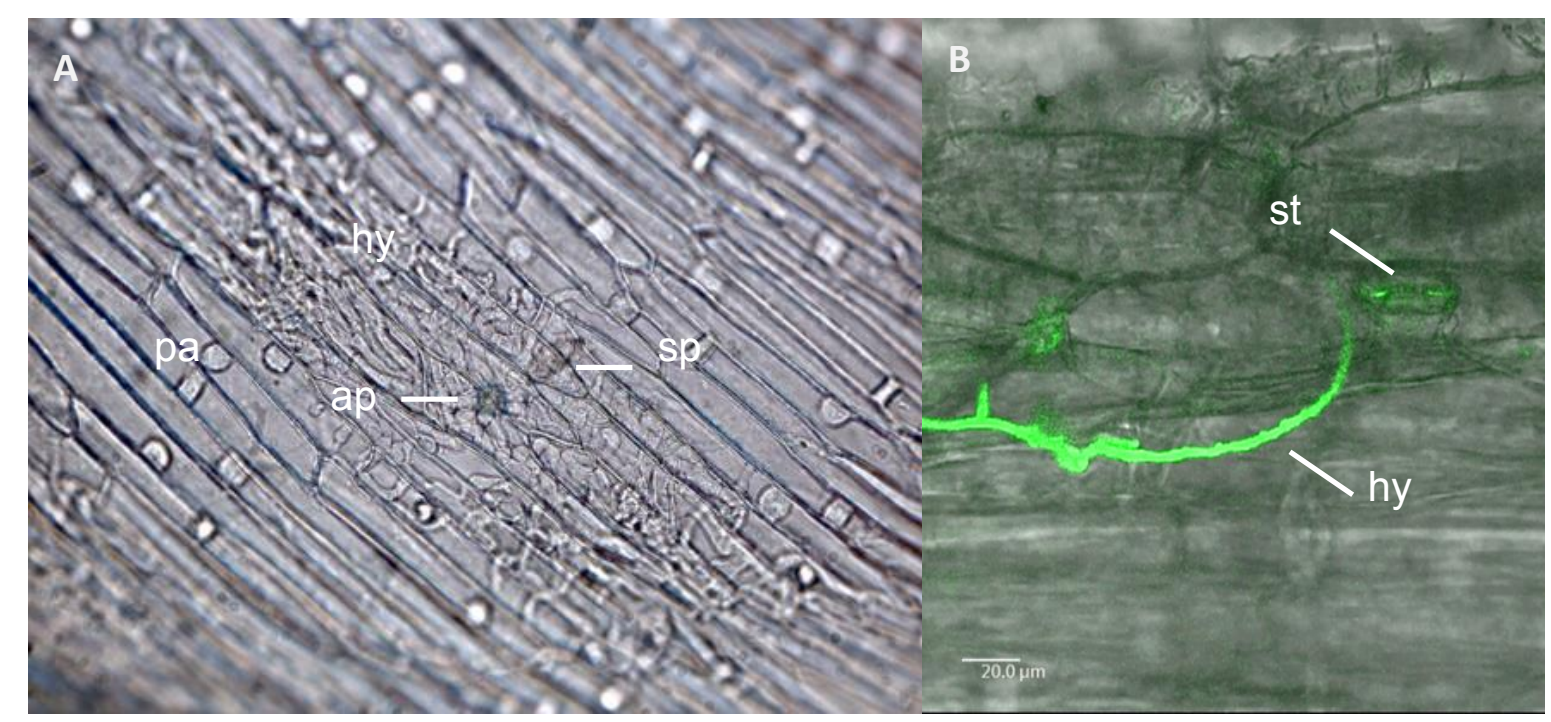

Fig. A 2. Microscopic views of the penetration behaviors from M. grisea and F. graminearum. A, a spore of $M$. grisea infects the palea of Sumai 3 at 48 hpi (200X). The spore was in the center, the light blue circle beneath indicates the appressorium and the penetration site. B, confocal microscopy overlay images of $F$. graminearum-GFP strain infection of palea, Sumai 3 at $48 \mathrm{hpi}$, the hyphae prepared to invade the stomata. Ap = appressorium, $\mathrm{sp}=$ conidiaspore, hy $=$ hyphae, $\mathrm{st}=$ stomata, $\mathrm{pa}=$ palea . 


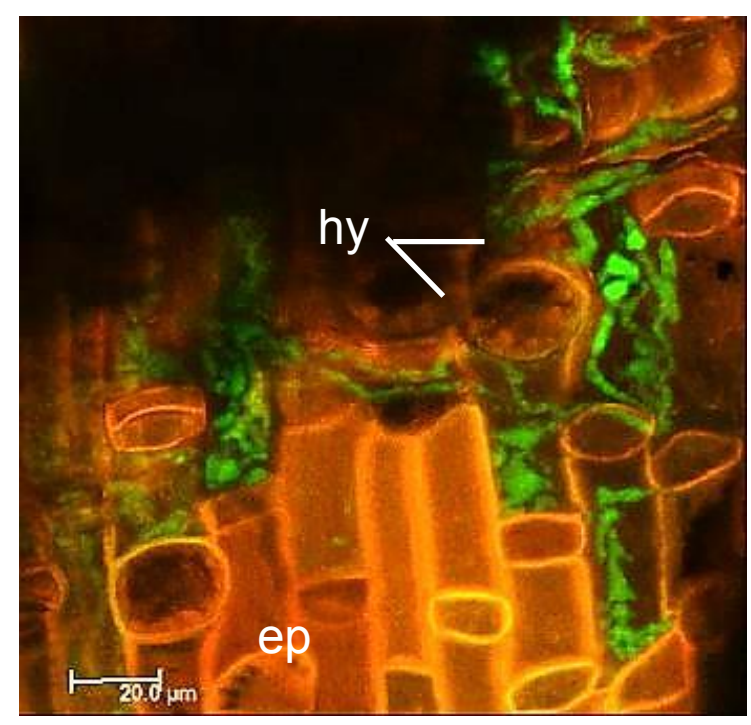

Fig. A 3. Confocal microscopy images of $F$. graminearum-GFP infecting the epidermal tissue of Sumai 3 at 7 dpi, longitudinal section, infected hyphae were going both intra- and intercellularly. Hy $=$ hyphae, $x y=$ xylem, ep $=$ epidermal. 


\section{Acknowledgements}

No one walks alone on the journey of life, especially in the scientific life. This work would not have been possible without the support of many people. First of all, I wish express my greatest gratitude to my supervisor: Prof. Dr. Andreas von Tiedemann, he kindly offered the opportunity to me to work further in the science, his gave many valuable guidance and advice, together with his encouragement and patience, all of these largely inspired me greatly to work in this project, also in my life.

I would like to show my sincere appreciation to Prof. Dr. Petr Karlovsky for his advice, guidance and support in the years and thanks for co-reviewing of my thesis.

I gratefully acknowledge Prof. Dr. Heiko Becker for evaluating my thesis and being a part of the defense committee.

I wish to acknowledge Prof. Dr. Wilhelm Schäfer for providing the GFP-tagged F. graminearum strain to compelte the microscopy work.

Deepest gratitude is also due to Dr. Birger Koopmann for the technical discussions and guidelines in different experiment, especially the melacular parts, the primer design and PCR analysis, also on the ROS response. Without his knowledge and assistance this study would not have been successful.

During this work, I sincerely thank the contribution from Evelin vorbeck for cultivars screening, the inoculation system and greenhouse guidance, her help gave a foundation for the work, and greatly thanks to some results support from Fluture Novakazi for the screening part. Besides, I would like thank to Katja Fröhlich for her assistant during the gene expression work, I got more motivation from her knowlegede and attitude.

I would like to greatly acknowledge Dr. Mark Winter for helping me with some experimental setup and general advice, also great thanks to Dr. Anke Sirrenberg and Dr. Magdalena Siebold for their critical comments on earlier version of my thesis. 
I wish to gratefully acknowledge Mr. Knobel and Mr. Hodyl, who take care of the plant in the green house all the time, to make the plant healthy and beautiful. I want to say thanks to Dagmar Tacke, she provided many good suggestions and a nice time when I was doing experiment in Lab 105.

I would like to thank Martina Bode, she always helps for settling the issues about study. Her helps, simle and kindness made the life brighter and easier.

Many thanks to my friends, Kerstin Höch, Geoffrey Onaga, Tingting Wei, Ines Eikenberg, Daniel Lopisso, Lucia Ramos-Romero, Jutta Schaper and others, the time we past together gave me much strengthen and warm, and the help from you is my precious memory, no where I can find.

I cannot express enough thanks to all my dear collegeue, with the care and attention, you are like a family for me during these years I stayed, and it always continued to encourage and help me in study and life. I was motivated and encouraged every time when I was in tha Lab. I really appreciated the group I have met.

I would like to thank the Göttingen University for providing me with a good environment and facilities to complete this work. And great thanks to the China Scholarship Council (CSC) for its financial support.

At last, my heartfelt thanks to my dear parents, for their endless love and understanding, to support me go further. 


\section{Curriculum vitae}

Name: Xia Ha

Date of birth: 18.08 .1983

Place of birth: Hanzhong, China

Address: Philip-Reis-Str. 8, 37075 Göttingen

E-mail: xha@gwdg.de

10/2010 until now PhD student at Department of Crop Sciences, Section Plant

Pathology and Plant Protection, University of Göttingen

09/2009- 09/2010 Internship in Ludwig-Maximilians University Munich

09/2006- 07/2009 Master of Science, agricultural sciences, Plant Pathology in College of Plant Protection, Northwest A\&F University, Yangling, China

09/2002- 07/2006 Bachelor of Science, agricultural sciences, College of Plant Protection, Northwest A\&F University, Yangling, China

09/1998- 08/2002 High school, Hanzhong, China

09/1995- 08/1998 Junior high school, Hanzhong, China

09/1989- 07/1995 Primary school, Hanzhong, China 


\section{Presentations on the conferences}

Ha, X., Wei, T., von Tiedemann, A. (2012) Epidemiological and phytopathological studies on wheat blast (Magnaporthe grisea)-characterization of pathotypes, host specificity and resistance in wheat. Poster presentation on the 58. Deutsche Pflanzenschutztagung, Braunschweig, Germany.

Ha, X., Wei, T., Koopmann, B., von Tiedemanh, A. (2012) Microclimatic Requirements for Wheat Blast (Magnaporthe grisea) and Characterisation of Resistance in Wheat. Poster presentation on the Tropentag 2012, Göttingen, Germany. 


\section{Declaration}

I, hereby, declare that this Ph.D. dissertation was undertaken independently and without any unauthorised aid.

Göttingen, 